Oslo Sports Trauma Research Center

Norwegian School of Sport Sciences

$\&$

Orthopaedic Center

Division of Neuroscience and Musculoskeletal Medicine

Ullevaal University Hospital

Faculty of Medicine

University of Oslo

\title{
Football and injuries
}

Screening, risk factors and prevention

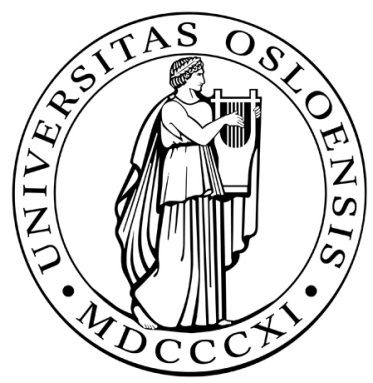

Oslo, April, 2010 
(C) Anders Hauge Engebretsen, 2010

Series of dissertations submitted to the Faculty of Medicine, University of Oslo No. 1057

ISBN 978-82-8264-114-2

All rights reserved. No part of this publication may be

reproduced or transmitted, in any form or by any means, without permission.

Cover: Inger Sandved Anfinsen.

Printed in Norway: AIT Oslo AS.

Produced in co-operation with Unipub.

The thesis is produced by Unipub merely in connection with the thesis defence. Kindly direct all inquiries regarding the thesis to the copyright holder or the unit which grants the doctorate. 
"Tom Lund dribler av to engelskemenn. Helt ned til... Så blir han felt... blir han felt av grisen Pbil Neal. Rampen Phil Neal sparker Tom overende bakfra. PHIL GRIS NEAL!! Begynn å ta igjen, gutter! Begynn å ta igjen! Engelskmennene har ramp både på banen og på tribunen. Tom Lund gike. forbi to engelskmenn. Phil Neal overfalt ham bakfra. For en gris! For en fotballramp Phil Neal er!

Dette skal han ha igjen, gutter. Ta ham ved forste anledning."

Bjørge Lillelien, Norge - England 9. september 1981 



\section{Summary}

\section{Background}

Football (soccer) is one of the most popular sports in Norway as well as in the rest of the world, and the injury risk is considerable and high compared to most other team sports. Studies have shown that the majority of football injuries occur in the lower extremities, especially affecting the ankle, knee, hamstrings and groin. Ankle and knee sprains and hamstring and groin strains may leave athletes out of play for several weeks, and in many cases full recovery takes much longer. These common injuries therefore represent a concern.

\section{Aims}

The main aims of this thesis were to identify risk factors for the four most common injury types in football, ankle and knee sprains and hamstring and groin strains, screen for players with the highest injury risk and to examine if exercise programs targeting the players with an increased risk of injury could prevent these injuries.

\section{Material and methods}

A total player population of 508 players representing 31 teams from Norwegian $1^{\text {st }}, 2^{\text {nd }}$ and $3^{\text {rd }}$ division of football for men was used for all studies (Paper I-V). A randomized controlled trial was carried out to prevent injuries (Paper I), while prospective cohort studies (Papers II-V) were carried out focusing on potential ankle (Paper II), knee (Paper III), hamstring (Paper IV) and groin risk factors (Paper V). During the preseason the players filled out a questionnaire and went through testing for potential risk factors for ankle, knee, hamstring and groin injury. Based on information from the questionnaire, the players were divided into a high risk and low risk group. The high risk players were randomized individually into an intervention group, which received equipment and training programs, and a control group (Paper I). The preseason testing made out the foundation for investigating the potential risk factors for injury (Paper II-V).

\section{Main results}

During the football season, 505 injuries were reported, sustained by $56 \%$ of the players. The total incidence of injuries during the season was 4.7 injuries per 1000 playing hours (95\% CI 4.3 to 5.1), 12.1 (95\% CI 10.5 to 13.7) for match injuries and 2.7 (95\% CI 2.4 to 3.1) for training injuries. The total exposure to match play and training was 108111 player hours. There were 56 acute ankle injuries affecting 46 legs (43 players), 61 acute knee injuries affecting 57 legs (53 players), 76 hamstring injuries affecting 65 legs (61 players) and 61 groin injuries affecting 55 legs 
(51 players) respectively. There was a significantly lower injury risk in the group of players with no previous injuries and normal function scores compared to the other players. However, the introduction of individual specific preventive training programs did not affect the injury risk in this intervention, most likely due to low compliance with the training programs prescribed (Paper I). In the multivariate analyses, number of previous acute ankle injuries (Paper II), previous acute hamstring injury (yes/no) (Paper IV) and previous acute groin injury and weak adductor muscles as determined clinically (Paper V) proved to be significant predictor of new injuries. Regarding risk factors for knee injuries, none of the tested factors were associated with an increased injury risk (Paper III) in the final multivariate analysis.

\section{Conclusions}

Risk factors for the most common injuries in football were mapped in the present study. This is an important step towards prevention of injuries, which make out a considerable concern in sports in general and football in particular. High risk players were successfully identified through simple self-report screening. Due to a low compliance with the training programs prescribed, it is impossible to tell if the preventive measures tested in the present study are useful. Preventive interventions must therefore be tested in future randomized controlled trials. 


\section{Table of Contents}

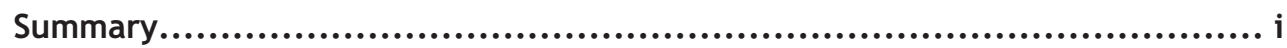

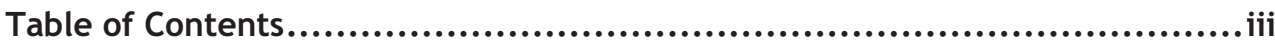

Acknowledgements.......................................................... vi

List of papers ................................................................ viii

Abbreviations ................................................................ ix

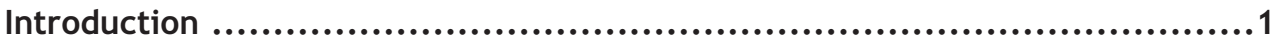

Football - the world's and Norway's most popular sport........................ 1

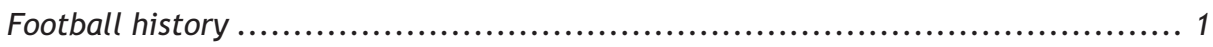

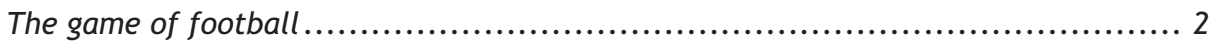

How to prevent injuries in football ........................................

Football - a high risk sport .................................................

Definition of injury ......................................................................... 3

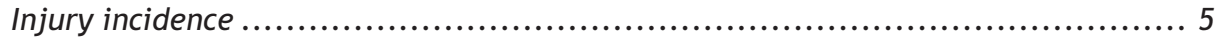

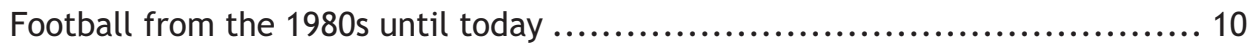

Multifactorial etiology model ............................................... 11

Risk factors for injuries ................................................ 13

Risk factors for ankle sprains .......................................................... 13

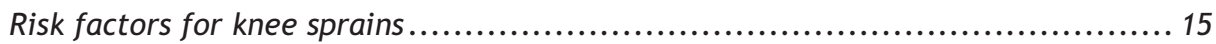

Risk factors for hamstring strains..................................................... 16

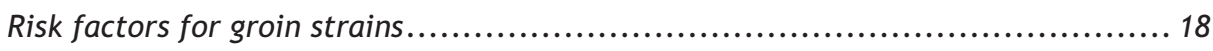

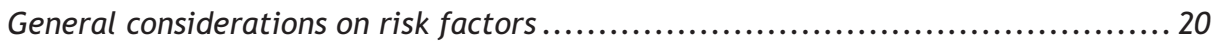

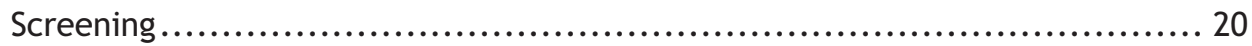

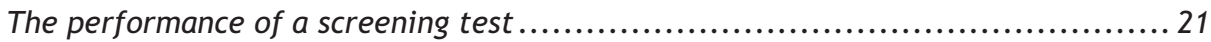

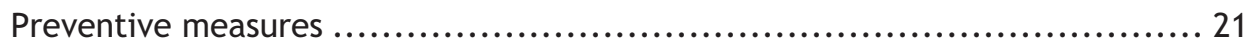

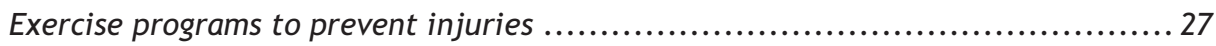

Aims of the thesis ......................................................... 30

Methods.......................................................................... 31

Participants ........................................................... 31

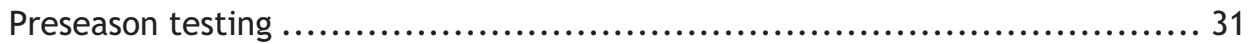




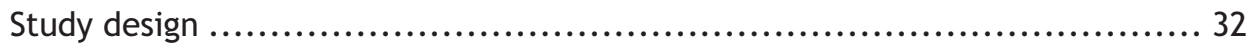

Injury definition ........................................................... 33

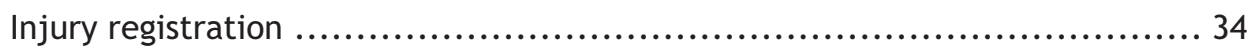

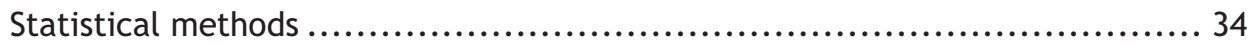

Reliability testing for the risk factor studies ........................................ 35

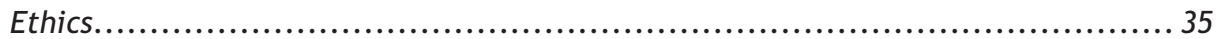

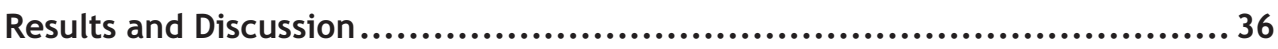

Overall results .................................................................. 36

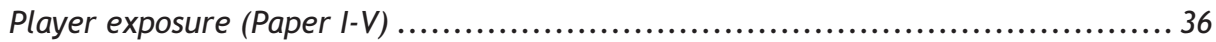

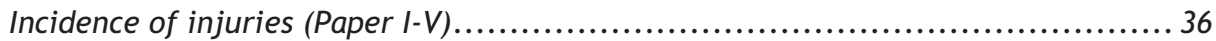

Prevention of injuries (Paper I) ............................................ 38

Intervention outcome - intention-to-treat analysis (Paper I) ........................... 39

Compliance with the training program and per-protocol analysis (Paper I) ............ 40

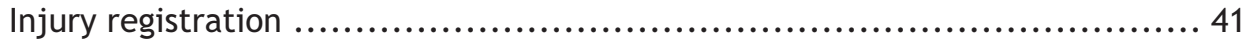

The preventive measures (Paper I) compared with other studies ............... 41

Prevention of ankle injuries ........................................................... 42

Prevention of knee injuries ............................................................ 42

Prevention of hamstring injuries....................................................... 43

Prevention of groin injuries................................................................ 43

General considerations regarding prevention of injuries .............................. 43

Risk factors for the most common injuries in football (Papers II-V)............. 45

Risk factors for ankle injuries (Paper II) ................................... 45

Risk factors for knee injuries (Paper III) ................................. 47

Risk factors for hamstring injuries (Paper IV) ............................. 49

Risk factors for groin injuries (Paper $\mathrm{V})$................................... 51

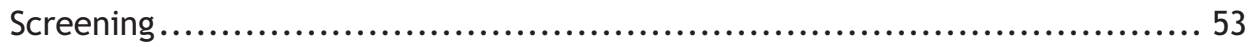

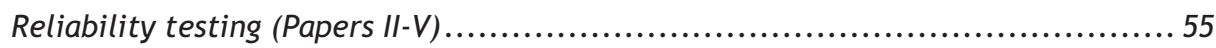

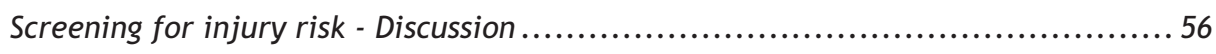

Limitations ............................................................... 58

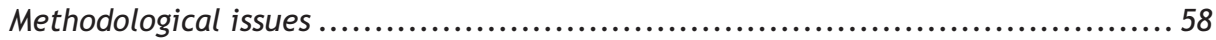

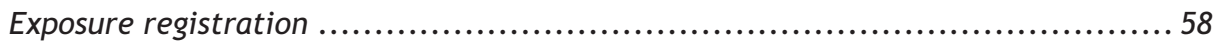

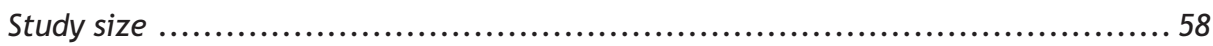

Validity for other sports, levels of play, ages or females ............................. 59 
Perspectives ............................................................. 59

Prevention of injuries in football - Laws of the game................................. 59

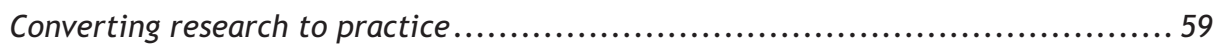

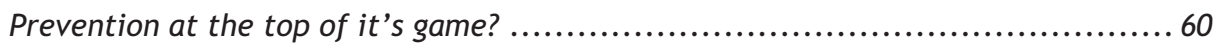

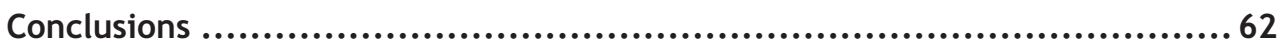

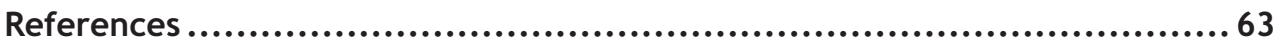

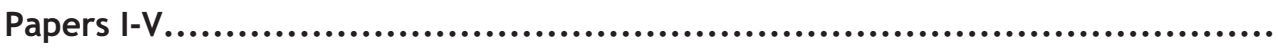

Appendix.

Ethics. 


\section{Acknowledgements}

Football is a team sport. Football medicine is team work. I wish to thank the following persons - My advisor, Lars Engebretsen, Professor and director of research at the Orthopaedic Center, Ullevaal University Hospital and co-founder of the Oslo Sports Trauma Research Center, for taking the time to see me after a lecture in 2001 to talk about research possibilities - that is where it all started. In addition to your incredible academic career, you possess unique personal qualities and build up respect and motivation through your including behaviour. You have a remarkable gift in simplifying difficult topics that many doctors and researchers should learn from. Deserving your $\mathrm{PhD}$ bow tie has for a long time been a personal goal for me.

- I am also sincerely grateful to my second advisor, Roald Bahr, Professor of sports medicine and co-founder of the Oslo Sports Trauma Research Center and the Department of Sports Medicine at the Norwegian School of Sport Sciences. I have enjoyed working with you in all parts of this study and thesis, and your feedback has moved my academic pursuits forward. I feel proud and lucky for having worked with you and for having been able to take advantage of your skills. Your overview and knowledge in sports medicine is outstanding, and your ability to see the big picture when others do not, is quite impressive. I especially admire your way of putting the family first, still achieving excellent academic results.

- I would like to pay a special tribute to Jostein Steene-Johannessen and Grethe Myklebust. Thank you for all your experience, motivating smiles, hours of planning, practical work and help with this project. Without you the project would never have been realized.

- Special thanks to Professor Ingar Holme for your statistical advice and for discussing different statistical methods.

- I would also like to thank Roald and Lars for giving me the opportunity of studying at the Oslo Sports Trauma Research Center at the Norwegian School of Sport Sciences. Thanks to all in this wonderful group, rich of energy and academic excellence. A special tribute to Tron Krosshaug, Tone R. Øritsland, Odd-Egil Olsen, Thor Einar Andersen and the late Unni Lund for including me as a young student in the best of ways.

- Along my way as a medical student, another Professor has made a big impression; Robert LaPrade. I learned from my stays in the U.S. to approach all science with the researcher's questioning way. Thank you for your respect and friendship and for reminding me that it is only 
oneself that sets the limits for the goals one can achieve. It has been inspiring to see how surgery truly can be an art.

- I would like to thank all the 31 physiotherapists, coaches and clubs that participated in the study. Also the hard-working group of students at the Norwegian School of Sport Sciences for making our research study possible; Gyda Kathrine Moan, Ingvild Aas, Guri Uvsløkk, Toril H. Akerhaugen, Tina H. E. Diseth, Ann-Elisabeth Ohnstad and Heidi Merete Pedersen. A special thanks to Gyda for her help in typing the 525 forms. Also, many thanks to Thomas Krogh for helping out with the Access database and Kathrine M. Owe for typing into excel.

Thanks also to the Medical Research Curriculum at the University of Oslo, represented by Jarle Breivik, Marie Eikrem, John-Arne Røttingen and Else-Marie Siebke for making it possible to combine medical school and my dream for research.

Most importantly, I wish to show my love and appreciation towards my parents, Solveig and Svein Erik, for teaching me the joy of knowledge and for always believing in me. I dedicate this to you. And, Erik, thank you for always having been a remarkable example to strive for, be it as a footballer, student, doctor and as a person. I owe everything to the three of you and Marit Kristine, Maria, Erik Andreas, Kamilla, and Mormor. Thank you for putting life and research into its right perspective.

Marit Kristine, my wonderful wife and best friend, thank you for showing me and discovering along with me what life is all about. I love you.

Oslo, April 2010.

This project was carried out in the period of 2003-2010 and financed by the Oslo Sports Trauma Research Center, which has been established at the Norwegian School of Sport Sciences through generous grants from the Royal Norwegian Ministry of Culture, the South-Eastern Norway Regional Health Authority, the International Olympic Committee, the Norwegian Olympic Committee \& Confederation of Sport, and Norsk Tipping AS. The support and working facilities provided for this project at this institution are greatly appreciated. 


\section{List of papers}

This dissertation is based on the following papers, which are referred to in the text by their Roman numerals:

I. Engebretsen AH, Myklebust G, Holme I, Engebretsen L, Bahr R. Prevention of injuries among male football players - a prospective, randomized intervention study targeting players with previous injuries or reduced function. Am J Sports Med. 2008; 36(6):1052-9.

II. Engebretsen AH, Myklebust G, Holme I, Engebretsen L, Bahr R. Risk factors for acute ankle injuries among male football players - a prospective cohort study. Scand J Med Sci Sports. 2009 Jun 23. [Epub ahead of print].

III. Engebretsen AH, Myklebust G, Holme I, Engebretsen L, Bahr R. Risk factors for acute knee injuries among male football players - a prospective cohort study. Scand J Med Sci Sports. 2010 Mar 11. [Epub ahead of print].

IV. Engebretsen AH, Myklebust G, Holme I, Engebretsen L, Bahr R. Risk factors for hamstring injuries among male football players - a prospective cohort study. Am J Sports Med. 2010 Mar 24. [Epub ahead of print].

V. Engebretsen AH, Myklebust G, Holme I, Engebretsen L, Bahr R. Risk factors for groin injuries among male football players - a prospective cohort study. Am J Sports Med. In press, May 2010. 


\section{Abbreviations}

FIFA

UEFA

FAOS

KOOS

$\mathrm{HaOS}$

GrOS

HR intervention group

HR control group

LR control group

BMI

OR

CI

SD

SEM
Fédération Internationale de Football Association

Union of European Football Associations

Foot and Ankle Outcome Score (Roos et al., 2001)

Knee Osteoarthritis Outcome Score (Roos et al., 1998)

Hamstring Outcome Score (see appendix to Paper I)

Groin Outcome Score (see appendix to Paper I)

High-risk intervention group

High-risk control group

Low-risk control group

Body mass index

Odds ratio

Confidence interval

Standard deviation

Standard error of the mean 



\section{Introduction}

\section{Football - the world's and Norway's most popular sport}

Football (soccer) is a complex contact sport, combining high demands for physical, physiological, technical, and tactical skills (Inklaar, 1994a; Reilly et al., 2000), and is characterized by short sprints, rapid acceleration or deceleration, turning, jumping, tackling and kicking (Wisløff et al., 1998). The immense joy and excitement that goals, great efforts and victories awaken have made it the world's probably most popular sport, including a total of 270 million licensed players (whereof 240 million male players) - or four per cent of the world's population - in 207 countries registered with the Fédération Internationale de Football Association (FIFA)(FIFA big count, 2007). Approximately 1\% of these participate at the professional level (Ekblom, 1986; Dvorak et al., 2000a). In Norway, 7.6\% of the total population are registered in the Norwegian Football Association (NFF) (NFF, 2009), with more than 250.000 male players.

\section{Football history}

According to FIFA, football as we know it today has developed from at least half a dozen different games played in different cultures (FIFA - The History of Football, 2010). Reports indicate that for thousands of years people have enjoyed kicking a ball about and is by no means to consider as an aberration of the more 'natural' form of playing a ball with the hands. The earliest described form of the game was called Tsu' Chu and stems from the Han Dynasty in China. It dates back to the second and third centuries BC (FIFA - The History of Football, 2010) and was an exercise from a military manual consisting of kicking a leather ball filled with feathers and hair through an opening, measuring only $30-40 \mathrm{~cm}$ in width, into a small net fixed onto long bamboo canes. Some 500-600 years later, another form of the game was the Japanese Kemari, which is still played today. In contrast to Tsu' Chu, there is no struggle for possession involved. Standing in a circle, the players had to pass the ball, in a relatively small space, trying not to let it touch the ground. Later, there were several other versions, such as the Greek "Episkyros" and the Roman "Harpastum".

However, the contemporary history began in 1863 in England, when rugby football and association football branched off on their different courses, forming the first governing body of the sport, the Football Association (FA) in England. By 1863, the first basic rules were established. Around 1885, football started to pick up in Norway, probably introduced by sailormen from England. After some failed attempts, a new club, "Idrætsforeningen Lyn", which 
would persist until today, was founded the $3^{\text {rd }}$ of March, 1896 (LYN, 2010). Together with the two clubs "Grane" and "Spring", they founded the Norwegian Football Federation (NFF) in 1902. The Federation of International Football Associations (FIFA) was founded two years later, in 1904.

\section{The game of football}

During recent decades, football has evolved and become faster and more aggressive and is played with higher intensity (Tumilty, 1993). Still, the total distance covered in the highest level football matches is reported to have stayed rather constant, approximately $10-12 \mathrm{~km}$ for the average outfielder (Tumilty, 1993; Stølen et al., 2005). Nowadays, individual GPS tracking keeps the spectators updated on every step made. And these steps is not just jogging around; the average intensity is close to the anaerobic threshold, representing $80-90 \%$ of maximal heart rate (Stølen et al., 2005).

During the past century the sport has changed substantially. The rules are thoroughly defined in the "Laws of the Game". Outdoor football of today is played by two teams of 11 players each, one goalkeeper and ten outfielders. An official match in senior football consists of two 45-min halves with a 15-min half-time break. The playing fields historically come with natural grass, but artificial turf is getting more and more common, especially here in Norway with unstable weather conditions. The playing field has to be rectangular, i.e. the length needs to be longer than the width. The fields vary in sizes from 90-120 $\mathrm{m}$ long (100-110 $\mathrm{m}$ in international matches) and 45$90 \mathrm{~m}$ in width (64-75 $\mathrm{m}$ in international matches).

\section{How to prevent injuries in football}

van Mechelen et al (1992) have presented a four-step research model for prevention of injuries in sports. First, the extent of injuries in sports must be mapped. Then, the risk factors and injury mechanisms have to be identified. When these two parts are known to satisfaction, one can start to investigate what can be done to prevent injuries. Finally, in this model the effect of the measures is evaluated by repeating the first step. Alternatively, the effectiveness of these measures can be assessed in a randomized controlled trial (van Mechelen, 1997).

\section{Football - a high risk sport}

Unfortunately, injuries are part of the game. Among the most common injuries are sprain and strain injuries which may leave athletes out of play for several weeks, and in many cases full recovery takes much longer. Football injuries therefore constitute a concern for the affected individuals and for the society, and result in large health expenses (Finch \& Cassell, 2006). A 
study from English professional football found the risks associated with minor, moderate, and major acute injuries and osteoarthritis in lower limb joints of footballers to be unacceptably high when evaluated against work based risk criteria used by the Health and Safety Executive (Drawer \& Fuller, 2002). Also, compared to other sports, football has been shown to have a high injury risk (Junge et al., 2004b) which results in high injury rates when the above stated popularity of football is taken into consideration. However, to compare injury risk across different occupations, sports, age groups and levels, it is of utmost importance to take differences in the injury definitions used into account.

\section{Definition of injury}

Differences in study design and injury definitions make a direct comparison between studies difficult. Several different definitions of what constitutes a sport injury occur in the literature (Inklaar, 1994a; Dvorak \& Junge, 2000; Junge \& Dvorak, 2000; Wong \& Hong, 2005), and many authors have therefore pointed out the need for a consensus in not just injury definitions, but also study design, data collection and procedure (van Mechelen et al., 1992; Inklaar, 1994a; Dvorak \& Junge, 2000; Junge \& Dvorak, 2000; Ekstrand \& Karlsson, 2003; Brooks \& Fuller, 2006). With respect to football medicine, this resulted in a methodological consensus statement (Fuller et al., 2006). The consensus suggests that an injury is defined as "Any physical complaint sustained by a player that results from a football match or football training, irrespective of the need for medical attention or time-loss from football activities." It refers to injuries causing the player to seek medical attention as "medical-attention" injuries, while injuries that force a player from taking full part in future football training or match play as "time-loss" injuries. Also, injuries occurring during leisure time or other sports are not counted as injuries. Previously, other authors have recorded injuries that caused insurance claims to be submitted or required treatment in a traumatology department or hospital. Obviously, such definitions would exclude less severe and also most overuse injuries. Historically, however, defining injury according to time loss has been most widely used when studying the injury characteristics of elite football. This definition requires the player to have missed at least one training session or match (Árnason et al., 1996; Witvrouw et al., 2003; Árnason et al., 2004b), the next training session or match (Ekstrand \& Tropp, 1990; Askling et al., 2003; Hägglund et al., 2003; Árnason et al., 2004c; Hägglund et al., 2005; Waldén et al., 2005b; Waldén et al., 2007), the next day (Hawkins \& Fuller, 1999; Drawer \& Fuller, 2002; Andersen et al., 2003; Andersen et al., 2004a; Andersen et al., 2004c; Árnason et al., 2005) or the next two days (Woods et al., 2002; Woods et al., 2003; Woods et al., 2004). A limitation is that it depends on the frequency of matches and training sessions. In this way, it may introduce bias when comparing different ages and levels of play, such as the elite and sub-elite levels. Also, as some 
players still elect to play despite discomfort, some overuse injuries may be missed. Hence, the medical attention injury definition has been introduced in order to include even less severe injuries than the time-loss definition. However, this definition depends on the level of access to medical personnel and personal factors such as a player's willingness to seek assistance for an injury. The anatomical tissue injury definition spans even broader, and includes injuries that occur as a result of playing football regardless of subsequent absence from participation or medical attention. This should enable comparison between different sports. Even so, it depends on how active observers are in finding the injured players and requires an evaluation by a medically qualified co-ordinator. Another potential disadvantage is the risk of including small, irrelevant complaints such as bruises and wounds. Finally, some authors have used a combination of the different injury definitions (Inklaar et al., 1996; Emery et al., 2005).

In conclusion, there are several different definitions of injury used in football medicine research, all with different strengths and limitations. According to the consensus statement (Fuller et al., 2006), "time loss" and "medical attention" are the definitions suggested for use in order to compare different studies. These two definitions are also the definitions used in the present studies (Papers $\mathrm{I}-\mathrm{V})$. 


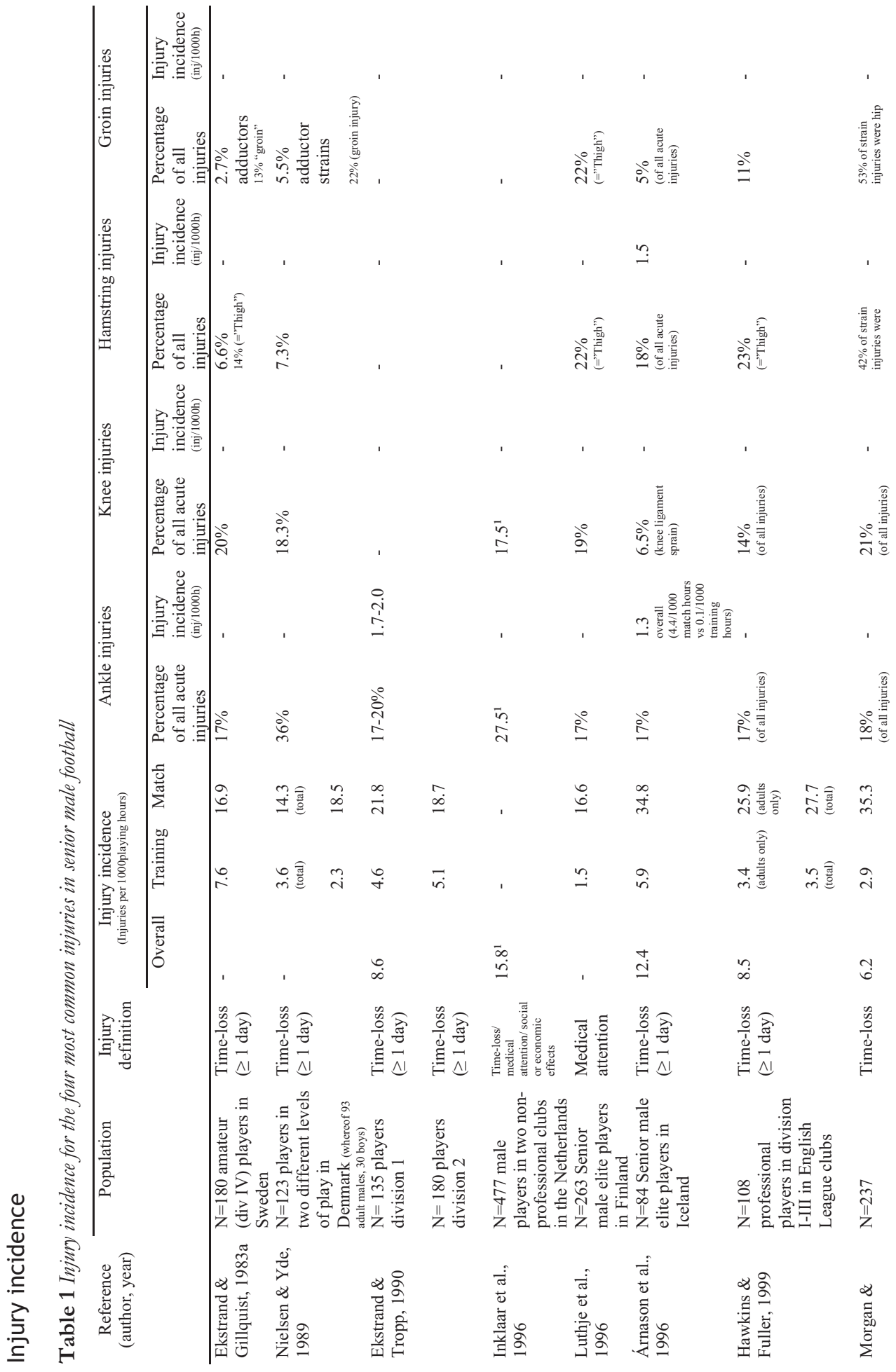




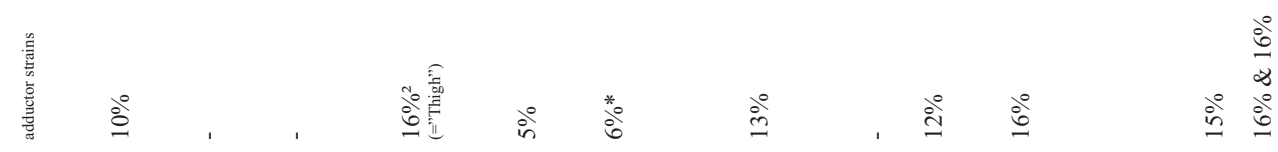

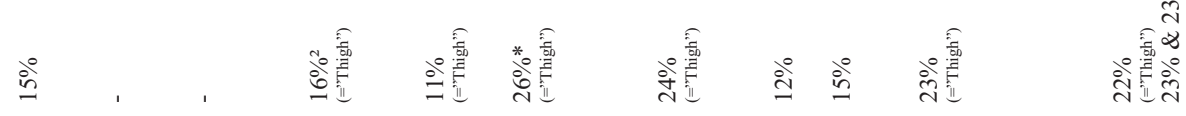

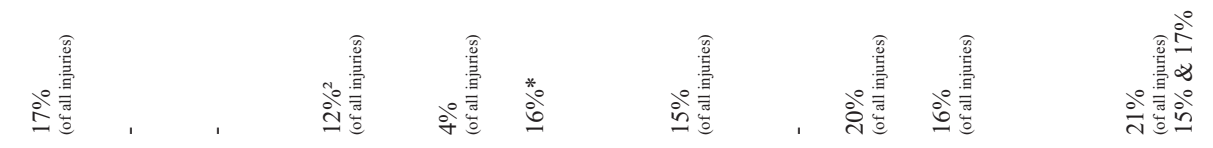

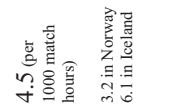

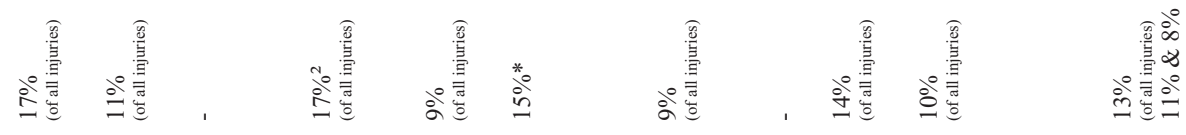

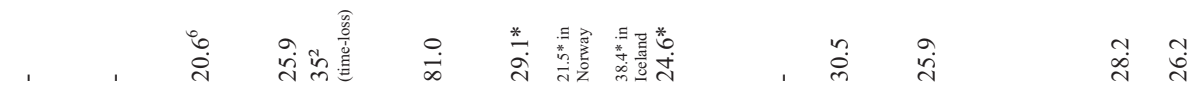

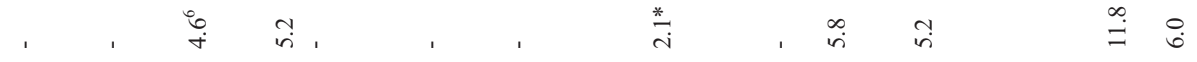

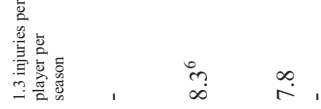

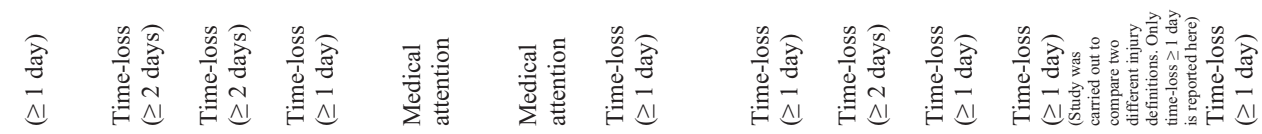

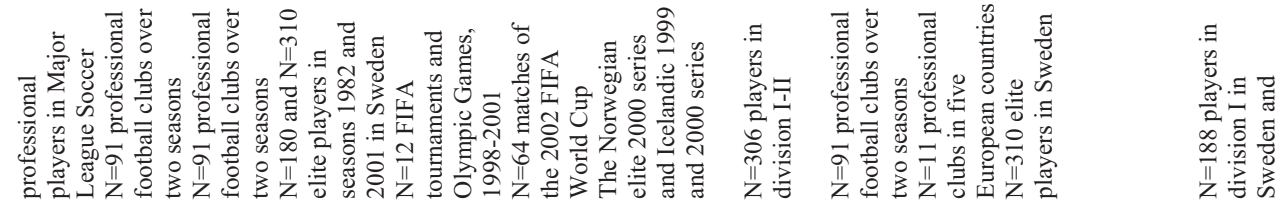

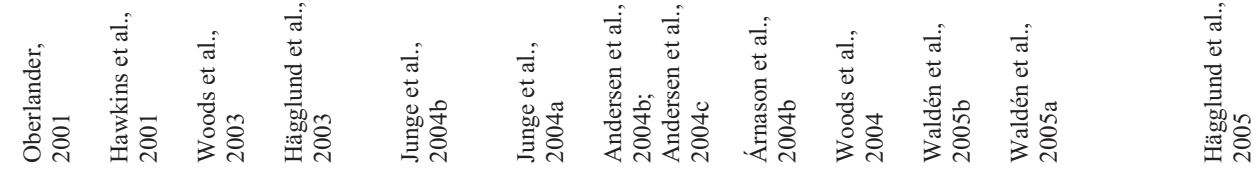




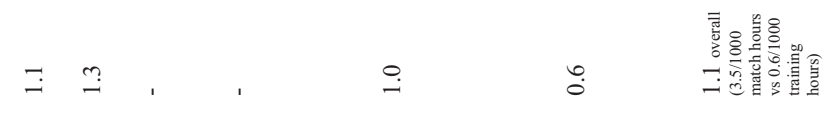

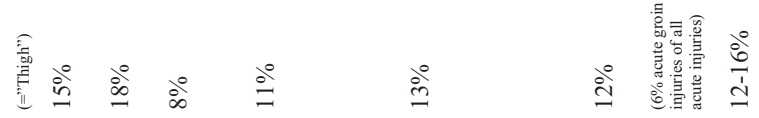

过 $\stackrel{n}{\square}$

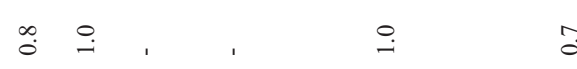

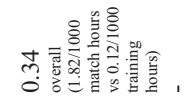

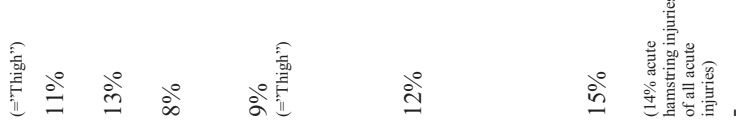

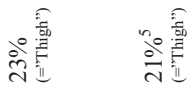

$\stackrel{\circ}{\circ}$

n?

$\stackrel{0}{0}$

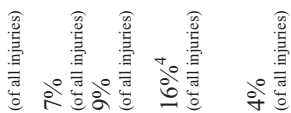

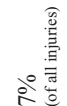

$\stackrel{0}{\stackrel{2}{\leftrightarrows}}$

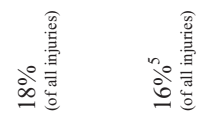

$\stackrel{n}{3}$ ?

$\stackrel{\infty}{\circ}$

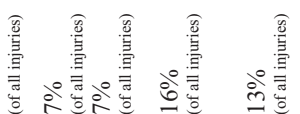

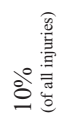

i̊

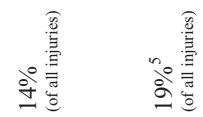

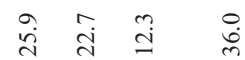

$\vec{\infty}$

$\overrightarrow{\mathrm{I}}$

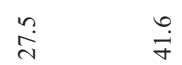

$\overrightarrow{\text { in }}$ in $\vec{i} \quad \vec{i}$

F

ì

$\underset{+}{i}$

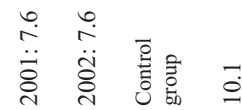

于

$\stackrel{+}{\circ} \stackrel{+}{\circ}$

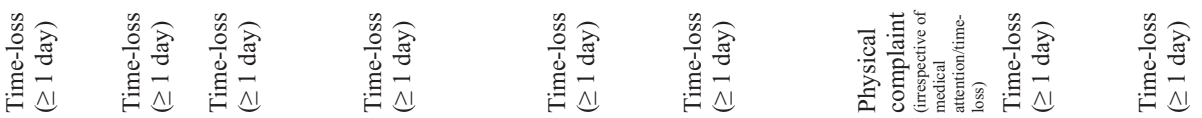

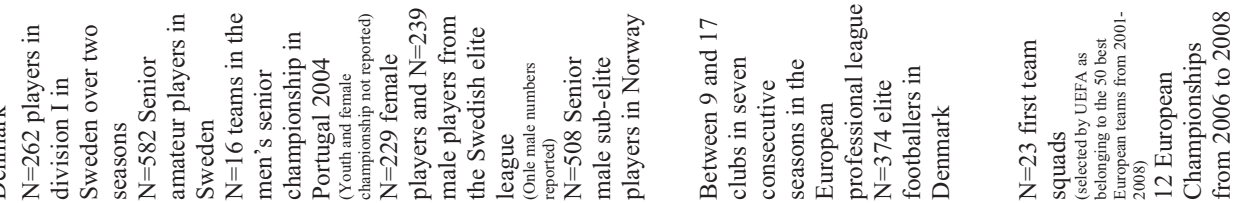

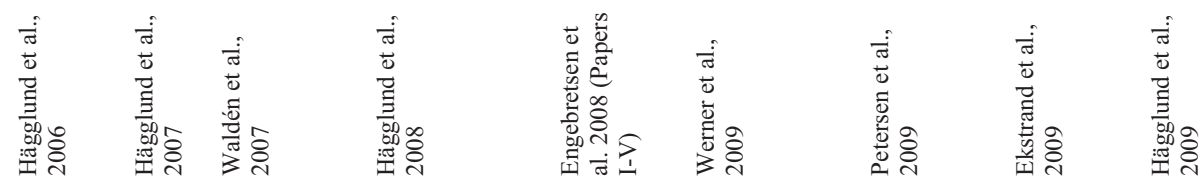




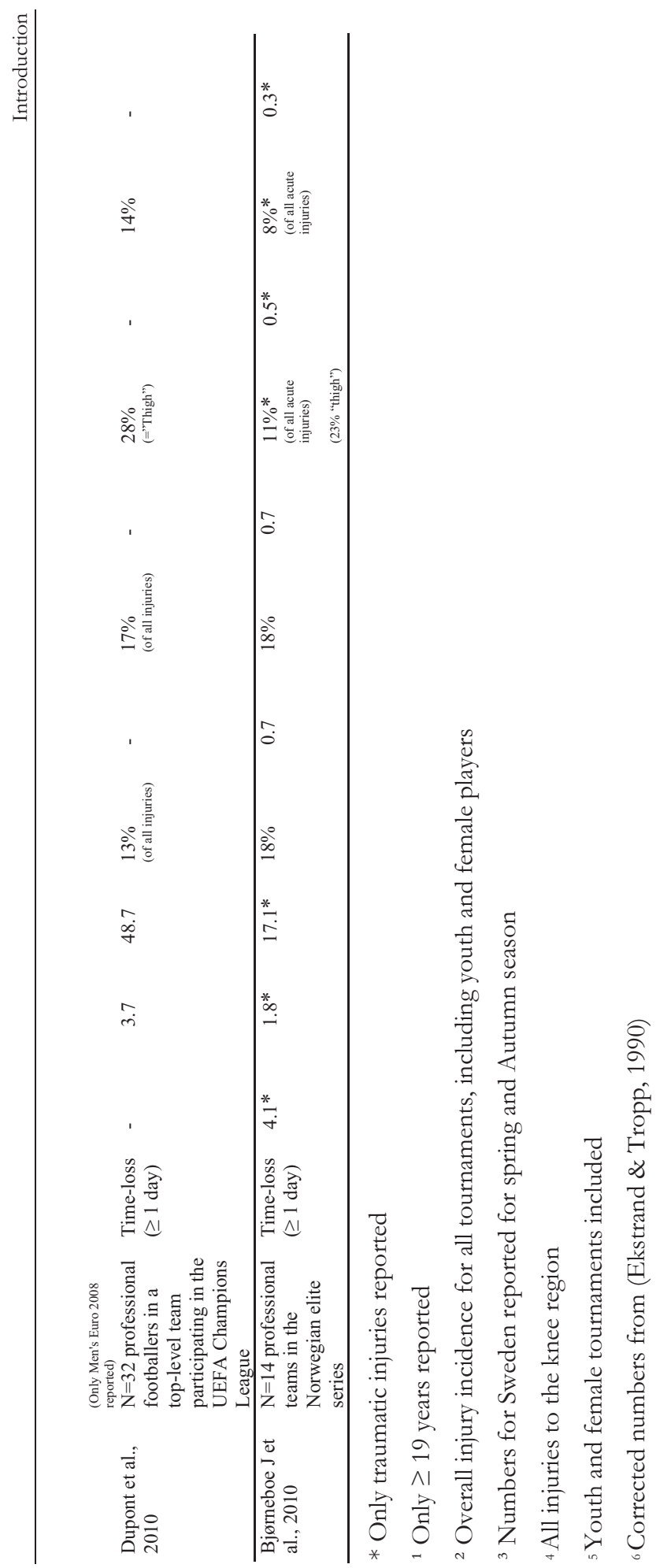


Injury incidence is a measure of injury risk corrected for exposure, and should preferably be expressed as the number of injuries per 1000 participation hours (van Mechelen et al., 1992). The incidence of injuries among adult male football players on the elite level has been estimated to range between 25 and 35 per 1000 game hours (Árnason et al., 1996; Hawkins \& Fuller, 1999; Junge et al., 2004b; Waldén et al., 2005b). Thus, the injury risk is considerable and high compared with most other team sports (Junge et al., 2004b). Studies from professional leagues in Europe (Norway, Sweden, Iceland, Britain, Fédération Internationale de Football Association [FIFA], and Union of European Football Associations [UEFA]) agree that injuries to the lower extremities constitute the biggest problem (Árnason et al., 1996; Hawkins \& Fuller, 1999; Junge et al., 2004b; Andersen et al., 2004c; Waldén et al., 2005a; Waldén et al., 2005b). The four dominating injury types in football are sprains to the ankle and knee and strains of the hamstring and groin. Together, these account for approximately $60-80 \%$ of all reported injuries (Hägglund et al., 2005; Waldén et al., 2005b; Hägglund et al., 2009; Ekstrand et al., 2009; Dupont et al., 2010) (Table 1). The incidence in senior male football for ankle injuries alone ranges from 0.5 to 2.0 injuries per 1000 playing hours (Ekstrand \& Tropp, 1990; Árnason et al., 1996; Hägglund et al., 2006; Bjørneboe J et al., 2010), accounting for 7\% to 20\% of all injuries (Ekstrand \& Gillquist, 1983a; Ekstrand \& Tropp, 1990; Árnason et al., 1996; Hawkins \& Fuller, 1999; Hawkins et al., 2001; Morgan \& Oberlander, 2001; Woods et al., 2003; Andersen et al., 2004b; Árnason et al., 2004b; Hägglund et al., 2005; Waldén et al., 2005a; Waldén et al., 2005b; Hägglund et al., 2006; Hägglund et al., 2009; Ekstrand et al., 2009; Bjørneboe J et al., 2010; Dupont et al., 2010). The incidence for knee injuries ranges from 0.5 to 0.7 injuries per 1000 playing hours (Hägglund et al., 2006; Hägglund et al., 2008; Bjørneboe J et al., 2010), and knee injuries account for $7 \%$ to $21 \%$ of all injuries (Ekstrand \& Gillquist, 1983a; Hawkins \& Fuller, 1999; Hawkins et al., 2001; Morgan \& Oberlander, 2001; Junge \& Dvorak, 2004; Árnason et al., 2004b; Hägglund et al., 2005; Waldén et al., 2005a; Waldén et al., 2005b; Hägglund et al., 2006; Ekstrand et al., 2009; Bjørneboe J et al., 2010; Dupont et al., 2010). Strain injuries of the hamstrings, with an injury incidence of 0.8 to 1.5 injuries per 1000 playing hours (Árnason et al., 1996; Hägglund et al., 2006), account for $11 \%$ to $15 \%$ of all injuries in football (Hawkins et al., 2001; Woods et al., 2004; Waldén et al., 2005b; Hägglund et al., 2006), while the injury incidence for groin strains is reported to be 1.1-1.3 injuries per 1000 playing hours (Hägglund et al., 2006; Werner et al., 2009), and groin injuries account for $10 \%$ to $18 \%$ of all injuries in senior male football (Ekstrand \& Gillquist, 1983b; Hawkins \& Fuller, 1999; Hawkins et al., 2001; Árnason et al., 2004b; Hägglund et al., 2005; Waldén et al., 2005a; Waldén et al., 2005b; Hägglund et al., 2006; Hägglund et al., 2008; Werner et al., 2009; Ekstrand et al., 2009; Dupont et al., 2010). 
While most of the epidemiology from football is based on the elite level, little is known about the injury incidence on the sub-elite levels among adults. However, there are a few studies from lower levels amateur football which have indicated that the injury incidence may be lower (Ekstrand et al., 1983b; Hägglund et al., 2007).

Consequently, there is a need for more studies to map the injury risk at sub-elite levels of football. This will be addressed in Paper I, and incidences of ankle, knee, hamstring and groin injuries will be reported in Papers II-V. However, as documented above, ankle, knee, hamstring and groin injuries constitute a major concern in football and efforts to prevent these injuries are needed. This issue will be addressed in Paper I.

\section{Football from the 1980s until today}

Football has evolved in professionalism during the last decades and become faster and with higher intensity (Tumilty, 1993). Each player has less time until challenged by an opponent, and the margin between victory and defeat is even smaller than before. The best teams continue to increase their physical capacities compared to values reported 30 years ago (Stølen et al., 2005). Accordingly, it may be expected that injury risk has increased correspondingly. As stated above, differences in injury definition make comparisons challenging. Still, as can be seen from table 1, there is no obvious trend towards an increasing injury incidence during the last decades. However, there seems to be a trend indicating an increased proportion of strain injuries, predominantly to the hamstring and groin, while the frequency of ankle and knee injuries has remained constant. Studies from the 1980s and early 1990s found ankle and knee sprains to be the most frequent injuries, accounting for 17-36\% (ankle) and 18-20\% (knee) of all acute injuries (Ekstrand \& Gillquist, 1983a; Nielsen \& Yde, 1989; Ekstrand \& Tropp, 1990). Hamstring and groin injuries accounted for 6.6-7.3\% ("thigh injuries") and 2.7-5.5\% of all injuries in the same studies (Ekstrand \& Gillquist, 1983a; Nielsen \& Yde, 1989). Also, Ekstrand and Gillquist reported strains of the quadriceps muscles to be more frequent than hamstring and hip adductor muscles (Ekstrand \& Gillquist, 1982). In contrast, more recent studies have found ankle and knee injuries to account for 15-18\% (Andersen et al., 2004b; Andersen et al., 2004c; Bjørneboe J et al., 2010) and 16-18\% (Andersen et al., 2004b; Andersen et al., 2004c; Bjørneboe J et al., 2010) of all acute injuries respectively, while hamstring and groin injuries account for 11-15\% (Woods et al., 2004; Waldén et al., 2005b; Hägglund et al., 2006) and 12-18\% (Árnason et al., 2004b; Hägglund et al., 2005; Waldén et al., 2005a; Waldén et al., 2005b; Hägglund et al., 2006; Werner et al., 2009; Ekstrand et al., 2009; Dupont et al., 2010) of all injuries, as shown in table 1. 
This trend towards a shift in frequency from joint injuries to strain injuries is, however, not by any means strong. If there really is a true change from joint to strain injuries, it might be explained by the early introduction of good preventive regimens for ankle and knee injuries (Ekstrand et al., 1983a; Tropp et al., 1985; Surve et al., 1994; Caraffa et al., 1996), and that professionalism in football has ensured the implementation of these measures in daily training by teams striving for success (Árnason et al., 2004a). In contrast, at the same time, the same teams have focused on stretching to prevent strains, a method which nowadays is left with less credibility in the literature (Herbert \& Gabriel, 2002; Thacker et al., 2004; Hart, 2005). Other strain-preventive exercises have been introduced later (Askling et al., 2003; Árnason et al., 2008).

\section{Multifactorial etiology model}

Understanding the risk factors for injuries is an important foundation for the prevention of injuries. Injury causation is complex and models have therefore been developed to take into account the multicausal etiology and chain of events that lead to injury (Figure 1) (Bahr \& Krosshaug, 2005). Traditionally, risk factors have been divided into two main categories; intrinsic athlete related factors and extrinsic environmental risk factors (van Mechelen et al., 1992). Intrinsic risk factors can be further classified as physical (such as height, weight, BMI, age, gender, previous injuries, level of play, flexibility, joint instability, anatomical malalignment, muscle strength, aerobic fitness, functional performance) (Taimela et al., 1990; Inklaar, 1994b; Engström \& Renström, 1998; Östenberg \& Roos, 2000; Dvorak et al., 2000b; Gissane et al., 2001) and psychological (such as life-event stress, fighting mentality and risk-taking behavior) (Taimela et al., 1990; Dvorak et al., 2000b). Extrinsic factors may be the playing surface, player exposure, playing position, time in match, equipment (shoes, shin guards, use of tape/orthosis), coaching-related factors (quality, training load), rules and foul play (Taimela et al., 1990; Inklaar, 1994b; Engström \& Renström, 1998; Gissane et al., 2001; Dvorak, 2009). The intrinsic and extrinsic risk factors contribute towards athlete susceptibility to injuries, but are usually distant from the time of injury and rarely sufficient as a cause of injury alone. 


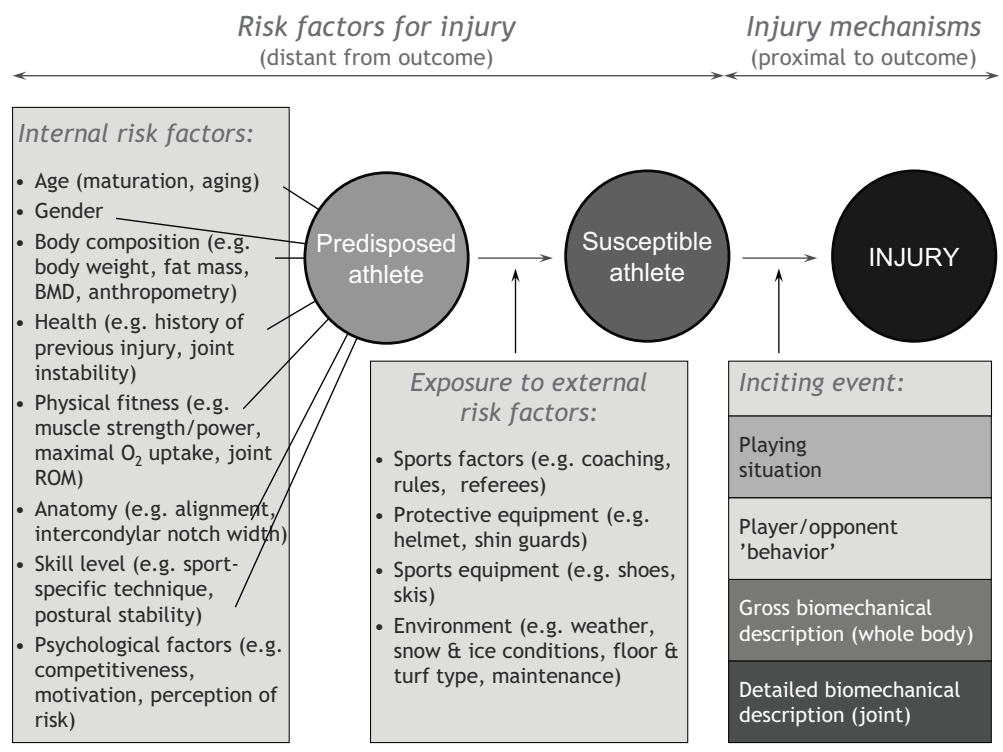

Figure 1. A multicausal etiology model illustrating the interaction of intrinsic and extrinsic risk factors and the inciting event leading to injury (Bahr \& Krosshang, 2005).

The classification put forward by Meeuwisse et al (1994) has later been modified by Bahr \& Krosshaug (2005) to underline the importance of understanding the inciting event. This way, possible interaction (when two factors work together to produce a risk which is greater or lesser than expected) and confounding (when an association between two variables of interest could be due to the effects of a third variable) are taken into account (Meeuwisse, 1994). As described by Bahr \& Holme (2003), there are three main study designs available to study risk factors for sports injuries; case-control studies, cohort studies and intervention studies (preferably done as a randomised controlled trial). Of these, the latter two are preferred, and although randomized controlled trials can provide the strongest evidence to evaluate cause-effect relationships and is the preferred method for testing different preventive measures, they are limited to risk factors that can be modified and are usually used to assess the effect of only one factor at the time. A cohort study design, with the main disadvantage being the size of the study required, was therefore the method chosen for risk factor analyses of ankle (Paper II), knee (Paper III), hamstring (Paper IV) and groin (Paper V) injuries. The risk factor studies (Papers II-V) in this thesis focus on intrinsic physical risk factors. Also, as injuries mainly result from a complex interaction of multiple risk factors and events, multivariate statistical analyses should be used for risk factor studies (Bahr \& Holme, 2003). 


\section{Risk factors for injuries}

Risk factors, whether intrinsic or extrinsic, are either modifiable or nonmodifiable.

Nonmodifiable factors cannot be altered, but may still affect the relationship between modifiable risk factors and injury (Meeuwisse, 1991). They can even be used to target intervention programs towards individuals at greater risk.

\section{Risk factors for ankle sprains}

Several authors have found previous ankle injury to be a significant risk factor for new injuries. This seems to be a consistent finding, especially when rehabilitation is inadequate, both among senior male soccer players (Ekstrand \& Gillquist, 1983a; Tropp et al., 1985; Kofotolis et al., 2007) and in male athletes in other sports (Bahr \& Bahr, 1997; McKay et al., 2001; Tyler et al., 2006; McGuine \& Keene, 2006; McHugh et al., 2006). In contrast, Trojian \& McKeag (2006) in a study among 230 senior male and female athletes from high school and college in American football, soccer and volleyball in the US, did not find a history of a previous injury to be significantly associated with increased injury risk. One has to bear in mind that the above mentioned studies have only included univariate analyses, which is a definite weakness of such studies. However, a multivariate analysis from the two highest divisions of play in male Icelandic football found that players with a history of previous ankle injury had a more than five times higher risk of sustaining a new ankle sprain (Árnason et al., 2004b). Another multivariate risk factor study identified previous injury as a risk factor for the other main injuries in football (knee, hamstring and groin) in Swedish elite male football, but did not succeed in doing so for the ankle (Hägglund et al., 2006). Even so, the authors did conclude that there was a tendency towards an increased risk for ankle sprain in the previously injured leg and a decrease in risk for ankle sprain with increasing age, but none of the variables reached statistical significance.

Amongst other potential risk factors for ankle injuries in male football (see table 2) are clinical instability (Ekstrand \& Gillquist, 1983b) and single leg balance test (Trojian \& McKeag, 2006). It has also been suggested that there is a greater risk of injury towards the end of a game and that ankle injuries most often occur during the first 2 months of the season (Kofotolis et al., 2007). Several other potential risk factors have been tested and suggested as possible predictors of increased risk among female players or among male athletes in other sports. These include slow reaction time (Taimela et al., 1990; Árnason et al., 2004b), personality factors (Taerk, 1977; Lysens et al., 1989; Taimela et al., 1990; Junge et al., 2000; Árnason et al., 2004b), age (Backous et al., 1988; Lindenfeld et al., 1994; Östenberg \& Roos, 2000), general joint laxity (Baumhauer et al., 1995; Östenberg \& Roos, 2000; Beynnon et al., 2001), ankle joint laxity (Beynnon et al., 2001) 
and balance tests (Trojian \& McKeag, 2006). Regarding body size measures such as height, weight and body mass index (BMI), the literature is also inconclusive (Backous et al., 1988; Baumhauer et al., 1995; Beynnon et al., 2001; Tyler et al., 2006). Later, after the start of the present study, a systematic review of postural control and lateral ankle instability (McKeon \& Hertel, 2008) has concluded that poor postural control is associated with increased risk of ankle injury.

In a large systematic review on epidemiological studies on sports injury from 1977-2005, Fong et al (2007) report that football is among the sports with the highest ankle injury incidence.

Consequently, they recommend that ankle sprain prevention programs should be implemented in these sports. Accordingly, some of the above mentioned risk factors have been tested further in intervention studies among senior male football players. Balance training (Tropp et al., 1985) and the use of orthoses (Tropp et al., 1985; Surve et al., 1994) have resulted in significantly fewer ankle sprains, indicating that reduced neuromuscular control may be an important risk factor for ankle injuries.

Table 2. Studies on risk factors for ankle injuries in senior male football

\begin{tabular}{|c|c|c|c|c|c|c|}
\hline $\begin{array}{l}\text { Reference (author, } \\
\text { year) }\end{array}$ & Population & Study design & $\begin{array}{l}\text { Injury } \\
\text { definition }\end{array}$ & $\begin{array}{l}\text { Univariate / } \\
\text { Multivariate }\end{array}$ & $\begin{array}{l}\text { Outcome } \\
\text { measure }\end{array}$ & Risk factors \\
\hline $\begin{array}{l}\text { Ekstrand \& } \\
\text { Gillquist 1983a }\end{array}$ & $\begin{array}{l}\mathrm{N}=180 \text { Senior male } \\
\text { amateur players in } \\
\text { Sweden }\end{array}$ & $\begin{array}{l}\text { Prospective } \\
\text { cohort study }\end{array}$ & $\begin{array}{l}\text { Time-loss } \\
\text { ( } \geq 1 \text { day) }\end{array}$ & Univariate & Ankle sprain & $\begin{array}{l}\text { Previous ankle injury } \\
\text { Clinical instability }\end{array}$ \\
\hline Tropp et al. 1985 & $\begin{array}{l}\mathrm{N}=439 \text { Senior male } \\
\text { amateur players in } \\
\text { Sweden, division VI }\end{array}$ & $\begin{array}{l}\text { Randomized } \\
\text { controlled } \\
\text { trial }\end{array}$ & $\begin{array}{l}\text { Time-loss } \\
\text { ( } \geq 1 \text { day) }\end{array}$ & - & Ankle injury & Previous ankle injury \\
\hline Surve et al. 1994 & $\begin{array}{l}\mathrm{N}=629 \text { Senior male } \\
\text { players in South- } \\
\text { Africa } \\
\text { Divisions } 1-4\end{array}$ & $\begin{array}{l}\text { Randomized } \\
\text { controlled } \\
\text { trial }\end{array}$ & $\begin{array}{l}\text { Time-loss } \\
\text { ( } \geq 1 \text { day) }\end{array}$ & - & Ankle injury & Previous ankle injury \\
\hline $\begin{array}{l}\text { Árnason et al. } \\
2004 b\end{array}$ & $\begin{array}{l}\mathrm{N}=306 \text { Senior male } \\
\text { players from the two } \\
\text { highest divisions in } \\
\text { Iceland }\end{array}$ & $\begin{array}{l}\text { Prospective } \\
\text { cohort study }\end{array}$ & $\begin{array}{l}\text { Time-loss } \\
(\geq 1 \text { day })\end{array}$ & Multivariate & Ankle injury & Previous ankle injury \\
\hline $\begin{array}{l}\text { Trojian \& McKeag } \\
2006\end{array}$ & $\begin{array}{l}\mathrm{N}=230 \text { Senior male } \\
\text { and female athletes } \\
\text { from high school and } \\
\text { college in American } \\
\text { football, soccer and } \\
\text { volleyball in the } \\
\text { U.S.A. }\end{array}$ & $\begin{array}{l}\text { Prospective } \\
\text { cohort study }\end{array}$ & $\begin{array}{l}\text { Time-loss } \\
\text { (caused the player } \\
\text { to miss the rest of } \\
\text { practice or } \\
\text { competition, or } \\
\text { miss the next } \\
\text { practice or } \\
\text { competition) }\end{array}$ & Univariate & Ankle injury & $\begin{array}{l}\text { Single leg balance test } \\
\text { Previous injury not } \\
\text { associated with } \\
\text { increased injury risk }\end{array}$ \\
\hline Hägglund et al 2006 & $\begin{array}{l}\mathrm{N}=263 \text { and } \mathrm{N}=262 \\
\text { elite male players in } \\
\text { two consecutive } \\
\text { seasons in Sweden }\end{array}$ & $\begin{array}{l}\text { Prospective } \\
\text { cohort study }\end{array}$ & $\begin{array}{l}\text { Time-loss } \\
\text { ( } \geq 1 \text { day) }\end{array}$ & Multivariate & Ankle injury & $\begin{array}{l}\text { No significant risk } \\
\text { factors for ankle injury } \\
\text { in the multivariate } \\
\text { analysis } \\
\text { (Previous injury } \\
\text { included) }\end{array}$ \\
\hline Kofotolis et al. 2007 & $\begin{array}{l}\mathrm{N}=312 \text { Senior male } \\
\text { amateur players }\end{array}$ & $\begin{array}{l}\text { Descriptive } \\
\text { epidemiology } \\
\text { study }\end{array}$ & $\begin{array}{l}\text { Time-loss } \\
\text { ( } \geq 1 \text { day) }\end{array}$ & Multivariate & Ankle injury & $\begin{array}{l}\text { Previous ankle injury } \\
\text { Implied that risk of injury is } \\
\text { higher toward the end of a game } \\
\text { and that ankle injuries most often } \\
\text { occur during the first } 2 \text { months of } \\
\text { the season }\end{array}$ \\
\hline
\end{tabular}




\section{Risk factors for knee sprains}

A history of previous knee injuries seems to be the most important risk factor for new injuries, both in male football (see table 3) (Ekstrand \& Gillquist, 1983a; Árnason et al., 2004b; Hägglund et al., 2006) and among male athletes in other sports (Taunton et al., 2003; Meeuwisse et al., 2003; Yung et al., 2007), especially when rehabilitation is inadequate (Árnason et al., 2004b; Hägglund et al., 2006). Árnason et al. (2004b) found previous knee injury to be the only significant risk factor for a new injury to the same knee in a large cohort study investigating several risk factors for football injuries. In the same study, increased valgus laxity was associated with a history of previous injury. After the start of the present study, previous injury was the only risk factor identified in a recent study from female youth football (Steffen et al., 2008a).

Studies from different sports, age groups or among female athletes have suggested other potential risk factors, but with limited documentation for senior male players. These include gender (Lindenfeld et al., 1994; Ahmad et al., 2006; McLean et al., 2007), age (Backous et al., 1988; Lindenfeld et al., 1994; Östenberg \& Roos, 2000), slow reaction time (Taimela et al., 1990), personality factors (Taerk, 1977; Lysens et al., 1989; Taimela et al., 1990; Junge et al., 2000), disobeying fair play (Roberts et al., 1996; Peterson et al., 2000), playing position (Lindenfeld et al., 1994), quadriceps-to-hamstring strength ratio (Ahmad et al., 2006), landing technique (Hass et al., 2005; McLean et al., 2007), fatigue (McLean et al., 2007), neuromuscular control of the knee (Hewett et al., 2005) or trunk (Zazulak et al., 2007), history of low back pain (Zazulak et al., 2007) and general joint laxity (Baumhauer et al., 1995; Östenberg \& Roos, 2000; Beynnon et al., 2001; Myer et al., 2008).

Intervention studies have shown that neuromuscular training may prevent knee sprains (Caraffa et al., 1996), indicating that reduced neuromuscular control may be an important risk factor for knee injuries. However, the evidence among adult male players is limited, as most studies have been carried out in other sports or among female or younger athletes (Myklebust et al., 2003; Mandelbaum et al., 2005; Olsen et al., 2005). 
Table 3. Studies on risk factors for knee injuries in senior male football

\begin{tabular}{|c|c|c|c|c|c|c|}
\hline $\begin{array}{c}\text { Reference (author, } \\
\text { year) }\end{array}$ & Population & $\begin{array}{l}\text { Study } \\
\text { design }\end{array}$ & $\begin{array}{l}\text { Injury } \\
\text { definition }\end{array}$ & $\begin{array}{l}\text { Univariate / } \\
\text { Multivariate }\end{array}$ & $\begin{array}{l}\text { Outcome } \\
\text { measure }\end{array}$ & Risk factors \\
\hline $\begin{array}{l}\text { Ekstrand \& } \\
\text { Guillquist 1983a }\end{array}$ & $\begin{array}{l}\mathrm{N}=180 \text { Senior male } \\
\text { amateur players in } \\
\text { Sweden }\end{array}$ & $\begin{array}{l}\text { Prospective } \\
\text { cohort study }\end{array}$ & $\begin{array}{l}\text { Time-loss } \\
(\geq 1 \text { day) }\end{array}$ & Univariate & $\begin{array}{l}\text { Knee } \\
\text { ligament } \\
\text { sprains }\end{array}$ & Previous knee injury \\
\hline $\begin{array}{l}\text { Árnason et al. } \\
2004 b\end{array}$ & $\begin{array}{l}\mathrm{N}=306 \text { Senior male } \\
\text { players from the } \\
\text { two highest } \\
\text { divisions in Iceland }\end{array}$ & $\begin{array}{l}\text { Prospective } \\
\text { cohort study }\end{array}$ & $\begin{array}{l}\text { Time-loss } \\
(\geq 1 \text { day) }\end{array}$ & Univariate & $\begin{array}{l}\text { Knee } \\
\text { ligament } \\
\text { injury }\end{array}$ & $\begin{array}{l}\text { Previous knee injury } \\
\text { (Especially important when } \\
\text { rehabilitation is inadequate) } \\
\text { (Only risk factors with }>0.20 \text {; } \\
\text { hence, no multivariate analysis } \\
\text { performed) }\end{array}$ \\
\hline $\begin{array}{l}\text { Hägglund et al. } \\
2006\end{array}$ & $\begin{array}{l}\mathrm{N}=263 \text { and } \mathrm{N}=262 \\
\text { elite male players in } \\
\text { two consecutive } \\
\text { seasons in Sweden }\end{array}$ & $\begin{array}{l}\text { Prospective } \\
\text { cohort study }\end{array}$ & $\begin{array}{l}\text { Time-loss } \\
(\geq 1 \text { day) }\end{array}$ & Multivariate & $\begin{array}{l}\text { Knee joint } \\
\text { trauma }\end{array}$ & $\begin{array}{l}\text { Previous knee injury } \\
\text { (Especially important when } \\
\text { rehabilitation is inadequate) }\end{array}$ \\
\hline Waldén et al. 2006 & $\begin{array}{l}\mathrm{N}=310 \text { elite male } \\
\text { players in Sweden }\end{array}$ & $\begin{array}{l}\text { Prospective } \\
\text { cohort study }\end{array}$ & $\begin{array}{l}\text { Time-loss } \\
(\geq 1 \text { day) }\end{array}$ & Univariate & Knee injury & Previous ACL injury \\
\hline
\end{tabular}

\section{Risk factors for hamstring strains}

The high incidence of injuries of the hamstring muscle group may partly be explained by the fact that this muscle group functions over two joints (Devlin, 2000; Hawkins et al., 2001; Orchard \& Seward, 2002) and is therefore subject to stretch at more than one point (Devlin, 2000; Orchard \& Seward, 2002). Also, the greater proportion of fast-twitch fibres in the hamstring muscles compared with other thigh and leg muscles means that they are capable of high force production (Hawkins et al., 2001). Following this chain of thought, a domination of fast twitch (type II) fibres would put a player at increased risk. Interestingly, therefore, Woods et al. (2004) in a large study in English professional football found that players with a black ethnic origin were at increased risk of sustaining hamstring strains compared to white players. No other studies in senior male football have looked into this, but Verrall et al., (2001) in a study from Australian rules football, found players of aboriginal descent to be at increased injury risk. They argue that this could be due to a greater proportion of type II fibres which may predispose them to injury (Verrall et al., 2001). However, the more common occurrence of anteriorally tilted pelvis in players of black origin is also a possible explanation (Brockett et al., 2001). Because ethnic origin was not recorded in the present study, this issue will not be further addressed, but an indirect measure of type II fibres was attained through the sprint and counter movement jump tests (papers III-V).

Indications of important risk factors may arise by examining injury mechanisms. In the study from English professional football, two-thirds of hamstring strains occurred in matches (Woods et al., 2004). Also, a strikingly high proportion of injuries occur during running, and hamstring strains were mostly sustained at the end of matches and training sessions. Furthermore, this is 
supported by studies suggesting fatigue as a risk factor for hamstring injuries (Worrell, 1994; Kujala et al., 1997; Greig, 2008). Also, a study found a significant reduction in peak eccentric knee flexor torque at high speeds due to passive players remaining seated throughout the halftime interval (Greig, 2008). Because insufficient warm-up is a potential risk factor for hamstring strains (Worrell, 1994; Kujala et al., 1997), it is suggested that re-warming strategies during the halftime interval should be considered, in order to reduce the negative influence of the passive halftime interval (Lovell et al., 2007; Greig, 2008).

The recurrence rate for hamstring strains in football is high (12\%) (Woods et al., 2004). The rationale for the high rate of recurrent strain injuries is not fully known, but may be the result of scar tissue formation or other structural changes (Noonan \& Garrett, Jr., 1992; Jarvinen et al., 2000) or that full function has not been restored. It is suggested that the shorter optimum of previously injured muscles makes them more prone to damage from eccentric exercise than uninjured muscles (Brockett et al., 2004). The shorter optimum may reflect the muscle's preinjury state or be a consequence of the healing process. Frequently, injuries occur due to too early return to play and incomplete rehabilitation (Croisier et al., 2002; Croisier, 2004). Also, strength deficits or imbalances have been suggested to increase hamstring injury risk (Croisier et al., 2008), although the relationship between advanced isokinetic testing and injury risk is not fully resolved (Bennell et al., 1998).

Given the high recurrence rate for hamstring strains, it is not surprising that previous hamstring injury, especially when rehabilitation is inadequate, is the best documented risk factor for hamstring strains in football (Árnason et al., 2004b) and other sports (Bennell et al., 1998; Verrall et al., 2001; Gabbe et al., 2006). Another study among senior male footballers, carried out after start of the present study, has also shown this association (Hägglund et al., 2006). Also, age has been shown to be a risk factor in Australian rules football (Orchard, 2001; Gabbe et al., 2006) and in football (Árnason et al., 2004b), even independent of history of previous injury (Árnason et al., 2004b). Studies have implied that low hamstring strength (Orchard et al., 1997; Croisier et al., 2002) and muscle imbalances (Worrell, 1994; Orchard et al., 1997; Kujala et al., 1997) may leave players at risk, and a study from American football examining two different rehabilitation programs after acute hamstring strain demonstrated that players who followed an isokinetic strength training program had a significant reduction in risk of reinjury (Heiser et al., 1984). Another study had shown that another eccentric exercise, "Nordic Hamstring lowers", was useful in injury prevention (Askling et al., 2003). Also, based on a randomized training study among 21 sub-elite and amateur players in Norway (Mjølsnes et al., 2004), the authors suggested that poor eccentric strength may be a risk factor. However, this study did not include any injury data. After 
the start of the present study, a study among male footballers has shown an injury preventive effect of strength training through systematic use of Nordic Hamstring lowers (Árnason et al., 2008). A listing of risk factors for hamstring strains in senior, male football can be found in table 4.

Among other potential risk factors mentioned in the literature, reduced flexibility has been suggested as a risk factor for hamstring strains (Witvrouw et al., 2003), which is in concordance with studies from other sports as well (Worrell, 1994; Kujala et al., 1997; Hartig \& Henderson, 1999). It has also been shown that soccer players were less flexible than a control group (Ekstrand \& Gillquist, 1982) and that soccer players often do not pay sufficient attention to stretching exercises (Ekstrand et al., 1983b; Inklaar, 1994b; Árnason et al., 1996; Hawkins \& Fuller, 1998). Studies from other sports and populations have suggested other factors that may predispose for hamstring strain injuries; neural tension (Turl \& George, 1998) and dyssynergic contraction of muscle groups (Agre, 1985). However, the largest study to date in male football examining the effect of flexibility training did not detect a preventive effect (Árnason et al., 2008).

Table 4. Studies on risk factors for hamstring injuries in senior male football

\begin{tabular}{|c|c|c|c|c|c|c|}
\hline $\begin{array}{l}\text { Reference } \\
\text { (author, year) }\end{array}$ & Population & $\begin{array}{l}\text { Study } \\
\text { design }\end{array}$ & $\begin{array}{l}\text { Injury } \\
\text { definition }\end{array}$ & $\begin{array}{l}\text { Univariate / } \\
\text { Multivariate }\end{array}$ & $\begin{array}{l}\text { Outcome } \\
\text { measure }\end{array}$ & Risk factors \\
\hline $\begin{array}{l}\text { Witvrouw et al. } \\
2003\end{array}$ & $\begin{array}{l}\mathrm{N}=146 \text { professional } \\
\text { players in Belgium }\end{array}$ & $\begin{array}{l}\text { Prospective } \\
\text { cohort study }\end{array}$ & $\begin{array}{l}\text { Time-loss } \\
(\geq 1 \text { day })\end{array}$ & Univariate & $\begin{array}{l}\text { Hamstring } \\
\text { muscle } \\
\text { group injury }\end{array}$ & $\begin{array}{l}\text { Decreased flexibility of the } \\
\text { hamstring muscles }\end{array}$ \\
\hline $\begin{array}{l}\text { Árnason et al. } \\
2004 b\end{array}$ & $\begin{array}{l}\mathrm{N}=306 \text { players } \\
\text { from the two } \\
\text { highest divisions in } \\
\text { Iceland }\end{array}$ & $\begin{array}{l}\text { Prospective } \\
\text { cohort study }\end{array}$ & $\begin{array}{l}\text { Time-loss } \\
(\geq 1 \text { day })\end{array}$ & Multivariate & $\begin{array}{l}\text { Hamstring } \\
\text { strain }\end{array}$ & $\begin{array}{l}\text {-Age } \\
\text {-Previous hamstring strain }\end{array}$ \\
\hline Woods et al 2004 & $\begin{array}{l}\mathrm{N}=91 \text { professional } \\
\text { English football } \\
\text { clubs over two } \\
\text { seasons }\end{array}$ & $\begin{array}{l}\text { Prospective } \\
\text { cohort study }\end{array}$ & $\begin{array}{l}\text { Time-loss } \\
(\geq 2 \text { days })\end{array}$ & Univariate & $\begin{array}{l}\text { Hamstring } \\
\text { strain }\end{array}$ & $\begin{array}{l}\text {-Younger players at lower risk } \\
\text {-Players with black ethnic origin at } \\
\text { increased risk compared to white players } \\
\text {-Player position; goalkeepers at decreased } \\
\text { risk compared to outfielders } \\
\text {-Play at the highest level }\end{array}$ \\
\hline $\begin{array}{l}\text { Hägglund et al. } \\
2006\end{array}$ & $\begin{array}{l}\mathrm{N}=263 \text { and } \mathrm{N}=262 \\
\text { elite players in two } \\
\text { consecutive seasons } \\
\text { in Sweden }\end{array}$ & $\begin{array}{l}\text { Prospective } \\
\text { cohort study }\end{array}$ & $\begin{array}{l}\text { Time-loss } \\
(\geq 1 \text { day })\end{array}$ & Multivariate & $\begin{array}{l}\text { Hamstring } \\
\text { injury }\end{array}$ & $\begin{array}{l}\text { Previous hamstring injury } \\
\text { Increasing age }\end{array}$ \\
\hline
\end{tabular}

\section{Risk factors for groin strains}

A listing of risk factors for groin injuries in senior male football can be seen in table 5 . As for ankle, knee and hamstring injuries, previous injury, especially when rehabilitation is inadequate, places an athlete at increased risk of suffering a new groin strain injury (Árnason et al., 2004b; Hägglund et al., 2006). Age has also been suggested as risk factor for groin injuries (Árnason et al., 2004b) in football, while age and experience have been suggested in elite ice hockey (Emery \& Meeuwisse, 2001). 
Among other potential risk factors, a study among 146 professional male players in Belgian football did not find any risk factors for adductor muscle injury when examining height, weight, training/game time or muscle flexibility (Witvrouw et al., 2003). Yet, studies from different sports have suggested strength imbalances between the propulsive muscles and the stabilizing muscles of the hip and pelvis (Garrett, Jr. et al., 1987) and between the synergistic abductors and adductors as risk factors for groin injuries (Maffey \& Emery, 2007). Also, delayed contraction of the transversus abdominis, as a measure of reduced core stability, has been suggested (Cowan et al., 2004). No previous studies (Tyler et al., 2001; Árnason et al., 2004b) have identified adductor length as a risk factor for groin injury in soccer, and stretching programs do not seem to influence injury risk (Thacker et al., 2004). As stated above, the study from Belgian elite soccer found no predictive value of adductor flexibility measurements (Witvrouw et al., 2003). Still, Árnason et al. (2004b) found decreased range of motion for hip abduction to be a significant risk factor for groin injuries.

In studies from other sports, other potential risk factors are mentioned, but the results and study groups differ widely. These include high level of play (Inklaar et al., 1996), age (Emery \& Meeuwisse, 2001), core stability (Leetun et al., 2004; Cowan et al., 2004), decreased range of motion in hip abduction (Árnason et al., 2004b) and weak adductor muscles and abnormal muscle ratios (Emery, 1999; Tyler et al., 2001).

Table 5. Studies on risk factors for groin injuries in senior male football

\begin{tabular}{|c|c|c|c|c|c|c|}
\hline $\begin{array}{l}\text { Reference } \\
\text { (author, year) }\end{array}$ & Population & $\begin{array}{l}\text { Study } \\
\text { design }\end{array}$ & $\begin{array}{l}\text { Injury } \\
\text { definition }\end{array}$ & $\begin{array}{l}\text { Univariate / } \\
\text { Multivariate }\end{array}$ & $\begin{array}{l}\text { Outcome } \\
\text { measure }\end{array}$ & Risk factors \\
\hline $\begin{array}{l}\text { Ekstrand \& } \\
\text { Guillquist } \\
1983 a\end{array}$ & $\begin{array}{l}\mathrm{N}=180 \text { amateur } \\
\text { players in Sweden }\end{array}$ & $\begin{array}{l}\text { Prospective } \\
\text { cohort study }\end{array}$ & $\begin{array}{l}\text { Time-loss } \\
\text { ( } \geq 1 \text { day) }\end{array}$ & Univariate & Groin injury & $\begin{array}{l}\text { Preseason hip abduction range of } \\
\text { motion was decreased in soccer } \\
\text { players who subsequently sustained } \\
\text { groin strains }\end{array}$ \\
\hline $\begin{array}{l}\text { Witvrouw et al. } \\
2003\end{array}$ & $\begin{array}{l}\mathrm{N}=146 \text { professional } \\
\text { players in Belgium }\end{array}$ & $\begin{array}{l}\text { Prospective } \\
\text { cohort study }\end{array}$ & $\begin{array}{l}\text { Time-loss } \\
(\geq 1 \text { day })\end{array}$ & Univariate & $\begin{array}{l}\text { Adductor } \\
\text { muscle } \\
\text { injury }\end{array}$ & $\begin{array}{l}\text { No significant difference between the } \\
\text { injured and uninjured groups in } \\
\text { height, weigth, training/game time or } \\
\text { muscle flexibility for adductors }\end{array}$ \\
\hline $\begin{array}{l}\text { Árnason et al. } \\
2004 b\end{array}$ & $\begin{array}{l}\mathrm{N}=306 \text { players } \\
\text { from the two } \\
\text { highest divisions in } \\
\text { Iceland }\end{array}$ & $\begin{array}{l}\text { Prospective } \\
\text { cohort study }\end{array}$ & $\begin{array}{l}\text { Time-loss } \\
(\geq 1 \text { day })\end{array}$ & Multivariate & Groin strain & $\begin{array}{l}\text {-Previous groin strain } \\
\text {-Decreased range of } \\
\text { motion in hip abduction } \\
\text { (Univariate analyses also found } \\
\text { increasing age to be a potential risk } \\
\text { factor) }\end{array}$ \\
\hline $\begin{array}{l}\text { Hägglund et al. } \\
2006\end{array}$ & $\begin{array}{l}\mathrm{N}=263 \text { and } \mathrm{N}=262 \\
\text { elite players in two } \\
\text { consecutive seasons } \\
\text { in Sweden }\end{array}$ & $\begin{array}{l}\text { Prospective } \\
\text { cohort study }\end{array}$ & $\begin{array}{l}\text { Time-loss } \\
\text { ( } \geq 1 \text { day) }\end{array}$ & Univariate & Groin injury & $\begin{array}{l}\text { Previous groin injury } \\
\text { (Only risk factors with } \mathrm{p}<0.20 \text {; hence, } \\
\text { no multivariate analysis performed) }\end{array}$ \\
\hline $\begin{array}{l}\text { Werner et al. } \\
2009\end{array}$ & $\begin{array}{l}\text { Between } 9 \text { and } 17 \\
\text { clubs in seven } \\
\text { consecutive seasons } \\
\text { in the European } \\
\text { professional league }\end{array}$ & $\begin{array}{l}\text { Prospective } \\
\text { cohort study }\end{array}$ & $\begin{array}{l}\text { Time-loss } \\
\text { ( } \geq 1 \text { day) }\end{array}$ & Univariate & Groin injury & $\begin{array}{l}\text { Carried out to investigate incidence, } \\
\text { pattern and severity of groin injuries. } \\
\text { Found re-injuries to account for } 15 \% \\
\text { of all registered injuries. }\end{array}$ \\
\hline $\begin{array}{l}\text { Hölmich et al. } \\
2009\end{array}$ & $\mathrm{~N}=977$ players & & & Univariate & Groin injury & $\begin{array}{l}\text {-Previous groin injury } \\
\text { (doubles the risk of developing a new } \\
\text { groin injury) } \\
\text {-Playing at a higher level } \\
\text { (almost triples the risk of developing } \\
\text { a groin injury) }\end{array}$ \\
\hline
\end{tabular}




\section{General considerations on risk factors}

Understanding the etiology of risk factors and mechanisms of injuries in football is an important foundation for the prevention of injuries (Meeuwisse, 1994). As described above, previous injury is the most consistent risk factor for new injury in all four body parts; ankle, knee, hamstrings and groin. Unfortunately, very little is known about risk factors in subelite level male footballers. Also, very few other potential risk factors have been studied in depth and there is a need for larger cohort studies mapping risk factors for the four most common injuries in football in a multivariate model. A range of previously suggested risk factors and also other potential risk factors for ankle, knee, hamstring and groin injuries among male football players were therefore studied in Papers II-V.

\section{Screening}

Screening, in medicine, is a strategy used in a population to detect disease in individuals without signs or symptoms of that disease. The intention is to identify disease early, thus enabling earlier intervention and management in the hope of reducing mortality and suffering. Although screening may lead to an earlier diagnosis, not all screening tests have been shown to benefit the person being screened; overdiagnosis, misdiagnosis, and creating a false sense of security are some potential adverse effects of screening. For these reasons, a test used in a screening program, especially for a disease with low incidence, must have good specificity in addition to acceptable sensitivity.

In sports medicine, screening tests may be used to assess susceptibility of sustaining injury, in order to target preventive interventions to the players in the most need of such measures (Dvorak et al., 2000b). The International Olympic Comittee (IOC) has recently stated that one priority is to protect the health of the athlete and that a preparticipation examination or periodic health evaluation to screen for injuries is an important enterprise in that matter (Ljungqvist et al., 2009). Implementing the preventive measures among the players in the greatest need of them may be important, partly because ensuring good compliance with specific exercise programs has been shown to be a challenge (Myklebust et al., 2003). Also, focusing mostly on one body region for a player with high risk of injury to that specific region might be more effective than a general preventive program.

Research on risk factors on the elite levels of football, where financial resources are much larger compared to amateur levels, may influence the choice of potential predictors tested. However, elite players only constitute a small portion of all football players, and advanced resources for screening tests are not available for the majority of players. Therefore, there is a need for 
investigation about whether simple screening tests, which are easy to do and do not require advanced equipment, can be used to identify individuals at risk. In this way, teams and players with no medical staff would be able to test themselves in the pre-season to find out whether they have an increased risk of injuries. Whether simple screening methods (e.g. questionnaires) are as effective as more advanced methods (e.g. advanced testing, clinical examination by experienced physicians), will be addressed in the risk factor studies (Papers II-V). Hence, an explicit goal of the randomized controlled study (Paper I) was to prospectively examine whether predefined high-risk and low-risk criteria can be used as screening method. In concordance with the documentation mentioned earlier, this screening tool was simple; A history of previous injury or reduced function in the ankle, knee, hamstrings or groin was set as predefined high risk of injury.

\section{The performance of a screening test}

Sensitivity and specificity are statistical measures of the performance of a screening test. Sensitivity measures the proportion of actual positives which are correctly identified as such. Applied to screening in football medicine, sensitivity equals the odds of a positive test if the player actually did sustain a new injury. Specificity measures the proportion of negatives which are correctly identified (e.g. the odds of negative test of a predictor if the player did not sustain a new injury). These terms are closely related to type 1 and 2 errors; a type 1 error is when the null hypothesis is rejected, even though it is true (i.e. false positive), and type 2 error is when one fails to reject the null hypothesis even though it is wrong (i.e. false negative). A positive predictive value is a measure of the percentage of players with a positive test result given that they sustained a new injury, while a negative predictive value is the percentage of players with a negative test result given that they did not sustain a new injury during the following season.

\section{Preventive measures}

As early as 1983, Ekstrand and co-workers demonstrated a significant reduction in the overall number of football injuries through a 7-part prevention program (Ekstrand et al., 1983a). In this randomized controlled trial including 180 male amateur players in Sweden, a 75\% reduction in injury incidence was found in the intervention group compared to the control group. The program included correction of training, equipment, prophylactic ankle taping, controlled rehabilitation, exclusion of players with knee instability, information and correction and supervision. Also, the rate of the most common types of football injuries, sprains and strains to ankles and knees, was reduced significantly. The following years, very little was done in the field of injury prevention in football. However, in recent years, especially after start of the present study, there has been a growth in preoccupation in sports injury prevention, illustrated by an 
abundance of scientific meetings and publications. However, relative to the magnitude of the problem, few injury prevention studies have been published in football until today; seven among female players (Hewett et al., 1999; Söderman et al., 2000; Heidt, Jr. et al., 2000; Mandelbaum et al., 2005; Soligard et al., 2008; Gilchrist et al., 2008; Steffen et al., 2008b), one among youth male players (Junge et al., 2002) and eleven (Including Paper I in this thesis) among senior male players (Ekstrand et al., 1983a; Tropp et al., 1985; Surve et al., 1994; Caraffa et al., 1996; Askling et al., 2003; Árnason et al., 2005; Hägglund et al., 2007; Árnason et al., 2008; Croisier et al., 2008; Hölmich et al., 2009). The preventive studies among male footballers are listed in table 6. When focusing on adult male football players, the results are promising. Two years after the study by Ekstrand et al. (1983a), Tropp and co-workers (1985) had a more specific approach, looking at only ankle injuries. In a randomized controlled trial among 439 male amateur players in division VI in Sweden they found a significant reduction in ankle injuries among previously ankle injured players both after use of orthoses or neuromuscular training on an ankle disk. Later, Surve et al. (1994) confirmed these findings in a randomized controlled trial among 629 senior male players in divisions 1-4 in South Africa; players with previous ankle sprains had a significant risk reduction when using orthoses. Caraffa et al. (1996) evaluated neuromuscular training for prevention of knee injuries - the main difference from the ankle training program of Tropp et al (1985) being a slightly bent knee, compared to straight-leg training for the ankle, in that way focusing on knee control to achieve balance correction. They included 600 senior male semi-pro and amateur players in Italy and found a significant decrease in ACL injuries from the intervention. However, this was not a randomized controlled study.

As outlined earlier, joint injuries to the ankle and knee may have been the most frequent injuries previously, which may also explain the reason for the focus of the studies mentioned. More recently. Askling et al. (2003) carried out a randomized controlled trail among 30 male senior elite players in Sweden in order to reduce the risk of hamstring injury. Through eccentric overloading 1-2 times per week for 10 weeks they managed to increase strength and speed, and most importantly, reduce the number of hamstring injuries in the training group. It was later found in a much larger controlled trial among 17-30 elite teams in Iceland and Norway that eccentric strength training (Nordic hamstring lowers) combined with warm-up stretching appeared to reduce the risk of hamstring strains (Árnason et al., 2008). The same group had three years earlier published a study from the top two divisions in Iceland, where 271 players were educated in how injuries occurred to increase awareness and avoid injury situations (Árnason et al., 2005). Moreover, this video-based awareness program did not succeed in preventing injuries. Other preventive measures have been tested more recently; in a study among 582 amateur players at the 
$6^{\text {th }}$ highest division level in Sweden, a coach-controlled rehabilitation program consisting of 10 steps, including return-to-play criteria, resulted in a $75 \%$ reduction in lower limb injuries. This underlines the importance of taking an injury and the rehabilitation seriously. More recently, 462 professional male players in the Belgian, Brazilian and French leagues were tested in the preseason and trained in order to compensate for strength imbalances of the hamstrings and quadriceps muscles. Interestingly, the rate of injured players was very low among players with no imbalances and significantly increased among players with untreated imbalances. The latter group had a more than a four-fold higher risk of sustaining a hamstring injury in comparison with the intervention group that had trained to normalize ratios. In addition to paper I in this thesis, the most recent prevention study among senior footballers was carried out among 977 amateur players in order to prevent groin injuries. Six exercises were implemented, including isometric adduction with the football between the feet, isometric adduction with a football between the knees, combined abdominal sit-ups and hip flexion, cross-country skiing on one leg, hip adduction against a partner's hip abduction and stretching of the iliopsoas muscle (Hölmich et al., 2009). There was a small, but non-significant reduction in the risk of groin injury found in this study. As can be seen from table 6, other preventive studies have been carried out in football, albeit among female or youth players. 


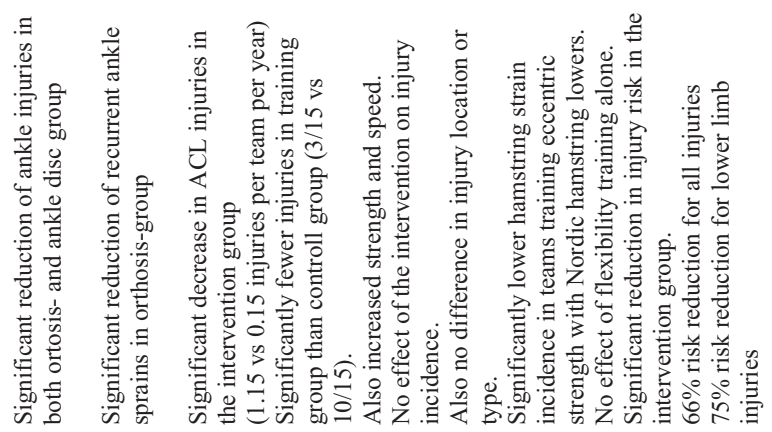

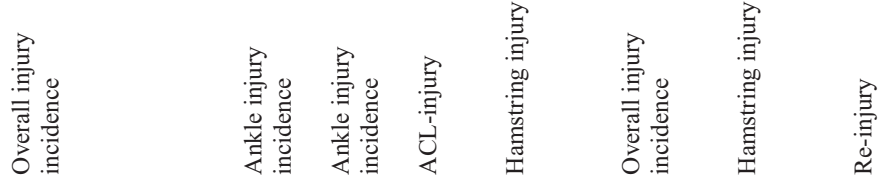

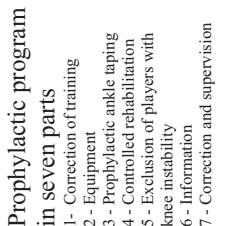

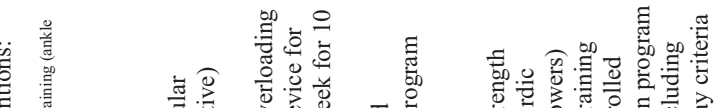

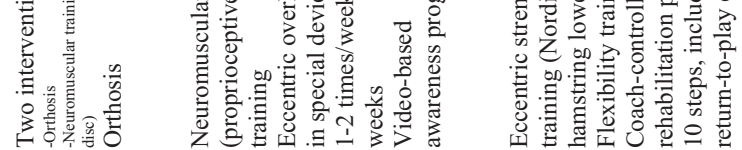

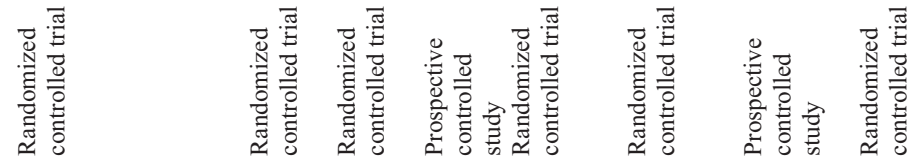

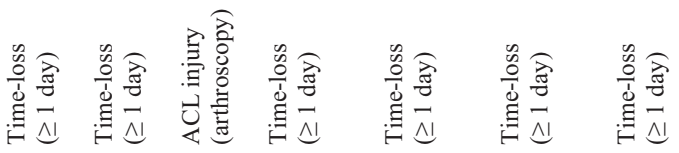

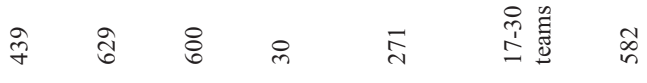

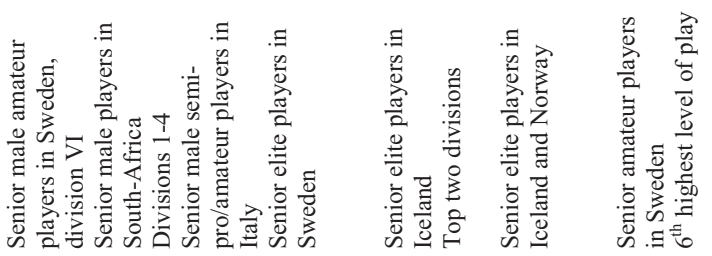

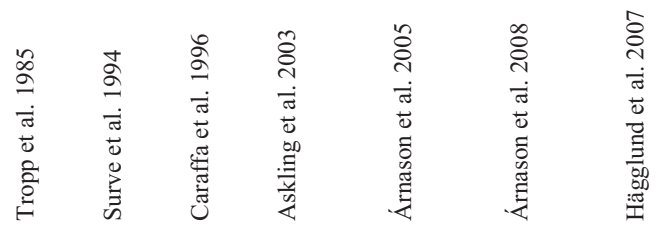



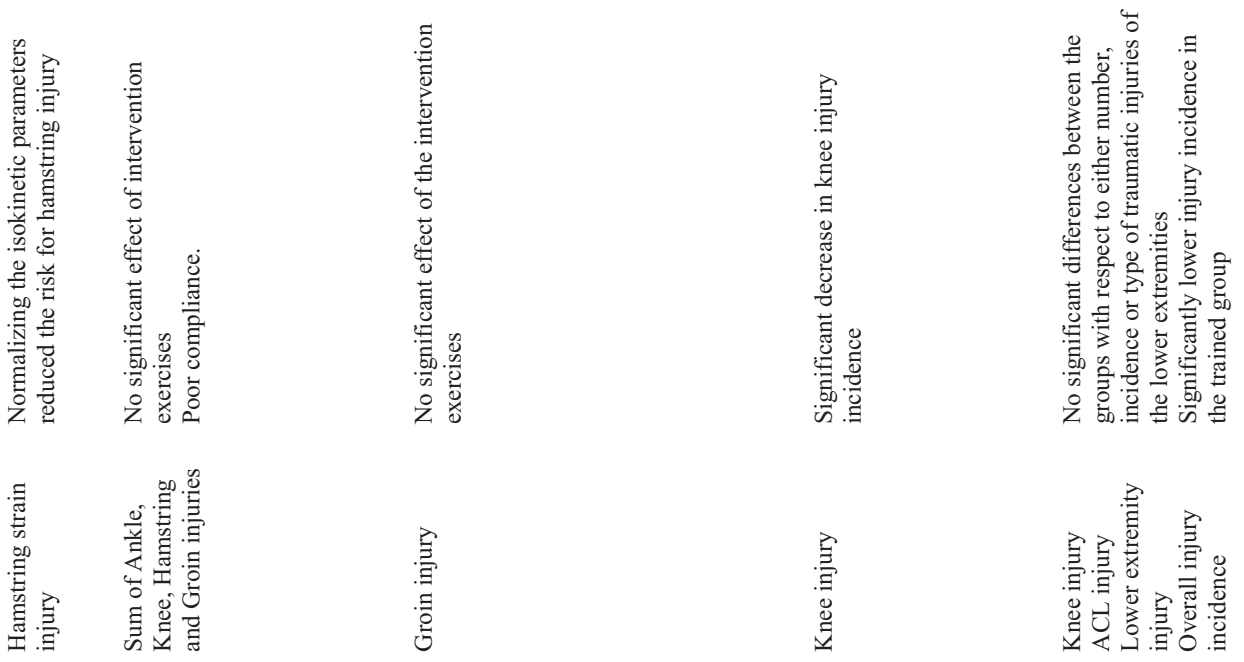

莺
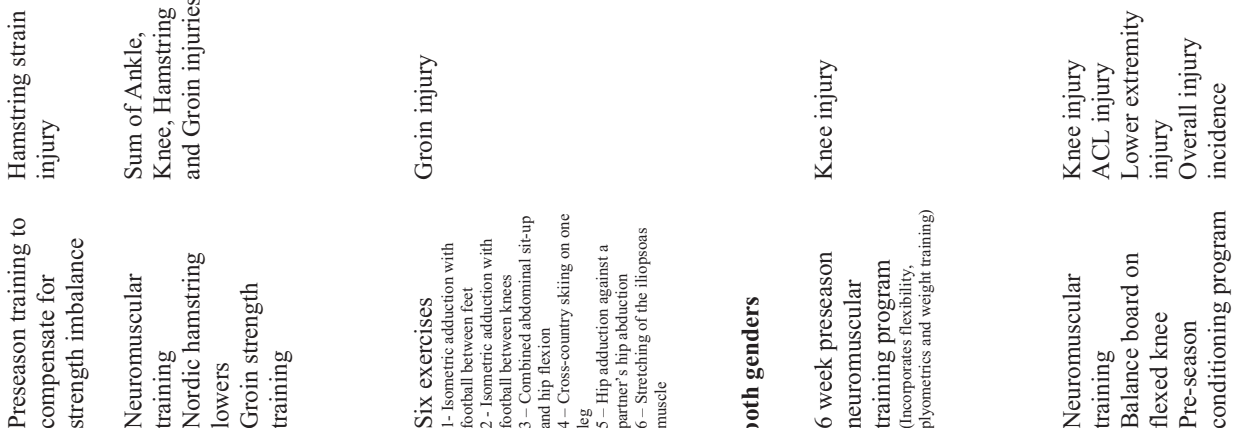

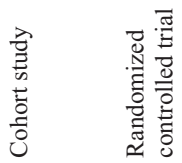

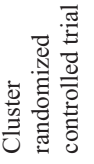

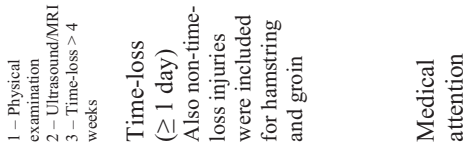

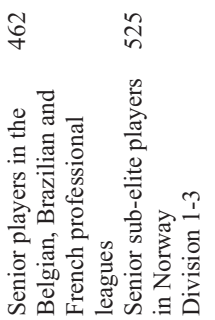

各
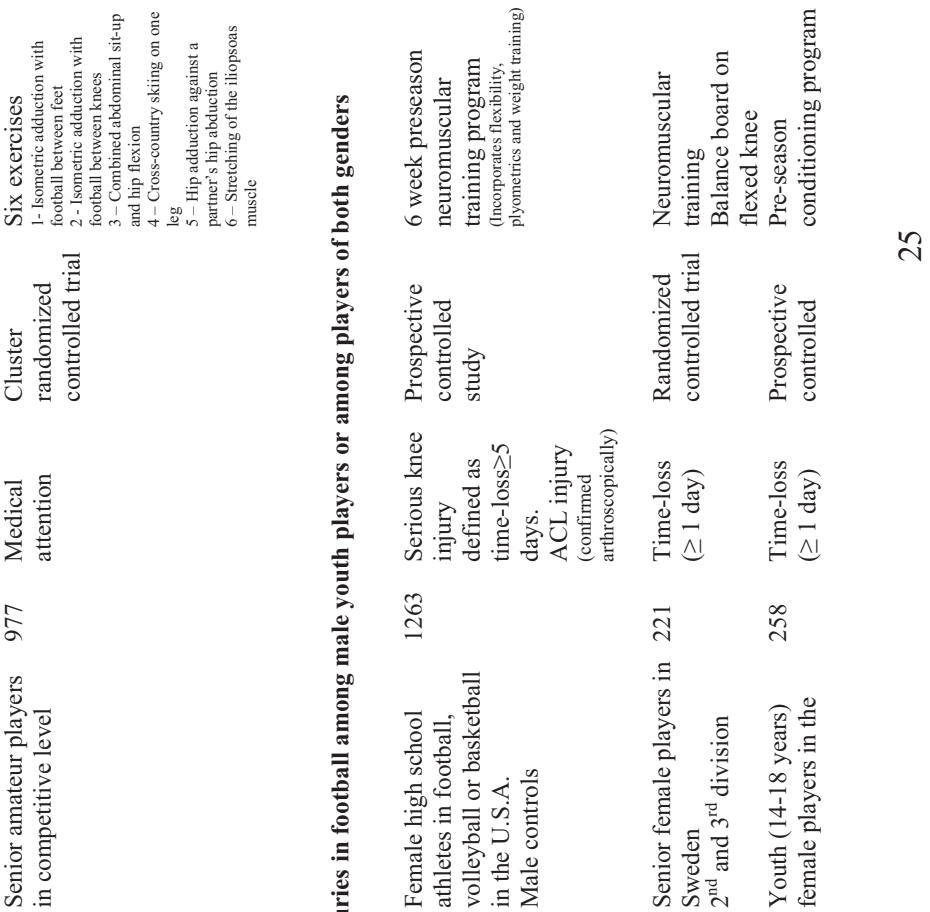

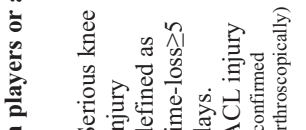

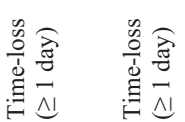

ถูำ

త్

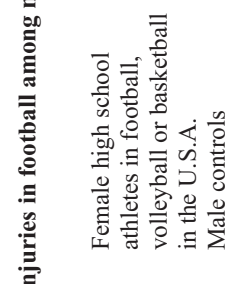

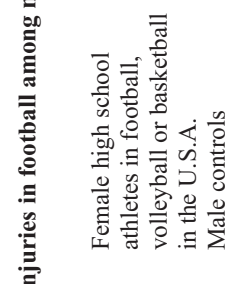

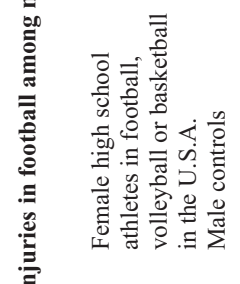

$\overrightarrow{\text { ส }}$

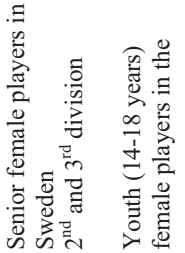

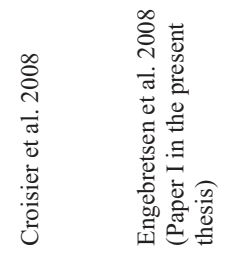

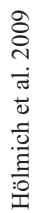

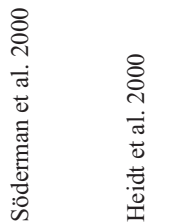




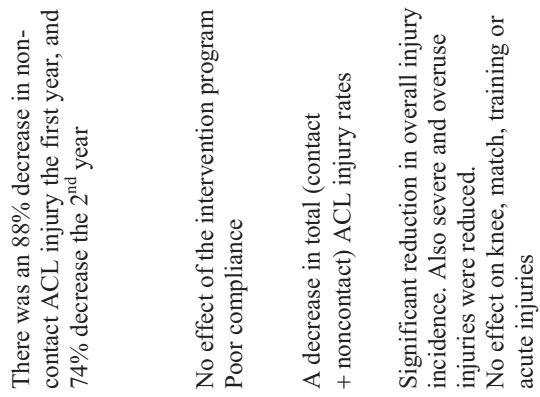

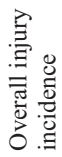
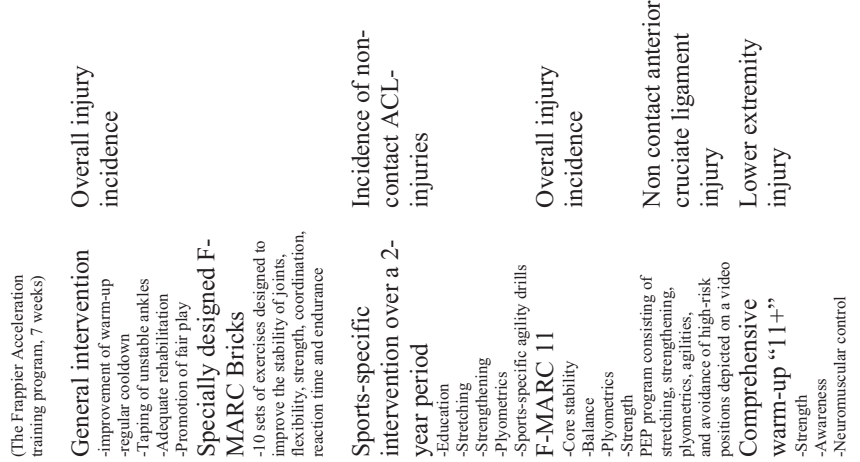

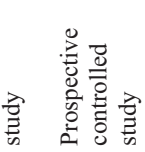

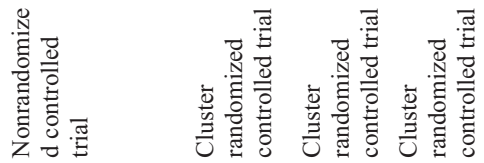

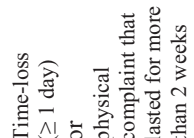

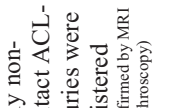

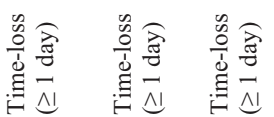

กั้

ํำ $+\stackrel{n}{\frac{n}{1}}$

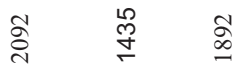

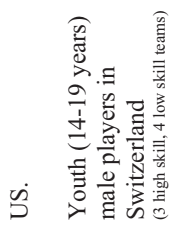

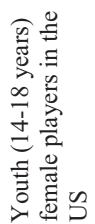

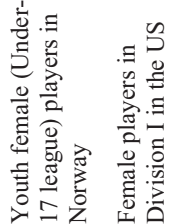

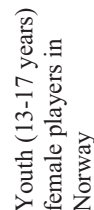

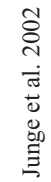

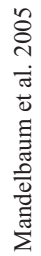

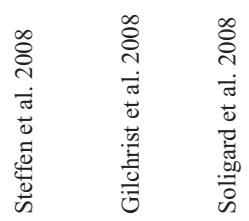




\section{Exercise programs to prevent injuries}

As described above, injuries to the ankle, knee, hamstring and groin constitute the majority of injuries in football. We therefore chose these four injury locations as our main focus areas. According to the above mentioned studies on prevention of injuries in football, it seemed as though neuromuscular training programs with straight and bent knee were useful in the prevention of ankle and knee sprain injuries respectively. For strain injuries of the hamstrings and groin, there existed indications of preventive effects of strength training. However, as outlined, relative to the magnitude of the problem, little was known about effective preventive exercises. Therefore, there was a need to test whether neuromuscular training and strength training could reduce the number of injuries in football. This was therefore tested in the present thesis in a randomized controlled trial (Paper I).

Ankle injuries. Regarding ankle injuries, the two important studies among male, senior football players (Tropp et al., 1985; Surve et al., 1994) found a significant reduction in incidence of ankle injuries after use of mechanical support in the form of orthosis or taping. Also one of the seven preventive actions taken by Ekstrand et al (1983a) in their study was prophylactic taping of previously injured ankles. Despite significant injury reduction, it is not possible to tell if that measure alone, or any of the other measures caused that effect, although it is supported by the above mentioned studies. A systematic review (Thacker et al., 1999) and two Cochrane reviews (Quinn et al., 2000; Handoll et al., 2001) concluded that there is good evidence for the beneficial effect of ankle supports in the form of orthoses. Although this reduction was greater for players with a previous history of ankle sprain, the effect was still observed for those without prior sprain. However, it is also stated that any potential prophylactic effect should be balanced against the baseline risk of the activity, the supply and cost of the particular device, and for some, the possible or perceived loss of performance. The latest Cochrane review (Handoll et al., 2001) (2005 update) also states that there was limited evidence for reduction in ankle sprain for those with previous ankle sprains who did ankle disk training exercises. Even though no studies on performance and perceived performance exist, there seems to be a negative attitude to using orthoses among football players in our opinion.

Neuromuscular training, especially among previously injured players/athletes, has shown promising effects among male, senior footballers (Tropp et al., 1985) and among athletes in other sports (Wester et al., 1996; Bahr et al., 1997; Verhagen et al., 2000) and in rehabilitation programs (Holme et al., 1999). In the study by Tropp et al. (1985), the ankle disc training was performed with one leg extended straight and the other raised and flexed at the knee. For the first 10 weeks 
the training time was $10 \mathrm{~min}$ five times weekly with one or both legs, depending on the previous problems, and then 5 min three times weekly. As stated above, this training resulted in a significant injury reduction.

We wanted to test such exercises further and therefore chose to use neuromuscular training exercises as the measure to prevent ankle injuries in the present study (Paper I). Similarly to the study by Tropp et al. (1985) all exercises were prescribed to be performed with a straight leg (no knee flexion) (see Figure 2, Paper I) and with a gradual progression in difficulty. The players were instructed to switch between the balance board and pad, and, as they became more proficient, to include ball-based exercises while keeping their balance. A complete description of the ankle exercises may be seen in Table 1, Paper I.

Knee injuries. As mentioned above, neuromuscular training has proven effective in reduction of ankle injuries among male, senior footballers (Caraffa et al., 1996) and in other study populations (Heidt, Jr. et al., 2000; Junge et al., 2002; Olsen et al., 2005). In regards of football specific interventions, the study by Caraffa et al. (1996) included 600 footballers in 40 semiprofessional or amateur teams. Three hundred of these were instructed to train $20 \mathrm{~min}$ per day with five different phases of increasing difficulty. The training was performed on four different types of wobbleboards wich ensured increasing difficulty. Despite a highly significant injury reduction in this study, a systematic review of prevention of knee injuries in sports (Thacker et al., 2003) concludes that structured training programs that emphasize neuromuskular and proprioceptive training offered encouraging evidence for the prevention of knee injuries, but that rigorously implemented research programs are needed. We therefore tested a preventive program consisting of neuromuscular training exercises based on the study by Caraffa et al. (1996) in the intervention study (Paper I). As with the ankle program, the players were instructed to switch between the balance board and pad, and include ball-based exercises as they progressed.All exercises were prescribed to be performed with the knee-over-toe position and a flexed knee (Figure 3, Paper I) with gradual progression in difficulty. A complete description of the knee exercises may be seen in Table 2, Paper I.

Other training regimens have been suggested in different sports or player populations, such as knee bracing (Albright et al., 1994), education and enhanced awareness of dangerous positions and mechanisms of non-contact ACL injury (Johnson RJ, 2001) or strength training. However, these studies provide limited evidence or relevance for our player population. A systematic review of prevention of knee injuries in sports (Thacker et al., 2003) concluded that there was no consistent evidence of benefit from bracing. Because of inadequate reporting of methodology, 
two studies comparing alternative cleat designs and a controlled study testing the effects of adjustments in the ski boot/binding system were difficult to interpret.

Hamstring injuries. The pilot study by Askling et al (2003) observed a reduction in hamstring strains through eccentric strength-training programs. The Nordic hamstring exercise is performed standing on the knees on a soft foundation, slowly lowering the body toward the ground using the hamstrings while the feet are held by a partner (Figure 5, Paper I). Progression is achieved by increasing the initial speed, and eventually having a partner push forward. Until study start, other methods for injury reduction such as thermal pants (Upton et al., 1996) and stretching (Herbert \& Gabriel, 2002) had been suggested, but with no definite conclusions in regards of injury prevention. Strength training therefore seemed to be the most promising preventive measure, and a randomized controlled trial was necessary to test this properly. The Nordic Hamstring Lowers program was therefore tested in the study described in Paper I. A complete description of the training program may be seen in Table 4, Paper I.

Groin injuries. Similarly to hamstring injuries, stretching had for a long time been believed to be preventive in regards of groin strain injuries. However, a recent review concluded that stretching does not confer protection from muscle soreness or useful reduction of injury risk, in contrast to the previously reigning understanding on the topic (Herbert \& Gabriel, 2002).

A study by Hölmich et al (1999) showed that an active training programme aimed at improving strength and coordination of the muscles acting on the pelvis was very effective in treatment of athletes with long-standing adductor-related groin pain. The authors proposed that a short programme based upon the principles of such an active training programme should be assessed in future, randomized clinical trials in order to examine the potential preventive value. Until start of the present study, the preventive effect of such a program had however not been tested in a randomized trial. In the present prospecitve controlled trial (Paper I), such strength exercises were put together in a shortened program to address this need. The players were therefore instructed to perform the exercise 3 times a week for approximately $15 \mathrm{~min}$. A ball was needed for some of the exercises (Figure 4, Paper I), and the exercises could be performed without warming up. A complete description of the ankle exercises may be seen in Table 3, Paper I. 


\section{Aims of the thesis}

1. To test whether we could identify players with an increased risk of injury using a questionnaire focusing on history of previous injury and joint/muscle function

2. To examine if exercise programs targeting players with an increased risk of injury could prevent the four most common injury types in football; ankle and knee sprains and hamstring and groin strains

3. To investigate possible risk factors for acute ankle injuries

4. To investigate possible risk factors for acute knee injuries

5. To investigate possible risk factors for hamstring injuries

6. To investigate possible risk factors for groin injuries 


\section{Methods}

The same players and testing were used for all articles (Paper I-V). A randomized controlled trial was carried out to prevent injuries (Paper I). Papers II-V are cohort studies on risk factors and were carried out focusing on potential risk factors for ankle (Paper II), knee (Paper III), hamstring (Paper IV) and groin injuries (Paper V).

\section{Participants}

A total of 35 teams ( $n=769$ players) from the Norwegian $1^{\text {st }}, 2^{\text {nd }}$ or $3^{\text {rd }}$ division of football for men, geographically located in the proximity of Oslo, were invited to participate in the study. In Norway, there are several different $3^{\text {rd }}$ division conferences, and the $3^{\text {rd }}$ division teams included either won their conference or finished as first runners up the previous season, resulting in a relatively homogenous group of teams, even if the 35 teams competed in three different divisions. Three of the teams ( $\mathrm{n}=60$ players) declined the invitation to participate, 177 players did not report for testing, three players did not speak Norwegian and could therefore not complete the questionnaire and four players were excluded for other reasons (See flow chart, figure 1, paper I). Hence, 244 of the players invited could not be included. In addition, one team ( $\mathrm{n}=17$ players) was later excluded because the physiotherapist did not record injuries, resulting in a final sample of 508 players representing 31 teams from three divisions $\left(1^{\text {st }}\right.$ division, $n=7,122$ players; $2^{\text {nd }}$ division, $\mathrm{n}=16,260$ players; and $3^{\text {rd }}$ division, $\mathrm{n}=8 ; 126$ players).

\section{Preseason testing}

During the preseason (January through March 2004) the teams were tested at the Norwegian School of Sports Sciences through a questionnaire and specific tests for potential risk factors. The questionnaire was in five parts. The first section consisted of general information (date of birth, team, field position, and player experience). The second through fifth sections included information about the ankle (Paper I and II), knee (Paper I and III), hamstring (Paper I and IV), and groin (Paper I and V), respectively. Each of these sections covered the history of previous injuries (severity, nature, and number of months since the most recent injury, use of protective equipment such as tape or brace, and if the injury had caused the player to miss matches), and a function score for each region. The questionnaires used to assess function were the Foot and Ankle Outcome Score (FAOS) (Paper I and II) and Knee Osteoarthritis Outcome Score (KOOS) (Paper I and III), which were translated to Norwegian (Roos et al., 1998; Roos et al., 2001). These forms consist of five major parts (symptoms, pain, activities of daily living, function 
in sports and recreation, quality of life) and are scored by calculating the mean value of the five parts in percent of the total possible score, where $100 \%$ is the maximal and $0 \%$ the lowest score. For the hamstring and groin, we developed similar function scores, the Hamstring Outcome Score (HaOS) (Paper I and IV) and Groin Outcome Score (GrOS) (Paper I and V), based on the same principles as FAOS and KOOS, only specific to these regions and their typical symptoms (see Appendix to Paper I). For the HaOS and GrOS, we replaced the category "function in daily living" with a category on muscle soreness.

Second, every player capable (not injured at the time) completed specific tests for ankle, knee, hamstring and groin and were also examined clinically for these four regions. The specific tests consisted of single leg balance tests for both legs, both on a balance mat and on the floor (Paper II), three counter movement jumps, two $40 \mathrm{~m}$ sprint tests (Paper III, IV, V), a Nordic hamstring strength test, hamstring length measurement (Paper IV) and an isometric adductor strength test (Paper V). Detailed descriptions of these tests are provided in Papers II-V.

The clinical testing of the players was performed by a group of ten sports physical therapists and sports physicians who were blinded for any injury history (scars were not concealed). Both legs were examined thoroughly, including a structural examination of the ankle, knee, hamstring and groin.

\section{Study design}

For the randomized controlled trial (Paper I), the 508 players were divided into two groups, a high-risk (HR) and a low-risk (LR) group based on information from the questionnaire. The criteria for classifying a player as having an assumed increased risk of injury were a history of an acute injury to the ankle, knee, hamstring or groin during the previous 12 months or a reduced function with an average score of less than $80 \%$ for any of the body parts mentioned. A player fulfilling any of the inclusion criteria for any of the four body parts was assigned to the HR group. The players in the HR group were randomized individually, but stratified within each team, into 2 groups, the HR intervention group and the HR control group (see Figure 1, Paper I). In this way, each team would normally have players from all three groups (HR intervention, HR control, and LR control). The players in the HR intervention group were only included on the basis of the inclusion criteria that they fulfilled, meaning that they only received a training program for the body part(s) assumed to have an increased risk of injury. In a situation in which a player ended up with four programs, the team physical therapist was asked to merge the programs into one continuous program. However, even if a player fulfilled the inclusion criteria for one body part on only one side, he was asked to perform the prevention exercises for both 
legs. The players were asked to complete the ankle, knee, and groin training programs three times a week for 10 weeks during the preseason, in separate training sessions done outside the regular team training. For the hamstring program, a 10-week progression was prescribed (Mjølsnes et al., 2004). The intervention players were also asked to perform the exercises once per week for the rest of the season as maintenance. The programs were meant to progress in difficulty, to challenge the players as their performance improved. The players were also asked to report all exercises they performed on a form, checking a box if they had carried out the preventive training that day. The form covered all 10 weeks for compliance assessment. A more detailed description of the training programs can be found in paper I.

The prospective cohort studies on risk factors for ankle (Paper II), knee (Paper III), hamstring (Paper IV) and groin (Paper V) injuries are based on the same data as the randomized trial (Paper I). Because no differences were seen in injury rates between the intervention and control groups (see Results section later), the entire cohort could be used to examine the effect of a number of risk factors assessed at baseline.

\section{Injury definition}

An injury was defined as any physical complaint sustained by a player that resulted from a football match or football training, resulting in a player being unable to take a full part in future football training or match play ("time-loss" injury). Acute injuries were defined as injuries with a sudden onset associated with a known trauma, whereas overuse injuries were those with a gradual onset without any known trauma. Injuries were classified into three severity categories according to the time it took until the player was fully fit to take part in all types of organized football play: minor (1-7 days), moderate (8-28 days), and major ( $>28$ days).

All injuries were categorized by the authors based on the injury reports from each physiotherapist. For the purpose of the different papers, an injury was classified as ankle sprain if it was recorded as an acute injury of the ankle ligaments (Paper II), knee injury if it was recorded as an acute injury of the knee ligaments, menisci, bone or joint cartilage, or if hemarthros had occurred as a result of knee sprain (Paper III), hamstring strain if it was recorded as either an acute or an overuse muscle injury of the posterior thigh (Paper IV) and groin strain if it was recorded as either an acute or an overuse injury of medial thigh (Paper V). Overuse injuries where there was no time loss were included to incorporate small repeated hamstring or groin strain injuries, as some players still elect to play despite discomfort. For such an injury to be recorded, the player would have to get in contact with the physiotherapist, i.e. fulfilling the criteria for a "medical attention" injury; an injury that results in a player receiving medical 
attention, not necessarily forcing the player to miss taking full part in future football training or match play. The head coach for every team registered each player's participation in training and the number of minutes played in matches. For the randomized controlled trial (Paper I), the main outcome measure was the sum of the risk for an ankle sprain, knee sprain, groin strain or hamstring strain.

We later found the injury definitions used to be in concordance with the consensus statement by the Injury Consensus Group convened by FIFA in 2006 (Fuller et al., 2006).

Match exposure was defined as play between teams from different clubs, while training exposure was defined as team-based and individual physical activities under the control or guidance of the team coaching or fitness staff aimed at maintaining or improving football skills or physical condition.

\section{Injury registration}

The team physical therapist was responsible for reporting injuries on their team throughout the preseason and the season. Most of the teams from the 1st and 2nd divisions already had a physical therapist working with the team. When there was no physical therapist attached to the team, we provided them with one. Each physical therapist was rewarded with a stipend (10 000 NOK, or approximately 1700 USD). In addition to reporting injuries throughout the preseason and season, the physical therapist was responsible for instructing all the players who were randomized into the HR intervention group in their training programs. Each player was given a folder describing the exercises he was asked to do, as well as any necessary equipment such as balance mats and balance boards.

\section{Statistical methods}

Exposure was calculated in hours as the sum of all individual exposures recorded during training and match play during the season.

For the randomized controlled trial (Paper I), the injury rate was compared between the HR control group and the HR intervention group, and the HR control group and the LR control group, respectively, using a ₹ test, reporting 95\% confidence intervals (CIs) based on the Poisson model. Chi-square tests were used to compare the proportion of injured players between the HR intervention group and the HR control group, and between the HR control group and the LR control group, respectively. Otherwise, results are presented as the means with standard deviations. 
The sample size calculation is based on injury frequences from the elite division in Norway and the two top divisions in Iceland (Árnason et al., 1996; Andersen et al., 2004b; Andersen et al., 2004c). Based on those studies, we expected at least $50 \%$ of the players in our study to obtain an injury in either the ankle, knee, groin or hamstring. We hoped to detect at least a $30 \%$ reduction of injury in the intervention group compared to the control group. With a $\beta$-value of 0.20 and an $\alpha$-value of 0.05 and with excess margins to account for possible drop-out, there was a need of approximately 30 teams with 20 players each. We therefore invited 35 teams, and 32 teams agreed to be included in the study.

For the continuous dependent variable risk factor analyses (Papers II-V), where each leg was the unit of analysis, generalized estimating equations (STATA, version 8; STATA, Texas, U.S.A.) were used, accounting for total individual exposure during the football season, any within-team correlations and the fact that the left and right foot belonged to the same player. Ankle, knee, hamstring or groin injury during the season was set as the dependent variable respectively, while total hours of football play during match and training was set as the total exposure. To account for the dependency within persons due to analyses by each leg as unit, the correlation pattern was chosen as unstructured, i.e. without any presumption about its structure. Logistic regression analyses were used to examine the relationships between per subject calculated dichotomous injury variables and their risk factors. All risk factor variables were examined in univariate analyses, and those with a $\mathrm{P}$ value $<0.10$ were investigated further in a multivariate model. $\mathrm{P}$ values of $<0.05$ were considered as statistically significant.

\section{Reliability testing for the risk factor studies}

Inter-test reliability was examined for the single leg balance test (Paper II), hamstring muscle length measurement (Paper IV), the Nordic hamstring strength test (Paper IV), adductor strength test (Paper V) and the clinical examination of ankle (Paper II) and knee (Paper III) by having the same player repeat the same test with different personnel after he had completed the first test. Each examiner was blinded to the other's results. The same scoring system/clinical forms were used at both stations. Inter-test reliability for the categorical variables was computed using kappa statistics, while the coefficient of variation for the continuous variables was calculated as the standard deviation of the difference between the first and second test as a percentage of the average test results for both tests.

\section{Ethics}

The study was approved by the Regional Committee for Medical Research Ethics, Helse Øst, and written consent was obtained. 


\section{Results and discussion}

\section{Overall results}

\section{Player exposure (Paper I-V)}

The total exposure to match play (19008 hours) and training (89103 hours) was 108111 player hours. In regards of the intervention study, there was no difference in mean player exposure between the HR intervention group ( $217 \pm 94$ hours), the HR control group ( $210 \pm 103$ hours) and the LR control group ( $211 \pm 88$ hours).

\section{Incidence of injuries (Paper I-V)}

An overview of the injuries reported in Papers I-V can be found in table 7.

\section{Incidence of ankle injuries (Paper II)}

A total of 34 players sustained one ankle injury, while 6 and 2 players sustained two and three injuries, respectively. One player sustained four ankle injuries throughout the season. Of the 56 injuries, 34 occurred on the right side, while 22 were on the left.

\section{Incidence of knee injuries (Paper III)}

A total of 46 players sustained one knee injury, six sustained two injuries, and one player sustained three injuries. Of the 61 injuries, 30 occurred on the right and 31 were on the left side. Incidence of hamstring injuries (Paper IV)

A total of 48 players sustained one hamstring injury, 11 sustained two injuries, and two players sustained three injuries. Of the 76 injuries, 40 occurred on the right side and 36 were on the left side. In five overuse injuries, there was no time loss

Incidence of groin injuries (Paper V)

A total of 44 players sustained one groin injury, five sustained two injuries, one sustained three injuries and one player sustained four injuries. Of the 61 injuries, 31 occurred on the right side and 30 on the left. In two overuse injuries there was no time loss. 


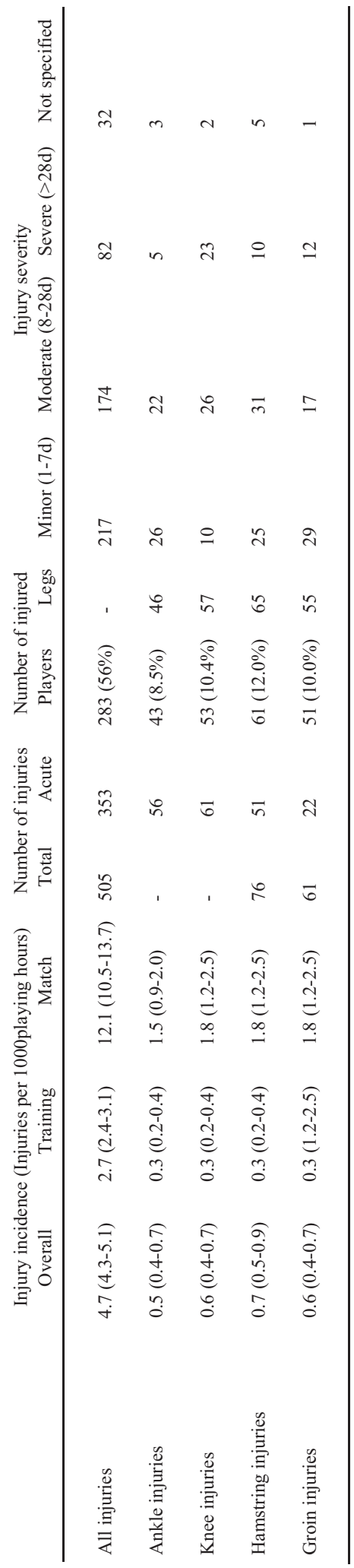




\section{Injury incidence (Papers I-V) compared with other studies}

As can be seen from table 1, there was a lower injury incidence reported in the present studies

(12.8 injuries /1000 match hours) compared to previous studies among senior male footballers (25 - 35 injuries /1000 match hours) (Ekstrand \& Gillquist, 1983a; Árnason et al., 1996; Hawkins \& Fuller, 1999; Andersen et al., 2004b; Waldén et al., 2005a; Waldén et al., 2005b). This could partly be explained by the lower level of play, but it could also be that our recording system did not capture all injuries. When using a time-loss definition of injury the definition depends on the frequency of training sessions and matches, and can therefore cause bias when comparing different levels of play. The physical therapists were rewarded with a stipend, but the resources were not sufficient to allow for daily follow-up of the teams by the physical therapist. Thus, there is a potential bias in injury reporting depending on the availability of the physical therapist, at least for minor injuries. However, it may be expected to have influenced all players, not any players with specific risk factors. Therefore, the greatest consequence of missing cases would be loss of statistical power. The same would probably be the case for the intervention outcome as well.

A recent publication documented that prospective injury surveillance by team medical staff in Norwegian male professional football underestimates the incidence of time-loss injuries by at least one-fifth (Bjørneboe J et al., 2009). It seems reasonable to assume that this underestimation may be even higher at lower levels, where follow-up is less consistent as in professional football. Mahler and Donaldson (2010) even announced a theory on a "threshold" incidence of injuries, below which it might be difficult to go. Because the injury incidence in our study was so low, it may be difficult to go any lower. However, a recent study from lower level senior male football (sixth highest division) (Hägglund et al., 2007) also resulted in lower injury rates than from the elite level, in correspondance with the present findings (Paper I). A study from the early 1980s also shows that the injury incidence in amateur football in Sweden was not that different from our results (Ekstrand et al., 1983b).

\section{Prevention of injuries (Paper I)}

In the LR control group there were 82 injuries, while there were 216 injuries in the HR control group and 207 injuries in the HR intervention group. There was no difference in the incidence of injuries between the HR intervention group and the HR control group (RR: 0.94, 95\% CI: 0.77 to 1.13). Also, no difference in injury severity was seen between any of the three groups (Figure 2). 
All injuries

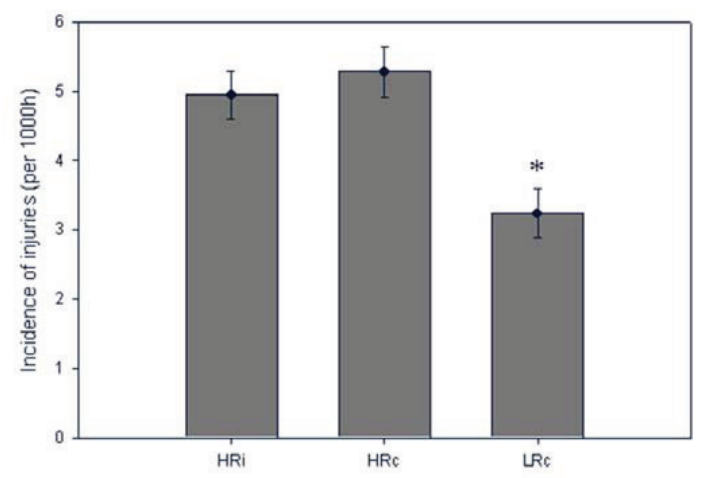

Figure 2. Intention-to-treat analysis - overall injury rates.

\section{Intervention outcome - intention-to-treat analysis (Paper I)}

For the main outcome measure, the sum of injuries to the ankle, knee, hamstrings and groin, the total incidence was 2.3 injuries per 1000 playing hours (95\% CI: 2.1 to 2.6). There was a significantly lower injury risk in the LR control group compared to the two other groups (RR: 0.49, $95 \%$ CI: 0.33 to 0.71 vs the HR control group; RR: 0.53 , 95\% CI: 0.36 to 0.77 vs the HR intervention group). However, no difference was seen between the HR intervention group and the HR control group (RR: 0.93, 95\% CI: 0.71 to 1.21) (Figure 3).

Ankle, knee, hamstring and groin injuries

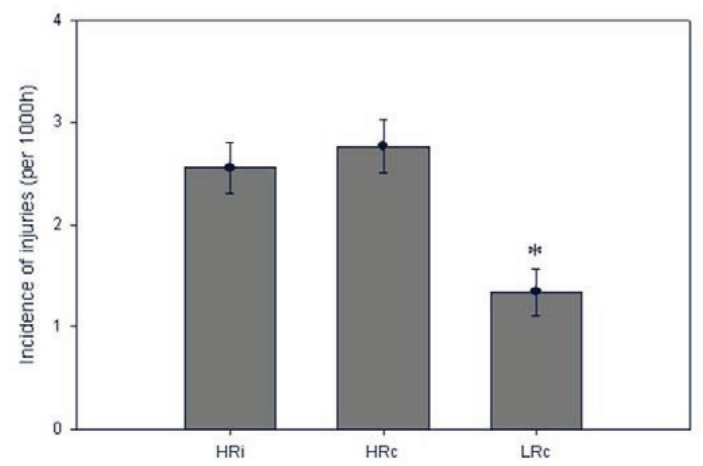

Figure 3. Intention-to-treat analysis for the main outcome measure, the sum of injuries to the ankle, knee, hamstrings and groin. 
When the players in the HR intervention and HR control groups with increased risk of injury were compared, we found no significant differences in the risk of injury to the body part in question between the two groups for any category (ankle: RR 0.64, 95\% CI: 0.32 to 1.29; knee: RR 0.96, 95\% CI: 0.35 to 2.64; hamstrings: RR 1.55, 95\% CI: 0.83 to 2.90; groin: RR 1.18, 95\% CI: 0.55 to 2.54 ) (Table 7 , Paper I).

\section{Compliance with the training program and per-protocol analysis (Paper I)}

Compliance with the training programs in the HR intervention group was poor, with only $27.5 \%$ (28 players) in the ankle group and 29.2\% (19 players) in the knee group having completed 30 or more training sessions. For the hamstring and groin exercises, compliance was even less, with only $21.1 \%$ (12 players) and 19.4\% (16 players) completing 20 or more training sessions, respectively. Hence, the compliant (more than 30 exercises for ankle and knee, and more than 20 training sessions for hamstring and groin) groups are small. As many as 15.7\% (16 players) reported not having done any ankle exercises, $11.8 \%$ (12 players) $1-9$ exercise sessions, $24.5 \%$ (25 players) 10-19 sessions, while 20.6\% (21 players) reported having carried out 20 or more sessions, but less than the target number of 30 . The corresponding figures for knee exercises were $23.1 \%$ (0 exercise sessions reported), 9.2\% (1-9 sessions), 13.8\% (10-19 sessions) and 24.6\% (20-29). For hamstring exercises the figures were $63.2 \%$ (0 exercise sessions reported), $7.9 \%$ (1-9 sessions) and $7.9 \%$ (10-19 sessions), and finally for groin exercises $67.7 \%$ (0 exercise sessions reported), 4.8\% (1-9 sessions) and 8.1\% (10-19 sessions).

In a per-protocol analysis on ankle injuries, the incidence of ankle injuries in the compliant group, which sustained 3 injuries (2 of 28 injured players), was 0.5 (95\% CI: -0.1 to 1.0) injuries per 1000 hours, compared to 0.9 (95\% CI: 0.5 to 1.3 ) injuries per 1000 hours among players with an increased risk of ankle injuries in the HR control group ( $R R=0.51,95 \%$ CI: 0.2 to 1.7 ). Similarly, we could not detect any difference in the risk of knee injury between players in the HR intervention group who were compliant with the knee program (0.2 (95\% CI: - 0.2 to 0.7 ) injuries per 1000 hours) and the high-risk players in the HR control group (0.5 (95\% CI: 0.2 to 0.9 ) injuries per 1000 hours, RR 0.46, 95\% CI: 0.1 to 3.7). In the same way, no difference was observed in the incidence of hamstring (RR 0.94, 95\% CI: 0.3 to 3.2) and groin injuries (RR 1.6, 95\% CI: 0.5 to 5.6) between players in the HR intervention group who were compliant with the respective training programs and the HR control group. 


\section{Injury registration}

One limitation of the intervention study is the difference in physical therapist contact between the HR intervention players and the other groups. To instruct in the intervention exercises, the physical therapist became well acquainted with each of the intervention players, and not always to the same extent with the other players in the team. Thus, there was a potential for a bias in injury reporting, because the same physical therapist also was responsible for reporting injuries. Because the HR intervention players constitute approximately half of the high risk players this also causes a potential bias for the risk factor studies. In this way, an increased amount of players with previous injuries could have had resulted in a slightly higher injury reporting rate.

\section{The preventive measures (Paper I) compared with other studies}

The most likely explanation for the abscence of any detectable effect of the targeted intervention on injury risk, was the low compliance with the exercise programs. With such low compliance in the intervention group (ranging between $20 \%$ and $30 \%$ for the different exercise programs), no effect could be expected on decreasing the injury rate.

In contrast to most previous intervention studies, players were randomized individually to the intervention or control group in the present study. We relied on the team physical therapists to instruct the players in the intervention program. However, to avoid contamination the players were asked to do the exercises outside the regular team training sessions; before or after training or at home. The low overall compliance in the intervention group indicates that significant contamination between groups is unlikely to have occurred. As seen in previous studies, the main challenge is getting players in the intervention group to follow preventive training programs, not keeping other players from such training (Myklebust et al., 2003).

However, a potentially bigger risk of contamination is the fact that 19 of the 31 teams did teambased preventive exercises similar to ours regularly throughout the pre-season, and 16 of these reported good training regimens. Also, we could not keep teams from carrying out their normal preventive exercises. Although these team-based exercises were done by players in both groups, the fact that players from the control group trained with exercises similar to our intervention exercises, did reduce the potential of showing a positive preventive effect of our intervention, and represents a limitation in this study. Moreover, exercises carried out by each player on his own are probably not as effective as when they are carried out under qualified supervision (Söderman et al., 2000), not just because of a lower compliance, but also because the quality of the exercises performed cannot be assured in the same way. Potentially negative factors such as 
initial muscle soreness or eventual boredom could possibly be overcome more effectively in a group training session with a qualified instructor.

Because the compliance was low, the statistical power was also too low to assess the effect of the training programs in the subgroups which did follow the training protocol (i.e. through the perprotocol analyses). The four programs used were selected either because there was evidence from previous prevention studies to indicate that they are effective, or because they have been shown to be effective as rehabilitation exercises after injury.

\section{Prevention of ankle injuries}

To prevent ankle and knee injuries, various forms of balance training and pre-season conditioning exercises had been shown to be effective in other study populations (Tropp et al., 1985; Caraffa et al., 1996; Heidt, Jr. et al., 2000; Verhagen et al., 2000; Junge et al., 2002). Since the study was carried out, also later studies and systematic reviews have reported that neuromuscular training can prevent ankle injuries (Verhagen et al., 2004; Stasinopoulos, 2004; Mohammadi, 2007; McKeon \& Mattacola, 2008; Lee \& Lin, 2008; Hupperets et al., 2008; Melnyk et al., 2009; Hupperets et al., 2009; Hubscher et al., 2010). Of all intervention strategies, the most consistent evidence supports the use of external support, either through use of orthoses or taping, especially among previously injured players (Thacker et al., 1999; Handoll et al., 2001; McKeon \& Mattacola, 2008). However, the use of orthoses may influence performance (Bot \& van Mechelen, 1999) in sports in general, and obviously football in particular. As we also demonstrated in the present study (Paper I), achieving a good compliance with our preventive measures is difficult, and we did not believe implementing the use of orthoses would be well received by the players. Hence, taping was thought to be the only option for external support that could be implemented. However, including this measure on such a big sample of players would be challenging to achieve in a standardized method. Also, as a main goal of the present study was to develop means available to all players, not just the elite players with good medical staff, we believed neuromuscular training would be of the greatest use.

\section{Prevention of knee injuries}

Since the study was carried out, also later studies and systematic reviews have found that neuromuscular training can prevent knee injuries (Thacker et al., 2003; Mandelbaum et al., 2005;

Olsen et al., 2005). Only one study has not found such training useful (Söderman et al., 2000). Regarding bracing as preventive means for knee injuries, a systematic review in collegiate American football players concluded that the results on the area of research are inconsistent. Also, bracing seems to influence performance (Greene et al., 2000). 


\section{Prevention of hamstring injuries}

Until the start of our study, recent publications had indicated that strain injuries to the hamstrings could be effectively prevented through eccentric strength training, such as the training program used in the present study (Askling et al., 2003; Mjølsnes et al., 2004; Árnason et al., 2008). Later, a prospective cohort study achieved significant reduction in injury risk through normalization of strength imbalances detected in the preseason (Croisier et al., 2008). A review from 2005 concluded that there was a need for further research on hamstring injury prevention in sports (Petersen \& Hölmich, 2005). A systematic Cochrane review has later looked at hamstring preventive exercises (including Paper I from the present thesis), and concluded that there is insufficient evidence from randomised controlled trials to draw conclusions on the effectiveness of interventions used to prevent hamstring injuries (Goldman \& Jones, 2010). Regarding other preventive measures, a systematic review from 2004 (Thacker et al., 2004) concurred with the review from two years earlier (Herbert \& Gabriel, 2002) and concluded that stretching was not significantly associated with a reduction in total injuries. This seems to be in contrast to Witvruov et al. who concluded that soccer players with an increased tightness of the hamstring muscles have a higher risk for a subsequent musculoskeletal lesion (Witvrouw et al., 2003).

\section{Prevention of groin injuries}

Equivalent to the exercises chosen for hamstring injuries, strengthening exercises were chosen for prevention of groin injuries as well. As stretching did not seem useful (Herbert \& Gabriel, 2002), strength training was the most promising preventive measure. The program of strength training and core stability had been shown to be highly effective in the treatment of long-standing groin pain in a population mainly consisting of football players (Hölmich et al., 1999). This program formed the basis for the present program, but because we thought it would be unrealistic to implement the entire groin program, we prescribed an abbreviated 10-15 minute session to increase compliance. Unfortunately, the results show that compliance was still poor, and therefore the true effect of the preventive program carried out cannot be assessed. The same group that suggested using strength training not only for treatment for chronic groin pain, but also in means of prevention, recently tested such a program in a large cluster-randomized controlled study. However, there was no significant reduction in groin injury incidence as a result of such training (Hölmich et al., 2009).

\section{General considerations regarding prevention of injuries}

In other words, each of the program components were based on studies indicating their effect in prevention or rehabilitation of the four main injury types. However, previous injury as a risk factor is not fully understood; it may be that ankles, knees, hamstrings and groins are not fully 
restored structurally or functionally. While the injury prevention literature supports several different exercises, there is limited evidence that reinjuries would be prevented through the same exercises. We do not know which exercises should be chosen to prevent reinjuries, and which have potential for primary prevention of the same injury types.

It is possible that the compliant players may have benefited from the programs if they had carried out more sessions. We know that a certain minimum of exercise must be performed before an effect may be expected (Myklebust et al., 2003). For the purposes of data analysis, we suggested that at least 30 exercises needed to be carried out. However, this number is arbitrary, as there is no evidence on the dose-effect relationship for any exercise program to prevent injuries. 


\section{Risk factors for the most common injuries in football (Papers II-V)}

Because these studies (Papers II-V) were based on the randomized controlled trial (Paper I), separate analyses controlling for group assignment (intervention or control group) were performed; however, with no change in the results for neither ankle (Paper II), knee (Paper III), hamstring (Paper IV) nor groin (Paper V) analyses. Also, a Poisson model approximating multinomial logistic regression analyses was used, in order to compare players who sustained no injuries versus those who sustained one injury versus those who sustained more than one injury. Again, the results did not differ from the original analyses. The risk factor analyses presented below therefore includes all players, regardless of team and group assignment.

\section{Risk factors for ankle injuries (Paper II)}

Univariate analyses revealed the number of previous acute ankle injuries and the FAOS sub score "Pain" as potential leg-dependent risk factors for acute ankle injuries. None of the balance tests on the floor or a balance mat, or clinical tests were candidates predictors for increased risk. Additionally, none of the player-dependent factors (age, height, body mass index, position on the field, having played at the junior national team or at the senior national team level, level of play this season or level of play the previous season) were significantly associated with the risk of ankle injury.

The two risk factors with $\mathrm{p}$-value of $<0.10$ were then considered as candidates to predict which players were more prone to sustain an acute ankle injury. Because these factors may be intercorrelated, a multivariate analysis was performed, and only previous acute ankle injury was found to be a significant risk factor for a new acute ankle. The importance of this risk factor increases with number of previous injuries (test of trend, $\mathrm{P}=0.001$ ), and seems to decrease with time since the last injury (test of trend, $\mathrm{P}=0.06$ ). A complete listing of the results may be seen in tables 1,2 and 3 in Paper II.

Several authors have found previous ankle injuries to be a significant risk factor for new injuries, both in male football (Ekstrand \& Gillquist, 1983a; Tropp et al., 1985; Árnason et al., 2004b; Kofotolis et al., 2007) and among male athletes in other sports (Bahr \& Bahr, 1997; McKay et al., 2001; Tyler et al., 2006; McGuine \& Keene, 2006; McHugh et al., 2006). The study by Árnason et al. (2004b), which is the only other large-scale study using a multivariate approach to examine several different factors, found previous ankle injury to be the only significant risk factor for a new injury to the same ankle in a large cohort study investigating risk factors for football injuries, the same way as we did. In the same study, lateral instability and a positive anterior drawer test were correlated with previous injury. In contrast to these findings, Trojian and McKeag (2006) 
and Hägglund et al. (2006) did not find a history of previous ankle injury to be associated with future ankle sprains. However, a limited number of acute ankle injuries were included in these studies (Árnason et al., 2004b; Hägglund et al., 2006; Trojian \& McKeag, 2006).

Ankle injuries have been prevented effectively through neuromuscular training, either on a balance board or balance mat, in football (Tropp et al., 1985; Árnason et al., 1996) and in other sports (Bahr et al., 1997; Garrick \& Requa, 2005; Olsen et al., 2005; McHugh et al., 2007). Therefore, it seemed reasonable to suggest that a similar exercise could be used as a screening test to identify players at risk. The literature is limited on the topic, and only two publications have looked at whether single leg balance tests can predict risk of new ankle injuries in male football (Trojian \& McKeag, 2006; McHugh et al., 2006). Trojian and McKeag (2006) found a predictive value of balance tests, while McHugh et al. (2006) did not. However, several publications looking at balance, measured in different ways, as a predictor of increased risk of injury among male athletes do exist from other sports (McGuine et al., 2000; Willems et al., 2005; Wang et al., 2006; Hrysomallis et al., 2007). In the present study, none of the balance tests, on the floor or a balance mat, turned out to be significant predictors. There are several potential explanations for this apparent discrepancy. First, even though this study is one of the largest cohort studies on risk factors for injuries to date, with as many as 56 acute ankle injuries, the statistical power is limited for multivariate tests. Nevertheless, the strength of the candidate risk factors studied does not indicate that any of these would be helpful as screening tools. Second, the results indicate that the intertester reliability for the balance tests used is low, with kappa values of 0.40 and 0.19 . This shows that the same player will not necessarily be scored the same way from two different tests of the same ankle, a factor which clearly influences the ability to identify players with reduced ankle control. Third, the floor test has a ceiling effect in this player population, with $97.4 \%$ of the subject obtaining a normal or supranormal test score. Because we suspected that this test could be too easy, we also included the balance mat test. For this, the test distribution was better (34.6\%, 34.5\% and $25.8 \%$ in categories 2,3 and 4 , respectively), and the main problem may be that the balance mat test is inconsistent, as indicated by the low kappa value. Also, data from Australian football suggest that balance deficits do not necessarily persist among previously injured athletes (Hrysomallis et al., 2005). To identify athletes at risk based on tests measuring balance and ankle control, we clearly need to develop new methodology with better test properties and reliability.

Using multivariate methods where we have controlled for significant risk factors as well as player exposure, this study confirms the consistent finding from previous studies that players with a history of ankle sprains are at increased risk (Ekstrand \& Gillquist, 1983a; Tropp et al., 1985; 
Árnason et al., 2004b; Kofotolis et al., 2007). The high risk period is the first 6 months after a previous injury, as also shown in a study among volleyball players (Bahr \& Bahr, 1997). It seems reasonable to recommend that injured players complete a program of balance training on a wobble board for 10 weeks, as first described by Tropp et al. (1985), and that they use tape or a brace during high risk activities until their rehabilitation is completed (Ekstrand et al., 1983a; Tropp et al., 1985). Studies have shown that taping (Ekstrand et al., 1983a; Tropp et al., 1985) or using an orthotic device (Surve et al., 1994) prevents reinjury in athletes with a history of ankle sprain, but that both methods have much greater effect on previously injured players. This may be due to the manner in which taping and braces apparently work; that is, they improve the ability of the ankle to react quickly to an inversion stress, but not as a passive mechanical support. Following these guidelines may prevent the athlete from entering a vicious circle with repeated ankle sprains and chronic ankle instability problems.

\section{Risk factors for knee injuries (Paper III)}

Univariate analyses revealed that the KOOS sub scores "Pain" and "Function in daily living" were potential leg-dependent risk factors for acute knee injuries. Also, the clinical examination was a potential means of identifying players at risk; any positive finding at clinical examination, deviations from the normal knee axis and flexion contraction in range of motion testing were candidate factors. As for the specific knee testing, a positive varus stress test in full extension and in 30 degrees of flexion were potential predictors of increased risk. None of the player-dependent factors tested were significantly associated with risk of knee injury. However, no significant risk factors for new acute knee injuries were identified in the final multivariate analysis when the candidate factors were included. Out of a total of 1016 cases, the final multivariate analysis was based on 812 cases after cases with missing data were excluded.

The literature on risk factors for acute knee injuries among male football players is limited. A history of previous knee injury seems to be the most important risk factor for new injuries, both in male football (Ekstrand \& Gillquist, 1983a; Árnason et al., 2004b; Hägglund et al., 2006) and among male athletes in other sports (Taunton et al., 2003; Meeuwisse et al., 2003; Yung et al., 2007). Árnason et al. (2004b) found previous knee injury to be the only significant risk factor for a new injury to the same knee in a large cohort study investigating risk factors for football injuries. In the same study, increased valgus laxity was associated with a history of previous injury. In a recent study among female youth football players previous injury was the only risk factor identified (Steffen et al., 2008a). These results are in contrast to the present study, where no association was seen between previous injury and new injuries in the categorical analysis. 
However, there is a trend suggesting an association between injury risk and the number of selfreported previous knee injuries. Also, as we observed a highly significant correlation between any pathological finding on the clinical knee examination and increased injury risk, this represents indirect evidence to the same association. It could be that the most serious injuries, causing abnormalities which could be detected through the clinical exam, do predispose a player for new injuries. Still, the overall findings in this study indicate that the strength of the candidate risk factor previous injury is low and alone it cannot be used to identify and target high-risk players with preventive measures, at least not in this player population.

Although one should think that significant injuries are easily remembered, there are indications in the literature that the number of previous injuries or even injury location may be difficult to report correctly (Gabbe et al., 2003). Therefore, recall bias may be a significant factor (Árnason et al., 2004b; Steffen et al., 2008a). A recent study from Swedish elite football bypassed this problem by including prospective data collected over two consecutive seasons. They showed that an injury in the first season increased injury risk during the subsequent season (Hägglund et al., 2006).

Of the other potential risk factors suggested from studies in different sports, age groups or among female athletes in the literature (gender (Lindenfeld et al., 1994; Ahmad et al., 2006; McLean et al., 2007), age (Backous et al., 1988; Lindenfeld et al., 1994; Östenberg \& Roos, 2000), slow reaction time (Taimela et al., 1990), personality factors (Taerk, 1977; Lysens et al., 1989; Taimela et al., 1990; Junge et al., 2000), disobeying fair play (Roberts et al., 1996; Peterson et al., 2000), playing position (Lindenfeld et al., 1994), quadriceps-to-hamstring strength ratio (Ahmad et al., 2006), landing technique (Hass et al., 2005; McLean et al., 2007), fatigue (McLean et al., 2007), neuromuscular control of the knee (Hewett et al., 2005) or trunk (Zazulak et al., 2007), history of low back pain (Zazulak et al., 2007) and general joint laxity (Baumhauer et al., 1995; Östenberg \& Roos, 2000; Beynnon et al., 2001; Myer et al., 2008), only age was tested in this study and this did not prove useful. It should be noted that knee joint laxity was tested through static stress tests; this should not be confused with the dynamic valgus pattern associated with non-contact ACL injuries among female athletes (Hewett et al., 2005). We also included maximal jump and sprint test in this study because we hypothesized that players generating the largest forces when running and cutting and in landings could be at greater risk of knee injury. Moreover, in the present study different self-reported measures of body size (height, weight, $\mathrm{BMI}$ ) were not associated with increased injury risk, which is in accordance with previous risk factor studies (Árnason et al., 2004b; Steffen et al., 2008c). 


\section{Risk factors for hamstring injuries (Paper IV)}

Univariate analyses revealed previous acute hamstring injury (yes/no), total $\mathrm{HaOS}$ function score and the four of five sub-scores symptoms, pain, function in sports and quality of life as potential leg-dependent risk factors for hamstring injuries. Of the player-dependent factors, age and player position were identified as potential predictors of increased injury risk. The multivariate analysis found history of previous acute hamstring injury to be a significant risk factor for new hamstring injuries (adjusted OR: 2.19 [1.19-4.03], $\mathrm{P}=0.01$ ). Out of a total of 1016 cases, the final multivariate analysis was based on 893 cases after cases with missing data were excluded.

Several authors have found previous acute hamstring strains to be a significant risk factor for new injuries, both in male football (Árnason et al., 2004b; Hägglund et al., 2006) and among male athletes in other sports (Gabbe et al., 2005; Gabbe et al., 2006). This is in correspondence with the present findings, showing that the injury risk is doubled among previously injured players. Although the results were not significant, the risk seems to increase gradually with the number of previous injuries and decrease with time since the previous injury.

The Nordic hamstring exercise is the best documented preventive exercise for hamstring injuries (Askling et al., 2003; Árnason et al., 2008), and has been shown to increase muscle strength and does not require advanced equipment (Mjølsnes et al., 2004). It therefore seems reasonable to suggest that all football players, especially players with a history of previous hamstring injury, use this exercise regularly (Askling et al., 2003). Because the compliance with preventive exercises is low (Myklebust et al., 2003) and (Paper I), we recommend that they are done during team practices under supervision.

Strength deficits or imbalances have been suggested to increase hamstring injury risk (Croisier et al., 2008), although the relationship between advanced isokinetic testing and injury risk is not fully resolved (Bennell et al., 1998). Isokinetic tests have been criticized for their lack of specificity and the fact that eccentric strength training can prevent strains made us hypothesize that the Nordic hamstring exercise could be used as a simple screening test to identify players at risk. However, there was no association between the test and injury risk. The most likely explanation for this is that the reliability for the Nordic hamstring strength test is low, with a kappa value of only 0.24. This shows that the same player will not necessarily be scored the same way on two separate tests, a factor which clearly influences the ability to identify players with poor hamstring strength. It could also be that the cut-off angle was set too high or low. Another factor may be that the test examines the combined strength of both sides, which means that side-to-side imbalances or weakness related to previous injury on one side therefore will be difficult to detect. 
In addition to previous injury, Árnason et al. (2004b) found age to be a significant risk factors for a new strain injury, independent of injury history. In the present study, age was associated with injury risk in the univariate analysis but not in the multivariate analysis.

Among other potential risk factors mentioned in the literature, reduced flexibility has been suggested as a risk factor for hamstring strains (Witvrouw et al., 2003; Bradley \& Portas, 2007). It has also been shown that football players are less flexible than a control group (Ekstrand \& Gillquist, 1982) and that football players often do not pay sufficient attention to stretching exercises (Ekstrand et al., 1983b; Inklaar, 1994b; Árnason et al., 1996; Hawkins \& Fuller, 1998). A study from Australian rules football examining a simple way of measuring hamstring flexibility the toe touch test - did not find it useful as a predictor of increased risk of hamstring strains in Australian rules football players (Bennell et al., 1999). The test used to measure hamstring muscle length in this study has been used in different studies (Fredriksen et al., 1997; Árnason et al., 2004b). Árnason et al. (2004b) did not find hamstring muscle length to be a significant predictor of injury risk, which is in correspondence with the present findings. The coefficient of variation for the measurements from the passive knee extension test in this study was $9 \%$, which means that the accuracy of the test is quite good. In other words, it seems that there is no association between hip flexion range of motion flexibility and hamstring injury risk, which may explain why stretching programs do not seem to influence injury risk (Thacker et al., 2004; Árnason et al., 2008).

From a biological perspective, it seems reasonable to suggest that explosive athletes with a dominant fast muscle fiber type would be more prone to sustain strain injuries. In this study, however, neither the $40 \mathrm{~m}$ sprint test nor the counter movement jump test was associated with injury risk.

We did not record whether injuries resulted from contact or non-contact. Injury resulting from contact with other players is rarely the case with hamstring strains. In fact, a study from English professional football non-contact injuries were found to be responsible for $91 \%$ of the hamstring injuries (Woods et al., 2004).

In this study, overuse injuries where no time-loss had occurred were also included as hamstring injuries. Because MRI or ultrasound examinations were not readily available, we did this to include small repeated strain injuries, as some players still elect to play despite discomfort in the posterior thigh. We cannot be sure that all of these represented true strain injuries to the hamstring muscles, but a separate statistical analysis using solely acute time-loss injuries as end point (data not shown) did not change the main findings. 


\section{Risk factors for groin injuries (Paper V)}

Univariate analyses revealed the following potential leg-dependent risk factors for groin injuries; previous acute groin injury, total GrOS and GrOS sub scores "symptoms", "soreness" and "pain" and the clinical tests pain at external rotation in the hip joint and reduced range of motion for external rotation, pain at functional testing of the rectal abdominal muscles, weak adductor muscles determined clinically, pain at functional testing of the iliopsoas muscles and weak iliopsoas muscles determined clinically. Of the player-dependent factors, age and counter movement jump test were significantly associated with risk of groin injury. In cases where two of the potential leg-dependent risk factors were strongly intercorrelated $(\mathrm{p}<0.05)$, only the most clinically relevant test was included in the final multivariate analysis. This includes pain at external rotation in the hip joint and reduced range of motion for external rotation (intercorrelation $\mathrm{p}=0.02$ ) (pain at external rotation chosen due to greater clinical relevance) and weak iliopsoas muscles determined clinically versus pain at functional testing (intercorrelation $\mathrm{p}=0.02$ ) (weak iliopsoas muscles chosen because this was believed to be clinically more specific).

The multivariate analysis showed that previous acute groin injury (adjusted OR 2.60, 95\% CI 1.10 to 6.11) and weak adductor muscles determined clinically (adjusted OR 4.28, 95\% CI 1.31 to 14.0) were significant predictors of increased risk of groin injuries. Out of 1016 cases, the final multivariate analysis was based on 560 cases after cases with missing data were excluded.

Separate statistical analysis using acute time-loss injuries only was also carried out. The univariate analyses identified the $40 \mathrm{~m}$ sprint test, counter movement jump test and level of play as additional potential player-dependent risk factors, while previous acute groin injury, GrOS and functional testing of the abdominal muscles were identified as potential leg-dependent risk factors. A multivariate analysis based on acute time-loss injuries only revealed $40 \mathrm{~m}$ sprint test result (adjusted OR 2.03, 95\% CI 1.06 to 3.88, $\mathrm{p}=0.03$ ) and functional testing of the abdominal muscles (adjusted OR 15.5, 95\% CI 1.11 to $217, \mathrm{p}=0.04$ ) as significant risk factors.

Previously injured players have more than twice as high risk of sustaining a new groin injury, while players with weak adductor muscles have a four times higher injury risk. Previous injury seems to be the most consistent intrinsic risk factor identified in the literature. A systematic review examining risk factors for acute muscle strains in different sports found previous injury to be a strong predictor of muscle strain injury (Emery, 1999). In a multivariate analysis in the largest cohort study to date in male football, previously injured players were found to have more than a seven-fold increased risk of sustaining new groin injuries compared with uninjured controls (Árnason et al., 2004b). A study from Swedish elite football also found previous injury 
to the same leg to be a significant risk factor (Hägglund et al., 2006). These findings are also consistent with studies from other sports with high demands on the groin area (Maffey \& Emery, 2007). The results from the present study are in accordance to these findings. As underlined earlier, adequate rehabilitation and preventing the first injury should be a high priority also for groin injuries. To accomplish this, the best method may be strength exercises. While a passive physical therapy programme of massage, stretching and modalities was ineffective in treating chronic groin strains, Hölmich et al (1999) demonstrated that an 8- to 12-week active strengthening programme, consisting of progressive resistive adduction and abduction exercises, balance training, abdominal strengthening and skating movements on a slide board, was effective in treating chronic groin strains. Our own intervention (Paper I) using a modified, shortened version of this programme did not find a preventive effect. However, due to poor compliance it is not possible to say whether the shortened programme would have been effective, if completed as prescribed. Also, in professional ice hockey adductor strengthening exercises reduced the number of groin injuries (Tyler et al., 2002).

The other main observation in the present study was that players assessed to have weak adductors in the clinical examination had four times the injury risk of players with normal strength. No publications exist from male football on the topic, but in a study from male elite ice hockey, significantly lower adductor strength was found among injured players (Tyler et al., 2001). However, in contrast to the clinical examination, adductor strength measured by a handheld dynamometer was not significantly associated with risk of injury. Still, the coefficient of variation for this test of $19.6 \%$ indicates that inter-test reliability was limited.

Hip and groin injuries are reported to often occur in sports involving side-to-side cutting, quick accelerations and decelerations, and sudden directional changes (Morelli \& Weaver, 2005). Strength imbalances between the propulsive muscles and the stabilizing muscles of the hip and pelvis (Garrett, Jr. et al., 1987) and between the synergistic abductors and adductors have been suggested as risk factors for groin injuries (Maffey \& Emery, 2007). Also, delayed contraction of the transversus abdominis (Cowan et al., 2004), as a measure of reduced core stability, has been suggested in the literature. Unfortunately, based on the tests performed in this study, these hypotheses cannot be addressed.

Neither this nor previous studies (Tyler et al., 2001; Árnason et al., 2004b) have identified adductor length as a risk factor for groin injury in football, and stretching programs do not seem to influence injury risk (Thacker et al., 2004). A study from Belgian elite football found no predictive value of adductor flexibility measurements (Witvrouw et al., 2003). Still, Árnason et al. (2004b) found decreased range of motion in hip abduction to be a significant risk factor for groin 
injuries, which is in contrast with the present findings. In the present study (Paper V), however, hip range of motion was only examined clinically.

Age and experience have been suggested as risk factors in elite ice hockey (Emery \& Meeuwisse, 2001). The present study found these factors to be strongly associated with injury risk in the univariate, but not in the multivariate analysis. This is in accordance with previous studies from football (Árnason et al., 2004b) and other sports (Orchard et al., 1998; Emery \& Meeuwisse, 2001).

It seemed reasonable to hypothesize that explosive athletes with a dominant fast-twitch muscle fiber type would be more prone to strain injuries. However, in this study neither the $40 \mathrm{~m}$ sprint test nor the counter movement jump test result was associated with injury risk in the main analysis. This is in accordance with Árnason et al (2004b), who found no predictive effect of jump tests. However, it should be noted that correspondingly to the hamstring analyses, overuse injuries where no time-loss had occurred were also included in our definition of groin injuries. Still, using acute time-loss injuries only as the end point identified the $40 \mathrm{~m}$ sprint test and functional testing of the abdominal muscles as significant risk factors. This could indicate that the risk for acute injuries is increased among "explosive" players, and that previous injury is less important as risk factor for new acute injuries. However, as this analysis is based on only 22 acute time-loss injuries it needs to be interpreted with caution.

\section{Screening}

In regards of the predefined high-risk and low-risk groups, the incidence was lower in the LR control group than both other groups (RR: 0.65 vs. the HR intervention group, 95\% CI: 0.51 to 0.85; RR: 0.61 vs. the HR control group, 95\% CI: 0.48 to 0.79) (Paper I). During the season, $45.8 \%$ of the players in the LR control group (55 of 120 players) sustained one or more injuries, compared to $58.5 \%$ in the HR control group (114 of 195 players; $P=0.029$ vs the LR control group; chi square test) and $59.1 \%$ in the HR intervention group (114 of 193 players; $P=0.90$ vs the HR control group). This implies that an overall, unspecific identification of high-risk athletes can be done. The sensitivity of this screening was $85 \%$, while the specificity using our predefined criteria was $28 \%$. The positive and negative predictive values were $39 \%$ and $78 \%$, respectively. However, the high risk groups (HRi and HRc) have a considerable amount of injuries. In order to target preventive training to the players with highest risk of injury, the information from the cohort studies (Papers II-V) must be considered.

Screening for ankle injury risk (Paper II). A history of previous acute ankle injury proved to be the only significant risk factor for new injuries to the same ankle in this prospective cohort study. 
Players with multiple and/or recent injuries are at a high risk. For practical use, the sensitivity of previous injury (yes or no) as a predictor for new ankle sprains was $74 \%$, which means $74 \%$ of the players who sustained an ankle injury during the season had a history of ankle sprains. However, the positive predictive value was only $6 \%$, which means that only $6 \%$ of previously injured players suffered a new ankle sprain during the season. This figure increases gradually with the number of previous injuries to $10 \%$ if the player has had five or more previous acute ankle injuries. The same is the case if there was a history of a recent sprain, i.e. during the last 6 months $(9 \%)$. Based on these results, it does not seem possible to target preventive measures based on a history of ankle sprains alone. The results from this study also show that additional information such as balance tests, player interviews or clinical examination does not increase our ability to identify players at risk.

Knee (Paper III). No significant predictors of knee injury risk were found in this study. More advanced tests requiring advanced laboratory equipment have been used in studies on risk factors for ACL injuries among female athletes (Hewett et al., 2005; Ahmad et al., 2006; Zazulak et al., 2007), and an association has been demonstrated with deficits in neuromuscular control of the trunk, biomechanical measures of neuromuscular control and valgus loading of the knee, and high quadriceps-to-hamstring ratio. However, the present findings, based on the simple screening methods examined, indicate that it is not possible to screen and identify players with high risk of knee injuries. In regards of the identification of players with self-reported previous ACL injuries, the sensitivity and specificity for the Lachman test were 36\% and 99\% in the present study.

Hamstring (Paper IV). For practical use, the sensitivity of previous injury (yes or no) as a predictor for new hamstring strains was $51 \%$, which means $51 \%$ of the players who sustained a hamstring injury during the season had a self-reported history of acute hamstring strains. The specificity of previous injury (yes or no) as a predictor for new hamstring strains was $70 \%$. The positive predictive value was $10 \%$, which means that $10 \%$ of previously injured players suffered a new hamstring injury during the season. The negative predictive value was $95 \%$. The sensitivity decreased gradually with the number of previous injuries to $11 \%$ for more than five previous hamstring strains, while the corresponding figures for the positive predictive value increase gradually to $21 \%$. When looking at the time since injury, it seems as though an injury during the last 12 months is as important as during the last 6 months, both with a positive predictive value of $14 \%$, while the sensitivity was $14 \%$ and $28 \%$ for the last 6 and 12 months, respectively. The sensitivity even increases for the category "previous hamstring strain during the last two years" to $42 \%$, with a positive predictive value of $13 \%$, until both values decline when looking at the 
category of more than two years since injury. This is in accordance with the findings by Árnason et al (2004b).

Groin (Paper V). For practical use, the sensitivity of previous injury (yes or no) as a predictor for new groin strains was $55 \%$, which means that $55 \%$ of the players who sustained a groin injury during the season had a self-reported history of acute groin strains. The specificity of previous injury (yes or no) as a predictor for new groin strains was $66 \%$. The positive predictive value was $9 \%$, which means that $9 \%$ of previously injured players suffered a new groin injury during the season. The negative predictive value was $96 \%$. The sensitivity decreased with number of previous injuries to $7 \%$ for more than five previous acute groin strains, while the corresponding figures for the positive predictive value only increases to $10 \%$, which implies that being previously injured (if only once) is relatively more important in regards of risk of new injuries than having had several previous acute groin strains which did not significantly increase the predictors value. When looking at time since injury, also here, it seems as though being previously injuried is the most important distinction, rather than if the injury is recent or not. The sensitivity and positive predictive values are 15\% and 9\% for previous injury during the last 6 months and $18 \%$ and $9 \%$ when the injury is more than 2 years ago, respectively. When looking at the second significant risk factor for new groin injuries, weak adductors as determined clinically, the sensitivity is $15 \%$ and the positive predictive value is $16 \%$.

\section{Reliability testing (Papers II-V)}

Ankle (Paper II). Inter-test reliability for the categorical variables, computed using kappa statistics, were 0.40 and 0.19 for balance tests on the floor and mat, respectively. For the clinical examination, kappa values were 0.45 (anterior drawer), 0.84 (foot type), 0.91 (standing rearfoot alignment), 1.00 (hallux position), and 1.00 (toe deformity).

The intertester reliability for especially the balance tests used was low. This shows that the same player will not necessarily be scored the same way from two different tests of the same ankle, a factor which clearly influences the ability of these tests to identify players with reduced ankle control.

Knee (Paper III). Inter-test reliability for the clinical examination was 1.00 for all tests examined; Lachman, posterior drawer, varus stress test in extension, varus stress test in 30 degrees of flexion, valgus stress test in extension) and valgus stress test in 30 degrees of flexion. These are optimal inter-test reliability and means that the same knee was scored the same when examined for the same test by two different physicians or physiotherapists in the study. 
Hamstring (Paper IV). Inter-test reliability was 0.24 for the Nordic hamstring strength test, which indicates poor reliability. Hence, it influences the test's ability to identify players with poor hamstring strength.

The coefficient of variation for the continuous variable hamstring muscle length was $9.1 \%$. In other words, the accuracy of the test is quite good.

Groin (Paper V). The coefficient of variation for the continuous variable adductor strength was $19.6 \%$, which is poor.

\section{Screening for injury risk - Discussion}

Although the intervention was ineffective, this study demonstrated that players who potentially had the most to gain from preventive exercises could be identified. The risk of injury was approximately twice as high among athletes with a history of previous injury and/or who reported reduced function. This identification was achieved through the use of a simple questionnaire only, and the addition of more elaborate functional tests did not increase the predictive value of the screening (Papers II-V). The rationale for the approach used, employing a self-completed questionnaire, was the potential for expanding the range of application of the athlete screening process. The increased risk associated with a history of previous injury and reduced function also has other implications. One is that preventing the first injury should be a high priority to keep players from entering the vicious circle of repeated injuries to the same body part. The most likely explanation for previous injury being such a consistent risk factor for reinjuries, is that the joints or muscles in question are not fully restored structurally and/or functionally. Based on this, it seems reasonable to suggest that one thing teams can do, even at lower levels of play, is to focus on improving rehabilitation after injury and implementing adequate return-to-play guidelines, such as demonstrated by Soligard et al. (2008). Players with reduced function after previous injury should undergo a structured rehabilitation program until full function is established. However, it remains to be proven whether this would reduce injury risk significantly. The present study (Paper I) also shows that this cannot be left to the players themselves; adequate supervision is necessary.

As stated in the introduction, history has shown that achieving good compliance with preventive exercises is a challenge (Myklebust et al., 2003). This was also the case in the present intervention study (Paper I). There is a wide gap between research and "real-world" implementation, which has taught us that seemingly effective preventive exercises are actually just effective when they both reduce injuries and are found interesting and fun enough to be carried out by the players. One aspect in trying to achieve this goal of developing meant-to-be preventive programs is to 
target the players in the most need of such. If a player is at high risk of sustaining for instance a groin injury, it is probably much more important for that player to carry out groin preventive exercises thoroughly than lots of general preventive exercises, and consequently less for the groin. This thesis confirms that screening in football medicine can be done (Paper I). Players with significantly increased risk of injury can be identified through self-reporting of history of previous injuries and function scores. The risk factor studies (Paper II-V) aid us further in the identification of the players with even higher risk of new injuries. However, it seems as though additional information and testing is of limited use; previous injury is generally (even though it did not prove useful in relation to knee injuries in paper III) the most important risk factor for new injuries, which is in concordance with previous studies in senior male football (Árnason et al., 2004b; Hägglund et al., 2006; Hölmich et al., 2009). This may implicate that sports medicine practitioners should emphasize firstly getting those players to carry out preventive exercises. Down the road, the ultimate goal would be to develop self-administered screening, maybe in the form of a web-based solution, which would fulfil one of the main goals of this thesis - making sports medicine available to every footballer, not just the elite players. Unfortunately, however, the positive predictive values of the identified risk factors for ankle, hamstring and groin injuries are only approximately $10 \%$. This means that targeting preventive training to all players who will sustain a new injury is not possible - we can only identify approximately $10 \%$ of these players through our screening methods.

Interestingly, the results from the main screening performed in Paper I, investigating the predefined high-risk and low-risk criteria (previous injury last year or function score $<80 \%$ in the ankle, knee, hamstring or groin) show a better test reliability. The sensitivity and positive predictive value of this screening was $85 \%$ and $39 \%$, respectively, which means that $85 \%$ of the players who sustained a new ankle, knee, hamstring or groin injury in the subsequent season were predefined as high-risk athletes, and more importantly that as many as 39\% of the players who were thought to have an increased injury risk actually did sustain a new injury. Also, the relatively high negative predictive value means that $78 \%$ of the players assigned to the low-risk group did not sustain a new ankle, knee, hamstring or groin injury in the following season. This implies that an overall, unspecific identification of high-risk athletes can be done. However, one has to bear in mind that as many as $76 \%$ of the players fulfilled the high-risk criteria. For the screening to have important relevance, the number of players identified as having low injury risk would optimally be much higher than $24 \%$.

Nevertheless, we suggest that information on previous recent injuries and reduced function in the ankle, knee, hamstring and groin is taken into account when injury risk is considered. However, 
even though a significant number of high risk players can be identified in this way, we suggest that all players should carry out the exercises in order to reduce the risk for all players who would sustain an injury in the following season. As discussed above, screening for injury risk cannot free some players from training preventive exercises; we can not say for sure that a player without for instance history of previous injury will not sustain an injury. Still, the present results aid us in identifying high-risk players who definitely should carry out preventive training programs.

\section{Limitations}

\section{Methodological issues}

In regards to the mechanism of injury, in the context of hamstring strains, intrinsic factors seem more predictive of injury than extrinsic ones (Orchard, 2001), which is why we had intrinsic risk factors as a focus area in the present study. Also, no registration of contact and non-contact injuries was made in this study. Contact injuries represent a much more heterogeneous group with respect to the reasons for injury and most of the potential and known intrinsic risk factors for injuries in male football are thought to apply best to non-contact injuries. However, to a player, the important issue is whether he is injured or not, and in this study the main goal was to look at simple ways of measuring potential risk factors for injuries, not injury mechanisms. Hence, the injury reporting form was simplified to possibly improve compliance from the physiotherapists. The risk of sustaining contact injuries is considerable in football, but one cannot eliminate the risk of contact and thereby contact injuries in football, and the risk factors tested in this study were therefore evaluated independently of contact or non-contact mechanisms. While contact with another player in the injury situation may play a role in a significant percentage of sprain injuries to the ankle and knee, contact is less dominant in strain injury mechanisms (Woods et al., 2004). If there were a number of contact injuries among the injuries recorded, these would presumably serve to dilute the effect of the risk factors studied. However, we cannot correct for this, because the mechanism of injury in each case was not known.

\section{Exposure registration}

We had to rely on the coaches for the exposure registration. We had no way to check their figures, but there should be no reason to misreport. If a game or practice session was missed, it would affect all players on the team, which is unlikely to influence the analysis regarding any specific risk factor or the intervention outcome.

\section{Study size}

The risk factor studies are among the largest cohort studies on risk factors for injuries to date, with as many as 56, 61, 76 and 61 ankle, knee, hamstring and groin injuries respectively. 
Nevertheless, the statistical power is limited for multivariate tests. Still, the strength of the candidate risk factors studied does not indicate that any of these would be helpful as screening tools. As pointed out by Bahr \& Holme (2003) in their review, to detect moderate to strong associations 20-50 injury cases are needed, whereas small to moderate associations would need about 200 injured subjects. However, for a risk factor to be clinically relevant with sufficient sensitivity and specificity, strong associations are needed. The objective of risk factor research is to identify clinically relevant, not just statistically significant factors. In this context, several of the factors that were found to be statistically significant in the univariate analysis are unlikely to be clinically relevant. Our conclusions are therefore based solely on the results of the final multivariate analysis.

\section{Validity for other sports, levels of play, ages or females}

This study was carried out among subelite male football players, and should not be extrapolated to other sports, females, youth players or other levels of play.

\section{Perspectives}

\section{Prevention of injuries in football - Laws of the game}

As described in this thesis, injuries in football constitute a major concern for society, teams and the individual athlete. Even though the intervention in Paper I did not reduce injuries, indications are that preventive exercises can reduce injury risk. No focus was made on contact injuries in the present study. It is believed that non-contact injuries are easiest to reduce through such exercises. Despite an optimistic attitude in football medicine and, in time, development of even more effective preventive exercises, some injuries in football will always remain, such as those due to foul play. In regards to injury prevention, an issue that has not been addressed in this thesis is therefore a more superior point of attack; maybe changes in the laws of the game are needed. Recently, an example of such a change, where players are given a red card when using elbows in heading duels has been implemented with success (Dvorak, 2009). However, du to the limitation of the studies.this issue will not be discussed here.

\section{Converting research to practice}

Another challenge in prevention of injuries is converting the results from encouraging injury preventing studies into life. It seems as advances in the science of injury prevention have not always led to advances in practice (MacKay \& Vincenten, 2009); effective approaches are not always adopted, or when adopted and transferred from one setting to another, they do not always achieve expected results. For interventions that have been efficacious in controlled trials to possibly matter in terms of public health impact, they also need to be widely adopted and 
sustained (Finch \& Donaldson, 2009). Oslo Sports Trauma Research Center, recently awarded a FIFA Medical Centre of Excellence, has taken this responsibility and is part of a serious engagement in research (www.ostrc.no). This has resulted in, inter alia, a separate area of effort ("Skadefri", www.skadefri.no) where players can see how to perform preventive exercises. But that is not enough; efforts are also paid in reaching players with the message. As demonstrated by Twomey et al (2009), there is still a long way left in order to convert research results into practice. In a survey among coaches in Australian football, they found that only one-third believed that balance training had some importance for injury prevention, despite accumulating scientific evidence to support it. They concluded that current training sessions do not give adequate attention to the development of skills most likely to reduce the risk of lower limb injury in players. There was therefore a need to improve the translation of the latest scientific evidence about effective injury prevention into coaching practices. Also a study from football indicated that there was a need for wider education of players in current injury prevention strategies (Hawkins \& Fuller, 1998).

Mahler and Donaldson (2010) recently questioned if currently known, but moderately evidencebased, prevention strategies are effective only if applied in a systematic and controlled way.

Despite encouraging sports- or injury-specific interventions (Aaltonen et al., 2007), little data are available to show significant reduction of sports injuries over longer periods of time or in larger populations in "real-world" implementation settings (Mahler \& Donaldson, 2010). On a general injury preventive basis, several authors have questioned if difficulties of translating research findings from the controlled environment of the research setting to the more complex environment of sports setting cause prevention strategies to be improperly implemented (Glasgow et al., 2003; Finch \& Donaldson, 2009; MacKay \& Vincenten, 2009). At least, from the present results, it seems as insufficient follow-up of effective interventions diminishes the chance of positive results. Systematic and controlled implementation may be necessary (Soligard et al., 2008).

\section{Prevention at the top of it's game?}

An interesting finding was revealed when looking at The Swiss National Injury Registry, which includes longitudinal data on sports injuries based on insurance claims; almost no change in the incidence of sporting injuries has been observed between 1998 and 2005 (39.7 \pm 0.17 injuries/1000 inhabitants/year). However, almost no significant injury preventive interventions were introduced in relation to this period. Also, when comparing the injuries of young sportspeople with injuries in the general, age and geographically adjusted, population there was no statistical difference (Mahler \& Donaldson, 2010). Mahler and Donaldson (2010) have 
therefore questioned if there might actually be a "threshold" incidence of injuries below which it might be difficult to go, hence wondering if injury prevention efforts have contributed significantly to performance enhancement in sports, while injuries have stayed relatively constant over time. Given the relatively low injury incidence in this thesis, such a "threshold hypothesis" may add partial explanation to the believed to be main reason for the negative results from intervention, the poor compliance.

However, as indicated in this thesis, there is still a potential for prevention of injuries in football. Just recently, a study showed that injury incidence increases when recovery time is insufficient (Dupont et al., 2010). 


\section{Conclusions}

1. Players with an increased injury risk were identified through a comprehensive questionnaire. The positive and negative predictive values of this screening were $39 \%$ and $78 \%$, respectively.

2. The targeted intervention did not affect injury risk. Due to low compliance it is difficult to conclude about the true effect of the training programs.

3. Previous ankle injury was the only significant predictor for new acute ankle injuries. The risk increases with the number of previous injuries and is highest during the first 6 months after injury.

4. None of the potential leg- or player-dependent risk factors studied could be used to predict increased risk of knee injury.

5. A history of previous acute hamstring injury is a significant risk factor for new hamstring injuries. Previously injured players have more than twice as high risk of sustaining a new injury.

6. A history of a previous acute groin injury and weak adductor muscles were found to be significant risk factors for new groin injuries. Previously injured players have a more than twice as high risk of sustaining a new groin injury, while the risk is four times higher in players with weak adductor muscles. 


\section{References}

Aaltonen, S., Karjalainen, H., Heinonen, A., Parkkari, J., Kujala, U. M., (2007). Prevention of sports injuries: systematic review of randomized controlled trials. Arch.Intern.Med. 167, $1585-1592$.

Agre, J. C., (1985). Hamstring injuries. Proposed aetiological factors, prevention, and treatment. Sports Med. 2, 21-33.

Ahmad, C. S., Clark, A. M., Heilmann, N., Schoeb, J. S., Gardner, T. R., Levine, W. N., (2006). Effect of gender and maturity on quadriceps-to-hamstring strength ratio and anterior cruciate ligament laxity. Am.J.Sports Med. 34, 370-374.

Albright, J. P., Powell, J. W., Smith, W., Martindale, A., Crowley, E., Monroe, J., Miller, R., Connolly, J., Hill, B. A., Miller, D., ., (1994). Medial collateral ligament knee sprains in college football. Effectiveness of preventive braces. Am.J.Sports Med. 22, 12-18.

Andersen, T. E., Engebretsen, L., Bahr, R., (2004a). Rule violations as a cause of injuries in male norwegian professional football: are the referees doing their job? Am.J.Sports Med. 32, $62 \mathrm{~S}-68 \mathrm{~S}$.

Andersen, T. E., Floerenes, T. W., Árnason, A., Bahr, R., (2004b). Video analysis of the mechanisms for ankle injuries in football. Am.J Sports Med 32, 69S-79S.

Andersen, T. E., Larsen, O., Tenga, A., Engebretsen, L., Bahr, R., (2003). Football incident analysis: a new video based method to describe injury mechanisms in professional football. Br.J.Sports Med. 37, 226-232.

Andersen, T. E., Tenga, A., Engebretsen, L., Bahr, R., (2004c). Video analysis of injuries and incidents in Norwegian professional football. Br.J.Sports Med. 38, 626-631.

Árnason, A., Andersen, T. E., Holme, I., Engebretsen, L., Bahr, R., (2008). Prevention of hamstring strains in elite soccer: an intervention study. Scand.J.Med.Sci.Sports 18, 40-48.

Árnason, A., Engebretsen, L., Bahr, R., (2005). No effect of a video-based awareness program on the rate of soccer injuries. Am.J.Sports Med. 33, 77-84.

Árnason, A., Gudmundsson, A., Dahl, H. A., Johannsson, E., (1996). Soccer injuries in Iceland. Scand.J.Med.Sci.Sports 6, 40-45.

Árnason, A., Sigurdsson, S. B., Gudmundsson, A., Holme, I., Engebretsen, L., Bahr, R., (2004a). Physical fitness, injuries, and team performance in soccer. Med.Sci.Sports Exerc. 36, 278-285.

Árnason, A., Sigurdsson, S. B., Gudmundsson, A., Holme, I., Engebretsen, L., Bahr, R., (2004b). Risk factors for injuries in football. Am.J.Sports Med. 32, 5S-16S. 
Árnason, A., Tenga, A., Engebretsen, L., Bahr, R., (2004c). A prospective video-based analysis of injury situations in elite male football: football incident analysis. Am.J.Sports Med. 32, 1459-1465.

Askling, C., Karlsson, J., Thorstensson, A., (2003). Hamstring injury occurrence in elite soccer players after preseason strength training with eccentric overload.

Scand.J.Med.Sci.Sports 13, 244-250.

Backous, D. D., Friedl, K. E., Smith, N. J., Parr, T. J., Carpine, W. D., Jr., (1988). Soccer injuries and their relation to physical maturity. Am.J Dis.Child 142, 839-842.

Bahr, R., Bahr, I. A., (1997). Incidence of acute volleyball injuries: a prospective cohort study of injury mechanisms and risk factors. Scand J Med Sci Sports 7, 166-171.

Bahr, R., Holme, I., (2003). Risk factors for sports injuries--a methodological approach. Br.J.Sports Med. 37, 384-392.

Bahr, R., Krosshaug, T., (2005). Understanding injury mechanisms: a key component of preventing injuries in sport. Br.J.Sports Med. 39, 324-329.

Bahr, R., Lian, O., Bahr, I. A., (1997). A twofold reduction in the incidence of acute ankle sprains in volleyball after the introduction of an injury prevention program: a prospective cohort study. Scand J Med Sci Sports 7, 172-177.

Baumhauer, J. F., Alosa, D. M., Renström, A. F., Trevino, S., Beynnon, B., (1995). A prospective study of ankle injury risk factors. Am.J Sports Med 23, 564-570.

Bennell, K., Tully, E., Harvey, N., (1999). Does the toe-touch test predict hamstring injury in Australian Rules footballers? Aust.J.Physiother. 45, 103-109.

Bennell, K., Wajswelner, H., Lew, P., Schall-Riaucour, A., Leslie, S., Plant, D., Cirone, J., (1998). Isokinetic strength testing does not predict hamstring injury in Australian Rules footballers. Br.J.Sports Med. 32, 309-314.

Beynnon, B. D., Renström, P. A., Alosa, D. M., Baumhauer, J. F., Vacek, P. M., (2001). Ankle ligament injury risk factors: a prospective study of college athletes. J Orthop.Res. 19, 213-220

Bjørneboe J, Bahr R, Andersen, T. E., (2010). Risk of injury on football turf in Norwegian professional football. British Journal of Sports Medicine, p. In press.

Bjørneboe J, Floerenes, T. W., Bahr R, Andersen, T. E., (2009). Injury surveillance in male professional football; is medical staff reporting complete and accurate? Scandinavian Journal of Medicine \& Science in Sports, p. In press.

Bot, S. D., van, M. W., (1999). The effect of ankle bracing on athletic performance. Sports Med. 27, 171-178.

Bradley, P. S., Portas, M. D., (2007). The relationship between preseason range of motion and muscle strain injury in elite soccer players. J Strength.Cond.Res. 21, 1155-1159. 
Brockett, C. L., Morgan, D. L., Proske, U., (2001). Human hamstring muscles adapt to eccentric exercise by changing optimum length. Med.Sci.Sports Exerc. 33, 783-790.

Brockett, C. L., Morgan, D. L., Proske, U., (2004). Predicting hamstring strain injury in elite athletes. Med.Sci.Sports Exerc. 36, 379-387.

Brooks, J. H., Fuller, C. W., (2006). The influence of methodological issues on the results and conclusions from epidemiological studies of sports injuries: illustrative examples. Sports Med. 36, 459-472.

Caraffa, A., Cerulli, G., Projetti, M., Aisa, G., Rizzo, A., (1996). Prevention of anterior cruciate ligament injuries in soccer. A prospective controlled study of proprioceptive training. Knee.Surg.Sports Traumatol.Arthrosc. 4, 19-21.

Cowan, S. M., Schache, A. G., Brukner, P., Bennell, K. L., Hodges, P. W., Coburn, P., Crossley, K. M., (2004). Delayed onset of transversus abdominus in long-standing groin pain. Med.Sci.Sports Exerc. 36, 2040-2045.

Croisier, J. L., (2004). Factors associated with recurrent hamstring injuries. Sports Med. 34, 681-695.

Croisier, J. L., Forthomme, B., Namurois, M. H., Vanderthommen, M., Crielaard, J. M., (2002). Hamstring muscle strain recurrence and strength performance disorders. Am.J.Sports Med. 30, 199-203.

Croisier, J. L., Ganteaume, S., Binet, J., Genty, M., Ferret, J. M., (2008). Strength imbalances and prevention of hamstring injury in professional soccer players: a prospective study. Am.J.Sports Med. 36, 1469-1475.

Devlin, L., (2000). Recurrent posterior thigh symptoms detrimental to performance in rugby union: predisposing factors. Sports Med. 29, 273-287.

Drawer, S., Fuller, C. W., (2002). Evaluating the level of injury in English professional football using a risk based assessment process. Br.J.Sports Med. 36, 446-451.

Dupont, G., Nedelec, M., McCall, A., McCormack, D., Berthoin, S., Wisløff, U., (2010). Effect of 2 Soccer Matches in a Week on Physical Performance and Injury Rate. Am.J.Sports Med.

Dvorak, J., (2009). Give Hippocrates a jersey: promoting health through football/sport. Br.J.Sports Med. 43, 317-322.

Dvorak, J., Graf-Baumann, T., Peterson, L., Junge, A., (2000a). Football, or soccer, as it is called in North America, is the most popular sport worldwide. Am.J.Sports Med. 28, S1-S2.

Dvorak, J., Junge, A., (2000). Football injuries and physical symptoms. A review of the literature. Am.J.Sports Med. 28, S3-S9.

Dvorak, J., Junge, A., Chomiak, J., Graf-Baumann, T., Peterson, L., Rosch, D., Hodgson, R., (2000b). Risk factor analysis for injuries in football players. Possibilities for a prevention program. Am.J.Sports Med. 28, S69-S74. 
Ekblom, B., (1986). Applied physiology of soccer. Sports Med. 3, 50-60.

Ekstrand, J., Gillquist, J., (1982). The frequency of muscle tightness and injuries in soccer players. Am.J.Sports Med. 10, 75-78.

Ekstrand, J., Gillquist, J., (1983a). Soccer injuries and their mechanisms: a prospective study. Med Sci Sports Exerc 15, 267-270.

Ekstrand, J., Gillquist, J., (1983b). The avoidability of soccer injuries. Int.J.Sports Med. 4, 124-128.

Ekstrand, J., Gillquist, J., Liljedahl, S. O., (1983a). Prevention of soccer injuries. Supervision by doctor and physiotherapist. Am.J.Sports Med. 11, 116-120.

Ekstrand, J., Gillquist, J., Moller, M., Oberg, B., Liljedahl, S. O., (1983b). Incidence of soccer injuries and their relation to training and team success. Am.J.Sports Med. 11, 63-67.

Ekstrand, J., Hägglund, M., Waldén, M., (2009). Injury incidence and injury patterns in professional football - the UEFA injury study. Br.J.Sports Med.

Ekstrand, J., Karlsson, J., (2003). The risk for injury in football. There is a need for a consensus about definitions of the injury and the design of studies. Scand J Med Sci Sports, pp. 147-149.

Ekstrand, J., Tropp, H., (1990). The incidence of ankle sprains in soccer. Foot Ankle 11, 4144.

Emery, C. A., (1999). Does decreased muscle strength cause acute muscle strain injury in sport? A systematic review of the evidence. Phys Ther Rev, pp. 141-151.

Emery, C. A., Meeuwisse, W. H., (2001). Risk factors for groin injuries in hockey. Med Sci Sports Exerc 33, 1423-1433.

Emery, C. A., Meeuwisse, W. H., Hartmann, S. E., (2005). Evaluation of risk factors for injury in adolescent soccer: implementation and validation of an injury surveillance system. Am.J.Sports Med. 33, 1882-1891.

Engström, B. K., Renström, P. A., (1998). How can injuries be prevented in the World Cup soccer athlete? Clin.Sports Med 17, 755-68, vii.

FIFA - The History of Football, (2010).

http://www.fifa.com/classicfootball/history/game/historygame1.html.

FIFA big count, (2007). FIFA big count 2006: 270 million people active in football. http://www.fifa.com/worldfootball/bigcount/index.html 31 May 2007.

Finch, C., Cassell, E., (2006). The public health impact of injury during sport and active recreation. J.Sci.Med.Sport 9, 490-497.

Finch, C. F., Donaldson, A., (2009). A sports setting matrix for understanding the implementation context for community sport. Br.J.Sports Med. 
Fong, D. T., Hong, Y., Chan, L. K., Yung, P. S., Chan, K. M., (2007). A systematic review on ankle injury and ankle sprain in sports. Sports Med 37, 73-94.

Fredriksen, H., Dagfinrud, H., Jacobsen, V., Maehlum, S., (1997). Passive knee extension test to measure hamstring muscle tightness. Scand.J.Med.Sci.Sports 7, 279-282.

Fuller, C. W., Ekstrand, J., Junge, A., Andersen, T. E., Bahr, R., Dvorak, J., Hägglund, M., McCrory, P., Meeuwisse, W. H., (2006). Consensus statement on injury definitions and data collection procedures in studies of football (soccer) injuries. Clin.J.Sport Med. 16, 97-106.

Gabbe, B. J., Bennell, K. L., Finch, C. F., Wajswelner, H., Orchard, J. W., (2006). Predictors of hamstring injury at the elite level of Australian football. Scand J Med Sci Sports 16, 7-13.

Gabbe, B. J., Finch, C. F., Bennell, K. L., Wajswelner, H., (2003). How valid is a self reported 12 month sports injury history? Br.J.Sports Med. 37, 545-547.

Gabbe, B. J., Finch, C. F., Bennell, K. L., Wajswelner, H., (2005). Risk factors for hamstring injuries in community level Australian football. Br.J.Sports Med. 39, 106-110.

Garrett, W. E., Jr., Safran, M. R., Seaber, A. V., Glisson, R. R., Ribbeck, B. M., (1987).

Biomechanical comparison of stimulated and nonstimulated skeletal muscle pulled to failure. Am.J.Sports Med. 15, 448-454.

Garrick, J. G., Requa, R., (2005). Structured exercises to prevent lower limb injuries in young handball players. Clin J Sport Med 15, 398.

Gilchrist, J., Mandelbaum, B. R., Melancon, H., Ryan, G. W., Silvers, H. J., Griffin, L. Y., Watanabe, D. S., Dick, R. W., Dvorak, J., (2008). A randomized controlled trial to prevent noncontact anterior cruciate ligament injury in female collegiate soccer players. Am.J.Sports Med. 36, 1476-1483.

Gissane, C., White, J., Kerr, K., Jennings, D., (2001). An operational model to investigate contact sports injuries. Med Sci Sports Exerc. 33, 1999-2003.

Glasgow, R. E., Lichtenstein, E., Marcus, A. C., (2003). Why don't we see more translation of health promotion research to practice? Rethinking the efficacy-to-effectiveness transition. Am.J.Public Health 93, 1261-1267.

Goldman, E. F., Jones, D. E., (2010). Interventions for preventing hamstring injuries. Cochrane.Database.Syst.Rev CD006782.

Greene, D. L., Hamson, K. R., Bay, R. C., Bryce, C. D., (2000). Effects of protective knee bracing on speed and agility. Am.J.Sports Med. 28, 453-459.

Greig, M., (2008). The influence of soccer-specific fatigue on peak isokinetic torque production of the knee flexors and extensors. Am.J.Sports Med. 36, 1403-1409.

Hägglund, M., Waldén, M., Ekstrand, J., (2003). Exposure and injury risk in Swedish elite football: a comparison between seasons 1982 and 2001. Scand.J.Med.Sci.Sports 13, 364-370. 
Hägglund, M., Waldén, M., Ekstrand, J., (2005). Injury incidence and distribution in elite football--a prospective study of the Danish and the Swedish top divisions.

Scand.J.Med.Sci.Sports 15, 21-28.

Hägglund, M., Waldén, M., Ekstrand, J., (2006). Previous injury as a risk factor for injury in elite football: a prospective study over two consecutive seasons. Br.J.Sports Med. 40, $767-$ 772 .

Hägglund, M., Waldén, M., Ekstrand, J., (2007). Lower reinjury rate with a coach-controlled rehabilitation program in amateur male soccer: a randomized controlled trial. Am.J.Sports Med. 35, 1433-1442.

Hägglund, M., Waldén, M., Ekstrand, J., (2008). Injuries among male and female elite football players. Scand.J.Med.Sci.Sports.

Hägglund, M., Waldén, M., Ekstrand, J., (2009). UEFA injury study--an injury audit of European Championships 2006 to 2008. Br.J.Sports Med. 43, 483-489.

Handoll, H. H., Rowe, B. H., Quinn, K. M., de, B. R., (2001). Interventions for preventing ankle ligament injuries. Cochrane.Database.Syst.Rev CD000018.

Hart, L., (2005). Effect of stretching on sport injury risk: a review. Clin.J.Sport Med. 15, 113.

Hartig, D. E., Henderson, J. M., (1999). Increasing hamstring flexibility decreases lower extremity overuse injuries in military basic trainees. Am.J.Sports Med. 27, 173-176.

Hass, C. J., Schick, E. A., Tillman, M. D., Chow, J. W., Brunt, D., Cauraugh, J. H., (2005). Knee biomechanics during landings: comparison of pre- and postpubescent females. Med.Sci.Sports Exerc. 37, 100-107.

Hawkins, R. D., Fuller, C. W., (1998). A preliminary assessment of professional footballers' awareness of injury prevention strategies. Br.J.Sports Med. 32, 140-143.

Hawkins, R. D., Fuller, C. W., (1999). A prospective epidemiological study of injuries in four English professional football clubs. Br.J.Sports Med. 33, 196-203.

Hawkins, R. D., Hulse, M. A., Wilkinson, C., Hodson, A., Gibson, M., (2001). The association football medical research programme: an audit of injuries in professional football. Br.J.Sports Med. 35, 43-47.

Heidt, R. S., Jr., Sweeterman, L. M., Carlonas, R. L., Traub, J. A., Tekulve, F. X., (2000). Avoidance of soccer injuries with preseason conditioning. Am.J.Sports Med. 28, 659-662.

Heiser, T. M., Weber, J., Sullivan, G., Clare, P., Jacobs, R. R., (1984). Prophylaxis and management of hamstring muscle injuries in intercollegiate football players. Am.J.Sports Med. 12, 368-370.

Herbert, R. D., Gabriel, M., (2002). Effects of stretching before and after exercising on muscle soreness and risk of injury: systematic review. BMJ 325, 468. 
Hewett, T. E., Lindenfeld, T. N., Riccobene, J. V., Noyes, F. R., (1999). The effect of neuromuscular training on the incidence of knee injury in female athletes. A prospective study. Am.J.Sports Med. 27, 699-706.

Hewett, T. E., Myer, G. D., Ford, K. R., Heidt, R. S., Jr., Colosimo, A. J., McLean, S. G., van den Bogert, A. J., Paterno, M. V., Succop, P., (2005). Biomechanical measures of neuromuscular control and valgus loading of the knee predict anterior cruciate ligament injury risk in female athletes: a prospective study. Am.J.Sports Med. 33, 492-501.

Holme, E., Magnusson, S. P., Becher, K., Bieler, T., Aagaard, P., Kjaer, M., (1999). The effect of supervised rehabilitation on strength, postural sway, position sense and re-injury risk after acute ankle ligament sprain. Scand.J.Med.Sci.Sports 9, 104-109.

Hölmich, P., Larsen, K., Krogsgaard, K., Gluud, C., (2009). Exercise program for prevention of groin pain in football players: a cluster-randomized trial. Scand.J.Med.Sci.Sports.

Hölmich, P., Uhrskou, P., Ulnits, L., Kanstrup, I. L., Nielsen, M. B., Bjerg, A. M., Krogsgaard, K., (1999). Effectiveness of active physical training as treatment for longstanding adductor-related groin pain in athletes: randomised trial. Lancet 353, 439-443.

Hrysomallis, C., McLaughlin, P., Goodman, C., (2005). Does a balance deficit persist in Australian Football players with previous lower limb ligament injury? J Sci Med Sport 8, 8591.

Hrysomallis, C., McLaughlin, P., Goodman, C., (2007). Balance and injury in elite Australian footballers. Int.J Sports Med 28, 844-847.

Hubscher, M., Zech, A., Pfeifer, K., Hansel, F., Vogt, L., Banzer, W., (2010). Neuromuscular training for sports injury prevention: a systematic review. Med.Sci.Sports Exerc. 42, 413-421.

Hupperets, M. D., Verhagen, E. A., van, M. W., (2008). The 2BFit study: is an unsupervised proprioceptive balance board training programme, given in addition to usual care, effective in preventing ankle sprain recurrences? Design of a randomized controlled trial.

BMC.Musculoskelet.Disord. 9, 71.

Hupperets, M. D., Verhagen, E. A., van, M. W., (2009). Effect of unsupervised home based proprioceptive training on recurrences of ankle sprain: randomised controlled trial. BMJ 339, b2684.

Inklaar, H., (1994a). Soccer injuries. I: Incidence and severity. Sports Med. 18, 55-73.

Inklaar, H., (1994b). Soccer injuries. II: Aetiology and prevention. Sports Med. 18, 81-93.

Inklaar, H., Bol, E., Schmikli, S. L., Mosterd, W. L., (1996). Injuries in male soccer players: team risk analysis. Int.J.Sports Med. 17, 229-234.

Jarvinen, T. A., Kaariainen, M., Jarvinen, M., Kalimo, H., (2000). Muscle strain injuries. Curr.Opin.Rheumatol. 12, 155-161.

Johnson RJ, (2001). The ACL injury in female skiers. Prevention of non-contact ACL injuries. American Academy of Orthopaedic Surgeons, Rosemont, pp. 230-257. 
Junge, A., Dvorak, J., Rösch, D., Graf-Baumann, T., Chomiak, J., Peterson, L., (2000). Psychological and Sport-Specific Characteristics of Football Players. Am.J Sports Med 28, 22-28.

Junge, A., Dvorak, J., (2000). Influence of definition and data collection on the incidence of injuries in football. Am.J.Sports Med. 28, S40-S46.

Junge, A., Dvorak, J., (2004). Soccer injuries: a review on incidence and prevention. Sports Med 34, 929-938.

Junge, A., Dvorak, J., Graf-Baumann, T., (2004a). Football injuries during the World Cup 2002. Am.J.Sports Med. 32, 23S-27S.

Junge, A., Dvorak, J., Graf-Baumann, T., Peterson, L., (2004b). Football injuries during FIFA tournaments and the Olympic Games, 1998-2001: development and implementation of an injury-reporting system. Am.J.Sports Med. 32, 80S-89S.

Junge, A., Rosch, D., Peterson, L., Graf-Baumann, T., Dvorak, J., (2002). Prevention of soccer injuries: a prospective intervention study in youth amateur players. Am.J.Sports Med. $30,652-659$.

Kofotolis, N. D., Kellis, E., Vlachopoulos, S. P., (2007). Ankle sprain injuries and risk factors in amateur soccer players during a 2-year period. Am.J Sports Med 35, 458-466.

Kujala, U. M., Orava, S., Jarvinen, M., (1997). Hamstring injuries. Current trends in treatment and prevention. Sports Med. 23, 397-404.

Lee, A. J., Lin, W. H., (2008). Twelve-week biomechanical ankle platform system training on postural stability and ankle proprioception in subjects with unilateral functional ankle instability. Clin.Biomech.(Bristol., Avon.) 23, 1065-1072.

Leetun, D. T., Ireland, M. L., Willson, J. D., Ballantyne, B. T., Davis, I. M., (2004). Core stability measures as risk factors for lower extremity injury in athletes. Med.Sci.Sports Exerc. 36, 926-934.

Lindenfeld, T. N., Schmitt, D. J., Hendy, M. P., Mangine, R. E., Noyes, F. R., (1994). Incidence of injury in indoor soccer. Am.J Sports Med 22, 364-371.

Ljungqvist, A., Jenoure, P. J., Engebretsen, L., Alonso, J. M., Bahr, R., Clough, A. F., de, B. G., Dvorak, J., Maloley, R., Matheson, G., Meeuwisse, W., Meijboom, E. J., Mountjoy, M., Pelliccia, A., Schwellnus, M., Sprumont, D., Schamasch, P., Gauthier, J. B., Dubi, C., (2009). The International Olympic Committee (IOC) consensus statement on periodic health evaluation of elite athletes, March 2009. Clin.J.Sport Med. 19, 347-365.

Lovell, R. J., Kirke, I., Siegler, J., McNaughton, L. R., Greig, M. P., (2007). Soccer half-time strategy influences thermoregulation and endurance performance. J.Sports Med.Phys Fitness 47, 263-269.

Luthje, P., Nurmi, I., Kataja, M., Belt, E., Helenius, P., Kaukonen, J. P., Kiviluoto, H., Kokko, E., Lehtipuu, T. P., Lehtonen, A., Liukkonen, T., Myllyniemi, J., Rasilainen, P., Tolvanen, E., Virtanen, H., Wallden, M., (1996). Epidemiology and traumatology of injuries in elite soccer: a prospective study in Finland. Scand.J.Med.Sci.Sports 6, 180-185. 
LYN, (2010). FK LYNs offisielle hjemmeside - Oppstarten.

http://www.lyn.no/index.aspx?id=28519, http://www.lyn.no/index.aspx?id=28519.

Lysens, R. J., Ostyn, M. S., Vanden, A. Y., Lefevre, J., Vuylsteke, M., Renson, L., (1989). The accident-prone and overuse-prone profiles of the young athlete. Am.J Sports Med 17, 612-619.

MacKay, J. M., Vincenten, J., (2009). Why isn't more injury prevention evidence-based? Int.J.Inj.Contr.Saf Promot. 16, 89-96.

Maffey, L., Emery, C., (2007). What are the risk factors for groin strain injury in sport? A systematic review of the literature. Sports Med. 37, 881-894.

Mahler, P. B., Donaldson, A., (2010). The limits of prevention - sports injuries as an example. Int.J.Inj.Contr.Saf Promot. 17, 69-72.

Mandelbaum, B. R., Silvers, H. J., Watanabe, D. S., Knarr, J. F., Thomas, S. D., Griffin, L. Y., Kirkendall, D. T., Garrett, W., Jr., (2005). Effectiveness of a neuromuscular and proprioceptive training program in preventing anterior cruciate ligament injuries in female athletes: 2-year follow-up. Am.J.Sports Med. 33, 1003-1010.

McGuine, T. A., Greene, J. J., Best, T., Leverson, G., (2000). Balance as a predictor of ankle injuries in high school basketball players. Clin J Sport Med 10, 239-244.

McGuine, T. A., Keene, J. S., (2006). The effect of a balance training program on the risk of ankle sprains in high school athletes. Am.J Sports Med 34, 1103-1111.

McHugh, M. P., Tyler, T. F., Mirabella, M. R., Mullaney, M. J., Nicholas, S. J., (2007). The effectiveness of a balance training intervention in reducing the incidence of noncontact ankle sprains in high school football players. Am.J Sports Med 35, 1289-1294.

McHugh, M. P., Tyler, T. F., Tetro, D. T., Mullaney, M. J., Nicholas, S. J., (2006). Risk factors for noncontact ankle sprains in high school athletes: the role of hip strength and balance ability. Am.J Sports Med 34, 464-470.

McKay, G. D., Goldie, P. A., Payne, W. R., Oakes, B. W., (2001). Ankle injuries in basketball: injury rate and risk factors. Br.J Sports Med 35, 103-108.

McKeon, P. O., Hertel, J., (2008). Systematic review of postural control and lateral ankle instability, part I: can deficits be detected with instrumented testing. J Athl.Train. 43, 293 304.

McKeon, P. O., Mattacola, C. G., (2008). Interventions for the prevention of first time and recurrent ankle sprains. Clin Sports Med 27, 371-82, viii.

McLean, S. G., Fellin, R. E., Suedekum, N., Calabrese, G., Passerallo, A., Joy, S., (2007). Impact of fatigue on gender-based high-risk landing strategies. Med.Sci.Sports Exerc. 39, $502-514$

van Mechelen, W., (1997). Sports injury surveillance systems. 'One size fits all'? Sports Med. 24, 164-168. 
van Mechelen, W., Hlobil, H., Kemper, H. C., (1992). Incidence, severity, aetiology and prevention of sports injuries. A review of concepts. Sports Med. 14, 82-99.

Meeuwisse WH, (1994). Assessing causation in sport injury: A multifactorial model. pp. 166170.

Meeuwisse, W. H., (1991). Predictability of sports injuries. What is the epidemiological evidence? Sports Med. 12, 8-15.

Meeuwisse, W. H., Sellmer, R., Hagel, B. E., (2003). Rates and risks of injury during intercollegiate basketball. Am.J.Sports Med. 31, 379-385.

Melnyk, M., Schloz, C., Schmitt, S., Gollhofer, A., (2009). Neuromuscular ankle joint stabilisation after 4-weeks WBV training. Int.J.Sports Med. 30, 461-466.

Mjølsnes, R., Árnason, A., Osthagen, T., Raastad, T., Bahr, R., (2004). A 10-week randomized trial comparing eccentric vs. concentric hamstring strength training in welltrained soccer players. Scand.J.Med.Sci.Sports 14, 311-317.

Mohammadi, F., (2007). Comparison of 3 preventive methods to reduce the recurrence of ankle inversion sprains in male soccer players. Am.J.Sports Med. 35, 922-926.

Morelli, V., Weaver, V., (2005). Groin injuries and groin pain in athletes: part 1. Prim.Care 32, 163-183.

Morgan, B. E., Oberlander, M. A., (2001). An examination of injuries in major league soccer. The inaugural season. Am.J.Sports Med. 29, 426-430.

Myer, G. D., Ford, K. R., Paterno, M. V., Nick, T. G., Hewett, T. E., (2008). The effects of generalized joint laxity on risk of anterior cruciate ligament injury in young female athletes. Am.J.Sports Med. 36, 1073-1080.

Myklebust, G., Engebretsen, L., Braekken, I. H., Skjolberg, A., Olsen, O. E., Bahr, R., (2003). Prevention of anterior cruciate ligament injuries in female team handball players: a prospective intervention study over three seasons. Clin.J.Sport Med. 13, 71-78.

NFF, (2009). NFF i tall - Her finner du nøkkeltall om norsk fotball. NFF http://www.fotball.no/toppmeny/Om-NFF/NFF-i-tall/ 30.juni 2009.

Nielsen, A. B., Yde, J., (1989). Epidemiology and traumatology of injuries in soccer. Am.J Sports Med 17, 803-807.

Noonan, T. J., Garrett, W. E., Jr., (1992). Injuries at the myotendinous junction. Clin.Sports Med. 11, 783-806.

Olsen, O. E., Myklebust, G., Engebretsen, L., Holme, I., Bahr, R., (2005). Exercises to prevent lower limb injuries in youth sports: cluster randomised controlled trial. BMJ 330, 449.

Orchard, J., Marsden, J., Lord, S., Garlick, D., (1997). Preseason hamstring muscle weakness associated with hamstring muscle injury in Australian footballers. Am.J.Sports Med. 25, 8185. 
Orchard, J., Seward, H., (2002). Epidemiology of injuries in the Australian Football League, seasons 1997-2000. Br.J.Sports Med. 36, 39-44.

Orchard, J., Wood, T., Seward, H., Broad, A., (1998). Comparison of injuries in elite senior and junior Australian football. J.Sci.Med.Sport 1, 83-88.

Orchard, J. W., (2001). Intrinsic and extrinsic risk factors for muscle strains in Australian football. Am.J.Sports Med. 29, 300-303.

Östenberg, A., Roos, H., (2000). Injury risk factors in female European football. A prospective study of 123 players during one season. Scand J Med Sci Sports 10, 279-285.

Petersen, J., Hölmich, P., (2005). Evidence based prevention of hamstring injuries in sport. Br.J.Sports Med. 39, 319-323.

Petersen, J., Thorborg, K., Nielsen, M. B., Hölmich, P., (2009). Acute hamstring injuries in Danish elite football: A 12-month prospective registration study among 374 players.

Scand.J.Med.Sci.Sports.

Peterson, L., Junge, A., Chomiak, J., Graf-Baumann, T., Dvorak, J., (2000). Incidence of football injuries and complaints in different age groups and skill-level groups. Am.J Sports Med 28, S51-S57.

Quinn, K., Parker, P., de, B. R., Rowe, B., Handoll, H., (2000). Interventions for preventing ankle ligament injuries. Cochrane.Database.Syst.Rev CD000018.

Reilly, T., Bangsbo, J., Franks, A., (2000). Anthropometric and physiological predispositions for elite soccer. J.Sports Sci. 18, 669-683.

Roberts, W. O., Brust, J. D., Leonard, B., Hebert, B. J., (1996). Fair-play rules and injury reduction in ice hockey. Arch.Pediatr.Adolesc.Med. 150, 140-145.

Roos, E. M., Brandsson, S., Karlsson, J., (2001). Validation of the foot and ankle outcome score for ankle ligament reconstruction. Foot Ankle Int. 22, 788-794.

Roos, E. M., Roos, H. P., Lohmander, L. S., Ekdahl, C., Beynnon, B. D., (1998). Knee Injury and Osteoarthritis Outcome Score (KOOS)--development of a self-administered outcome measure. J.Orthop.Sports Phys. Ther. 28, 88-96.

Söderman, K., Werner, S., Pietila, T., Engström, B., Alfredson, H., (2000). Balance board training: prevention of traumatic injuries of the lower extremities in female soccer players? A prospective randomized intervention study. Knee.Surg.Sports Traumatol.Arthrosc. 8, 356363.

Soligard, T., Myklebust, G., Steffen, K., Holme, I., Silvers, H., Bizzini, M., Junge, A., Dvorak, J., Bahr, R., Andersen, T. E., (2008). Comprehensive warm-up programme to prevent injuries in young female footballers: cluster randomised controlled trial. BMJ 337, a2469.

Stasinopoulos, D., (2004). Comparison of three preventive methods in order to reduce the incidence of ankle inversion sprains among female volleyball players. Br.J.Sports Med. 38, 182-185. 
Steffen, K., Myklebust, G., Andersen, T. E., Holme, I., Bahr, R., (2008a). Self-reported injury history and lower limb function as risk factors for injuries in female youth soccer.

Am.J.Sports Med. 36, 700-708.

Steffen, K., Myklebust, G., Olsen, O. E., Holme, I., Bahr, R., (2008b). Preventing injuries in female youth football--a cluster-randomized controlled trial. Scand.J.Med.Sci.Sports 18, 605614.

Steffen, K., Pensgaard, A. M., Bahr, R., (2008c). Self-reported psychological characteristics as risk factors for injuries in female youth football. Scand.J.Med.Sci.Sports.

Stølen, T., Chamari, K., Castagna, C., Wisløff, U., (2005). Physiology of soccer: an update. Sports Med. 35, 501-536.

Surve, I., Schwellnus, M. P., Noakes, T., Lombard, C., (1994). A fivefold reduction in the incidence of recurrent ankle sprains in soccer players using the Sport-Stirrup orthosis. Am.J Sports Med 22, 601-606.

Taerk, G. S., (1977). The injury-prone athlete: a psychosocial approach. J Sports Med Phys.Fitness 17, 186-194.

Taimela, S., Kujala, U. M., Osterman, K., (1990). Intrinsic risk factors and athletic injuries. Sports Med 9, 205-215.

Taunton, J. E., Ryan, M. B., Clement, D. B., McKenzie, D. C., Lloyd-Smith, D. R., Zumbo, B. D., (2003). A prospective study of running injuries: the Vancouver Sun Run "In Training" clinics. Br.J.Sports Med. 37, 239-244.

Thacker, S. B., Gilchrist, J., Stroup, D. F., Kimsey, C. D., Jr., (2004). The impact of stretching on sports injury risk: a systematic review of the literature. Med.Sci.Sports Exerc. 36, 371-378.

Thacker, S. B., Stroup, D. F., Branche, C. M., Gilchrist, J., Goodman, R. A., Porter, K. E., (2003). Prevention of knee injuries in sports. A systematic review of the literature. J.Sports Med.Phys Fitness 43, 165-179.

Thacker, S. B., Stroup, D. F., Branche, C. M., Gilchrist, J., Goodman, R. A., Weitman, E. A., (1999). The prevention of ankle sprains in sports. A systematic review of the literature.

Am.J.Sports Med. 27, 753-760.

Trojian, T. H., McKeag, D. B., (2006). Single leg balance test to identify risk of ankle sprains. Br.J Sports Med 40, 610-613.

Tropp, H., Askling, C., Gillquist, J., (1985). Prevention of ankle sprains. Am.J.Sports Med. $13,259-262$.

Tumilty, D., (1993). Physiological characteristics of elite soccer players. Sports Med. 16, 8096.

Turl, S. E., George, K. P., (1998). Adverse neural tension: a factor in repetitive hamstring strain? J.Orthop.Sports Phys Ther 27, 16-21. 
Twomey, D., Finch, C., Roediger, E., Lloyd, D. G., (2009). Preventing lower limb injuries: is the latest evidence being translated into the football field? J.Sci.Med.Sport 12, 452-456.

Tyler, T. F., McHugh, M. P., Mirabella, M. R., Mullaney, M. J., Nicholas, S. J., (2006). Risk factors for noncontact ankle sprains in high school football players: the role of previous ankle sprains and body mass index. Am.J Sports Med 34, 471-475.

Tyler, T. F., Nicholas, S. J., Campbell, R. J., Donellan, S., McHugh, M. P., (2002). The effectiveness of a preseason exercise program to prevent adductor muscle strains in professional ice hockey players. Am.J.Sports Med. 30, 680-683.

Tyler, T. F., Nicholas, S. J., Campbell, R. J., McHugh, M. P., (2001). The association of hip strength and flexibility with the incidence of adductor muscle strains in professional ice hockey players. Am.J.Sports Med. 29, 124-128.

Upton, P. A., Noakes, T. D., Juritz, J. M., (1996). Thermal pants may reduce the risk of recurrent hamstring injuries in rugby players. Br.J.Sports Med. 30, 57-60.

Verhagen, E., van der, B. A., Twisk, J., Bouter, L., Bahr, R., van, M. W., (2004). The effect of a proprioceptive balance board training program for the prevention of ankle sprains: a prospective controlled trial. Am.J.Sports Med. 32, 1385-1393.

Verhagen, E. A., van, M. W., de, V. W., (2000). The effect of preventive measures on the incidence of ankle sprains. Clin.J.Sport Med. 10, 291-296.

Verrall, G. M., Slavotinek, J. P., Barnes, P. G., Fon, G. T., Spriggins, A. J., (2001). Clinical risk factors for hamstring muscle strain injury: a prospective study with correlation of injury by magnetic resonance imaging. Br.J Sports Med 35, 435-439.

Waldén, M., Hägglund, M., Ekstrand, J., (2005a). Injuries in Swedish elite football--a prospective study on injury definitions, risk for injury and injury pattern during 2001. Scand J Med Sci Sports 15, 118-125.

Waldén, M., Hägglund, M., Ekstrand, J., (2005b). UEFA Champions League study: a prospective study of injuries in professional football during the 2001-2002 season. Br.J.Sports Med. 39, 542-546.

Waldén, M., Hägglund, M., Ekstrand, J., (2006). High risk of new knee injury in elite footballers with previous anterior cruciate ligament injury. Br.J.Sports Med. 40, 158-162.

Waldén, M., Hägglund, M., Ekstrand, J., (2007). Football injuries during European Championships 2004-2005. Knee.Surg.Sports Traumatol.Arthrosc. 15, 1155-1162.

Wang, H. K., Chen, C. H., Shiang, T. Y., Jan, M. H., Lin, K. H., (2006). Risk-factor analysis of high school basketball-player ankle injuries: a prospective controlled cohort study evaluating postural sway, ankle strength, and flexibility. Arch.Phys.Med Rehabil. 87, 821825 .

Werner, J., Hägglund, M., Waldén, M., Ekstrand, J., (2009). UEFA injury study: a prospective study of hip and groin injuries in professional football over seven consecutive seasons. Br.J.Sports Med. 43, 1036-1040. 
Wester, J. U., Jespersen, S. M., Nielsen, K. D., Neumann, L., (1996). Wobble board training after partial sprains of the lateral ligaments of the ankle: a prospective randomized study. J.Orthop.Sports Phys Ther 23, 332-336.

Willems, T. M., Witvrouw, E., Delbaere, K., Mahieu, N., De, B., I, De, C. D., (2005). Intrinsic risk factors for inversion ankle sprains in male subjects: a prospective study. Am.J Sports Med 33, 415-423.

Wisløff, U., Helgerud, J., Hoff, J., (1998). Strength and endurance of elite soccer players. Med Sci Sports Exerc. 30, 462-467.

Witvrouw, E., Danneels, L., Asselman, P., D'Have, T., Cambier, D., (2003). Muscle flexibility as a risk factor for developing muscle injuries in male professional soccer players. A prospective study. Am.J.Sports Med. 31, 41-46.

Wong, P., Hong, Y., (2005). Soccer injury in the lower extremities. Br.J.Sports Med. 39, 473482 .

Woods, C., Hawkins, R., Hulse, M., Hodson, A., (2002). The Football Association Medical Research Programme: an audit of injuries in professional football-analysis of preseason injuries. Br.J Sports Med 36, 436-441.

Woods, C., Hawkins, R., Hulse, M., Hodson, A., (2003). The Football Association Medical Research Programme: an audit of injuries in professional football: an analysis of ankle sprains. Br.J Sports Med 37, 233-238.

Woods, C., Hawkins, R. D., Maltby, S., Hulse, M., Thomas, A., Hodson, A., (2004). The Football Association Medical Research Programme: an audit of injuries in professional football--analysis of hamstring injuries. Br.J Sports Med 38, 36-41.

Worrell, T. W., (1994). Factors associated with hamstring injuries. An approach to treatment and preventative measures. Sports Med. 17, 338-345.

Yung, P. S., Chan, R. H., Wong, F. C., Cheuk, P. W., Fong, D. T., (2007). Epidemiology of injuries in Hong Kong elite badminton athletes. Res.Sports Med. 15, 133-146.

Zazulak, B. T., Hewett, T. E., Reeves, N. P., Goldberg, B., Cholewicki, J., (2007). Deficits in neuromuscular control of the trunk predict knee injury risk: a prospective biomechanicalepidemiologic study. Am.J.Sports Med. 35, 1123-1130. 
Papers I-V 

Papers I-V

\section{Paper I}





\section{Paper II}



Paper III 

Paper IV 


Paper V 



\title{
Intrinsic risk factors for groin injuries among male soccer players - a prospective cohort study
}

\author{
Engebretsen $A H, M D^{1} *$ \\ Myklebust $G, P T, P h D^{1}$ \\ Holme I, PhD ${ }^{1}$ \\ Engebretsen L, MD PhD ${ }^{1,2}$ \\ Bahr R, MD PhD ${ }^{l}$
}

${ }^{1}$ Oslo Sports Trauma Research Center

Norwegian School of Sports Sciences

PO Box 4014 Ullevål Stadion

N-0806 Oslo

Norway

${ }^{2}$ Department of Orthopaedic Surgery

Ulleval University Hospital

University of Oslo

N-0407 Oslo

Norway

Corresponding Author:

*Engebretsen AH, MD

Oslo Sports Trauma Research Center

Norwegian School of Sports Science

PO Box 4014 Ullevål Stadion

N-0806 Oslo

Norway

Tel: (+47) 23262357

Fax: 23262307

E-mail: Anders.Engebretsen@nih.no

Key terms: Groin injuries; football; risk factors; prospective cohort study; previous injuries. 


\section{Abstract}

Background: This study was conducted to see if we could identify risk factors for groin injuries among male soccer players.

Hypothesis: We hypothesized that previous groin injuries, reduced function scores, age, findings on clinical examination and low isometric groin strength is associated with increased risk of new groin injuries.

Study design: Prospective cohort study.

Methods: A total of 508 players representing 31 amateur teams were tested during the 2004 preseason for potential risk factors for groin injury through a questionnaire on previous injury and function score (Groin Outcome Score; GrOS) and a clinical examination of the groin. Generalized estimating equations were used in univariate analyses to identify candidate risk factors, and factors with a $\mathrm{p}$-value of $<0.10$ were then examined in a multivariate model.

Results: During the soccer season, 61 groin injuries, affecting 55 legs (51 players), were registered. The total incidence of groin injuries was 0.6 injuries per 1000 playing hours $(95 \%$ CI 0.4 to 0.7$), 0.3$ injuries per 1000 training hours (95\% CI 0.2 to 0.4 ) and 1.8 injuries per 1000 match hours (95\% CI 1.2 to 2.5$)$. In a multivariate analysis, previous acute groin injury (adjusted OR 2.60, 95\% CI 1.10 to 6.11 ) and weak adductor muscles as determined clinically (adjusted OR 4.28, 95\% CI 1.31 to 14.0 ) were significantly associated with increased risk of groin injuries.

A multivariate analysis based on acute time-loss injuries only revealed the $40 \mathrm{~m}$ sprint test result (adjusted OR 2.03 for $1 \mathrm{SD}$ change (injured group faster), 95\% CI 1.06 to $3.88, \mathrm{p}=0.03$ ) and functional testing of the abdominal muscles (adjusted OR 15.5 (4\% scored as weak in the uninjured group compared to none in the injured group), $95 \% \mathrm{CI} 1.11$ to $217, \mathrm{p}=0.04$ ) as significant risk factors. 
Conclusions: A history of previous acute groin injury and weak adductor muscles were significant risk factors for new groin injuries. 


\section{Introduction}

Strain injuries to the groin are among the most common injuries in adult male soccer and the incidence has been reported to be $1.0^{15}$ and $1.1^{33}$ per 1000 playing hours, accounting for 11 $16 \%$ of all injuries. ${ }^{5,13,15,16,32,33}$ Also, a vicious circle with recurrent groin strains may occur, resulting in a recurrent problem. ${ }^{33}$ Hence, primary and secondary prevention are equally important.

To identify the athlete at risk and possibly even correct the predisposing factor(s), the specific intrinsic and extrinsic risk factors for the injury type in question must be known. ${ }^{25}$ Regarding intrinsic risk factors in soccer, it seems that previous groin injury places an athlete at increased risk of suffering a strain injury of the groin, especially when rehabilitation is inadequate. ${ }^{1,14}$ Also age has been suggested as a risk factor for injuries. ${ }^{1}$

Other potential risk factors are mentioned in the literature from different sports, but the results and study groups differ widely. These include high level of play, ${ }^{20}$ age, ${ }^{7}$ core stability ${ }^{3,22}$, decreased range of motion in hip abduction ${ }^{1}$ and weak adductor muscles and abnormal muscle ratios. $^{6,31}$

To examine the contribution of the various risk factors of injuries and etiology and to explore their interrelationship, it is necessary to include all candidate factors in a multivariate analysis. ${ }^{25}$ Even though a large number of risk factor studies have been carried out, only a few

of them have used this approach. ${ }^{24}$ We therefore planned the present prospective cohort study on soccer players to screen for several potential risk factors for groin injuries, some of which have not been studied in depth earlier.

Elite players only constitute a small portion of all soccer players, and advanced resources for screening tests are not available for the majority of players. Therefore, one goal of this study was to investigate if simple screening tests, which are easy to do and do not require advanced 
equipment, can be used to identify individuals at risk. In this way, if a self-report questionnaire on groin function and symptoms or simple strength/sprint tests used in this study were shown to be useful, teams and players with no medical staff can test themselves in the pre-season to find out whether they have an increased risk of injuries.

We included clinical examination performed by experienced physicians for comparison with the simple self-assessment and to see if such an examination could predict injury risk. In addition, counter movement jump test and $40 \mathrm{~m}$ sprint test were included in order to investigate if explosive athletes with a dominant fast-twitch muscle fiber type would be more prone to strain injuries, and if it could be evaluated through such tests. Also, as weak adductors have been suggested as risk factors for groin injury in ice hockey, ${ }^{31}$ and strengthening exercises have been introduced as well-documented treatment of adductorrelated groin pain and also suggested as possible means of preventing injuries, ${ }^{19}$ the isometric adductor strength test was included.

We hypothesized that previous acute groin injuries, reduced function scores, weak groin muscles or abnormalities on a clinical examination could predict increased risk of new groin injuries. In addition, we included clinical examination and self-reported player information such as age, height, weight, BMI, level of play and player position to investigate if there were any correlations between these variables and injury risk.

Hence, the aim of this study was to examine potential intrinsic risk factors for acute and overuse groin strain injuries in a prospective cohort study among sub-elite male soccer players. 


\section{Methods}

\section{Design and participants}

This study is based on data from a randomized trial on male amateur soccer players examining the effect of a training program designed to prevent injuries. The design, the intervention program, and the results of the study have previously been described in detail in a

separate paper. ${ }^{8}$ Because no differences were seen in injury rates between the intervention and control groups, ${ }^{8}$ the entire cohort could be used to assess the effect of a number of risk factors assessed at baseline.

A total of 35 teams ( $n=769$ players) from the Norwegian $1^{\text {st }}, 2^{\text {nd }}$ or $3^{\text {rd }}$ division of soccer for men, geographically located in the proximity of Oslo, were invited to participate in the study. In Norway there are several different $3^{\text {rd }}$ division conferences, and the $3^{\text {rd }}$ division teams included either won their conference or finished as first runners up the previous season, resulting in a relatively homogenous group of teams, even if the 35 teams competed in three different divisions. Three of the teams ( $\mathrm{n}=60$ players) declined the invitation to participate, 177 players did not report for testing, three players did not speak Norwegian and could therefore not complete the questionnaire and four players were excluded for other reasons (Figure 1). Hence, 244 of the players invited could not be included. In addition, one team $(\mathrm{n}=17$ players) was later excluded because the physiotherapist did not record injuries, resulting in a final sample of 508 players representing 31 teams from three divisions $\left(1^{\text {st }}\right.$ division, $\mathrm{n}=7,122$ players; $2^{\text {nd }}$ division, $\mathrm{n}=16,260$ players; and $3^{\text {rd }}$ division, $\mathrm{n}=8 ; 126$ players). The study was approved by the Regional Committee for Medical Research Ethics, Helse Øst, and written consent was obtained. 


\section{Risk factor screening}

The teams were tested for potential risk factors for groin injuries during the 2004 pre-season, January through March, at the Norwegian School of Sport Sciences. Every player capable (not injured at the time) completed three counter movement jumps, two $40 \mathrm{~m}$ sprint tests, an isometric adductor strength test, a clinical examination and a questionnaire.

The counter movement jump test was performed on a force plate (AMTI LG6-4-1, Advanced Mechanical Technology, Inc., Watertown, MA, USA), with hands held at the hips as described by Lian et al. ${ }^{23}$ From a standing position with straight knees the player squatted down to at least $90^{\circ}$ before jumping as high as he could. All three tests were scored as the maximal height of rise of the center of gravity in centimeters, calculated based from data on body weight and ground reaction forces on the force plate during the jump. The best result was used for the analysis.

The $40 \mathrm{~m}$ sprint test was performed with a contact mat and double beam timing gates at the Norwegian Olympic Training Center, measuring the time from when the front foot left the floor to the time sensor at $40 \mathrm{~m}$.

The clinical testing of the players was performed by a group of ten sports physical therapists and sports physicians who were blinded for any injury history (scars were not concealed). In accordance with the FIFA F-FMARC pre-season medical assessment, ${ }^{4}$ both legs were examined for hip flexibility and range of motion, pain at palpation of adductor muscles, short adductor muscles, pain in adduction against resistance, painful muscle insertions of the adductor longus muscle, rectal abdominal muscles or at the pubic bone, pain in passive stretching of the adductors and functional testing of the rectal abdominal muscles.

All players were tested twice on each leg for isometric adductor strength measured using a hand-held dynamometer (Hydraulic Push-Pull Dynamometer, Baseline ${ }^{\circledR}$ Evaluation 
Instruments, White Plains, NY, USA) similar to Krause et al. (2007). ${ }^{21}$ The tests were conducted with the players lying in supine position on a bench, keeping the leg extended. The dynamometer was positioned $5 \mathrm{~cm}$ proximal to the medial ankle malleolus. The dynamometer was held stationary while the player pushed maximally against the resistance. The arms were held alongside the body during the test. Both legs were tested, with two maximal contractions for each test variable and a $10 \mathrm{~s}$ rest period between the two attempts, and the highest value for each leg was registered.

The players also completed a questionnaire in two parts, where the first part covered general player information (age, height, body mass index, position on the field, number of junior or senior national team matches played, level of play this season, and level of play the previous season), and self-reported history of previous groin injuries (number, severity, nature and number of months since the most recent acute groin injury and if the most recent injury had caused the player to miss matches). The second part was a function score for the groin (Groin Outcome Score; $\operatorname{GrOS}^{8}$ ), which was developed as a screening tool. This form has a similar outline as the KOOS form, ${ }^{28}$ which consists of five major parts (symptoms, pain, activities of daily life, function in sports and recreation, quality of life) and is scored by calculating the mean value of the five parts in percent of the total possible score, where $100 \%$ is the maximal and $0 \%$ the lowest score. For the GrOS, we replaced the category "function in daily living" with a category on muscle soreness resulting in five categories (symptoms, pain, soreness, function in sports and quality of life).

In addition, a similar screening was done for risk factors for ankle, knee and hamstring injuries. The data from these tests are/will be reported in separate papers. ${ }^{9-11}$ 


\section{Injury reporting}

An injury was defined as any physical complaint sustained by a player that resulted from a soccer match or soccer training, forcing the player to miss or being unable to take full part in future soccer training or match play ("time-loss" injury). Acute injuries were defined as injuries with a sudden onset associated with a known trauma, whereas overuse injuries were those with a gradual onset without any known trauma. There is no consensus on definitions or diagnostic criteria for groin injuries ${ }^{17,18}$ and the diagnosis is difficult. Therefore, based on information on injured region, injury type and diagnosis in the injury reports from the physiotherapists, two of the authors who were blinded to all other information regarding risk factors classified all injuries as a groin injury or not. For the purpose of the present paper, an injury was classified as groin injury if it was recorded as either an acute or an overuse injury of the inside thigh/groin area.

Injuries were classified into three severity categories according to the time it took until the player was fully fit to take part in all types of organized soccer play: minor (1-7 days), moderate (8-28 days) and major ( $>28$ days). However, overuse injuries where there was no time loss were also included to incorporate small repeated strain injuries, as some players still elect to play despite discomfort in the groin. The head coach for every team registered each player's participation in training and the number of minutes played in matches.

The team physical therapist was responsible for reporting injuries on their team throughout the preseason and the season. Most of the teams from the $1^{\text {st }}$ and $2^{\text {nd }}$ division already had a physical therapist working with the team. In case there was no physical therapist involved, we assigned one for the team. However, the physical therapist was not required to be present at every training session and match; the degree of follow-up therefore varied from team to team participating in the study. 


\section{Reliability testing}

Inter-test reliability tests were done for the adductor strength test by having the same player repeat the same test with different personnel after he had completed the first test. Each examiner was blinded to the other's results. The same scoring system/clinical forms were used at both stations. The coefficient of variation for the continuous variable adductor strength was calculated as the standard deviation of the difference between the first and second test as a percentage of the average test results for both tests.

\section{Statistical methods}

Exposure to matches and training was calculated by adding the individual duration of all training and match play during the season.

For the continuous dependent variable risk factor analyses, where each leg was the unit of analysis, generalized estimating equations (STATA, version 8; STATA, Texas, U.S.A.) were used, accounting for total individual exposure during the soccer season, any within-team correlations and the fact that the left and right foot belonged to the same player. Logistic regression analyses were used to analyse the relationships between per subject calculated dichotomous injury variables and their risk factors.

All risk factor variables were examined in univariate analyses, and those with a $\mathrm{P}$ value $<0.10$ were investigated further in a multivariate model.

\section{Results}

The total incidence of injuries during the season was 4.7 injuries per 1000 playing hours $(95 \%$ CI 4.3 to 5.1$), 12.1$ (95\% CI 10.5 to 13.7$)$ for match injuries and 2.7 (95\% CI 2.4 to 3.1 ) for training injuries. The total exposure to match play and training was 108111 player hours. 
A total of 61 groin injuries were reported, affecting 55 legs and $51(10.0 \%)$ of the 508 players in the study. The total incidence of groin injuries was 0.6 injuries per 1000 playing hours (95\% CI 0.4 to 0.7 ), 0.3 injuries per 1000 training hours (95\% CI 0.2 to 0.4 ) and 1.8 injuries per 1000 match hours $(95 \%$ CI 1.2 to 2.5$)$.

A total of 44 players sustained one groin injury, five sustained two injuries, one sustained three injuries and one player sustained four injuries.

Of the 61 injuries, 31 occurred on the right side and 30 on the left. There were 22 acute and 39 overuse groin injuries reported. Of these, 29 were minor injuries (time loss 1 to 7 days), 17 moderate injuries ( 8 to 28 days) and 12 severe injuries ( $>28$ days), while information on the duration of time loss was missing in one case. In two overuse injuries there was no time loss. The coefficient of variation for the continuous variable adductor strength was $19.6 \%$.

Univariate analyses (Table 1, online appendix) revealed the following potential leg-dependent risk factors for groin injuries; previous acute groin injury, total GrOS and GrOS sub scores "symptoms", "soreness" and "pain" and the clinical tests pain at external rotation in the hip joint and reduced range of motion for external rotation, pain at functional testing of the rectal abdominal muscles, weak adductor muscles determined clinically, pain at functional testing of the iliopsoas muscles and weak ilipsoas muscles determined clinically.

Of the player-dependent factors, age and counter movement jump test were significantly associated with risk of groin injury (Table 2, online appendix). Because this study is based on data from a randomized trial, separate analyses controlling for group assignment (intervention or control group) were performed; however, with no change in the results. Also, a Poisson model approximating multinomial logistic regression analyses was used, in order to compare players who sustained no injuries versus those who sustained one injury versus those who sustained more than one injury. Again, the results did not differ from the original analyses. 
In cases where two of the potential leg-dependent risk factors were strongly intercorrelated $(\mathrm{p}<0.05)$, only the most clinically relevant test was included in the final multivariate analysis. This includes pain at external rotation in the hip joint and reduced range of motion for external rotation (intercorrelation $\mathrm{p}=0.02$ ) (pain at external rotation chosen due to greater clinical relevance) and weak ilipsoas muscles determined clinically versus pain at functional testing (intercorrelation $\mathrm{p}=0.02$ ) (weak ilipsoas muscles chosen because this was believed to be clinically more specific).

Risk factors with $\mathrm{p}$-value of $<0.10$ were then considered as candidates to predict which players are more prone to sustain a groin injury. Because these factors may be intercorrelated or confounded by each other, a multivariate analysis was performed which showed that previous acute groin injury (adjusted OR 2.60, 95\% CI 1.10 to 6.11 ) and weak adductor muscles determined clinically (adjusted OR 4.28, 95\% CI 1.31 to 14.0 ) were significant predictors of increased risk of groin injuries. Out of 1016 cases, the final multivariate analysis was based on 560 cases after cases with missing data were excluded.

We also completed a separate statistical analysis using acute time-loss injuries only. The univariate analyses identified the $40 \mathrm{~m}$ sprint test, counter movement jump test and level of play as additional potential player-dependent risk factors, while previous acute groin injury, GrOS and functional testing of the abdominal muscles were identified as potential legdependent risk factors. A multivariate analysis based on acute time-loss injuries only revealed the $40 \mathrm{~m}$ sprint test result (adjusted OR 2.03 for 1SD change (injured group faster), 95\% CI 1.06 to $3.88, \mathrm{p}=0.03)$ and functional testing of the abdominal muscles (adjusted OR $15.5(4 \%$ scored as weak in the uninjured group compared to none in the injured group), $95 \%$ CI 1.11 to $217, \mathrm{p}=0.04)$ as significant risk factors. 


\section{Discussion}

The main finding of this cohort study investigating potential risk factors for groin injuries in soccer was that a history of previous acute groin injury and weak adductor muscles are significant risk factors. Previously injured players have more than twice as high risk of sustaining a new groin injury, while players with weak adductor muscles have a four times higher injury risk. Other candidates for identification of players with increased risk of groin injuries were age, counter movement jump test, groin function score and clinical examination of external rotation, abdominal and iliopsoas muscles. However, none of these held up in the multivariate analysis. Among other potential predictors, such as isometric adductor strength and function, $40 \mathrm{~m}$ sprint speed, level of play or other self-reported player characteristics, none were associated with increased risk in this study.

Previous injury seems to be the most consistent intrinsic risk factor identified in the literature. A systematic review examining risk factors for acute muscle strains in different sports found previous injury to be a strong predictor of muscle strain injury. ${ }^{6}$ In a multivariate analysis in the largest cohort study to date in male soccer, previously injured players were found to have more than a seven-fold increased risk of sustaining new groin injuries compared with uninjured controls. ${ }^{1}$ A study from Swedish elite soccer also found previous injury to the same leg to be a significant risk factor. ${ }^{14}$ These findings are consistent with studies from other sports with high demands on the groin area, as well. ${ }^{24}$ The results from the present study are in accordance to these findings, and underline the importance of adequate rehabilitation before full return to play. Also, they suggest that preventing the first injury should be a high priority, to keep players from entering the vicious cycle of recurrent injuries to the same body part. To accomplish this, the best method may be strength exercises. While a passive physical therapy programme of massage, stretching and modalities was ineffective in treating chronic groin strains, Hölmich et al ${ }^{19}$ demonstrated that an 8 - to 12 -week active strengthening 
programme, consisting of progressive resistive adduction and abduction exercises, balance training, abdominal strengthening and skating movements on a slide board, was effective in treating chronic groin strains. A randomized controlled trial in Norwegian male soccer using a modified shortened version of this programme did not find a preventive effect. ${ }^{8}$ However, due to poor compliance it is not possible to say whether the shortened programme would have been effective, if completed as prescribed. Also, in professional ice hockey adductor strengthening exercises reduced the number of groin injuries. ${ }^{30}$

The other main observation in the present study was that players assessed to have weak adductors in the clinical examination had four times the injury risk of players with normal strength. No publications exist from male soccer on the topic, but in a study from male elite ice hockey, significantly lower adductor strength was found among injured players. ${ }^{31}$ However, in contrast to the clinical examination, adductor strength measured by a handheld dynamometer was not significantly associated with risk of injury. Still, the coefficient of variation for this test of $19.6 \%$ indicates that inter-test reliability was poor.

Hip and groin injuries are reported to often occur in sports involving side-to-side cutting, quick accelerations and decelerations, and sudden directional changes. ${ }^{26}$ Strength imbalances between the propulsive muscles and the stabilizing muscles of the hip and pelvis ${ }^{12}$ and between the synergistic abductors and adductors have been suggested as risk factors for groin injuries. ${ }^{24}$ Also, delayed contraction of the transversus abdominis, ${ }^{3}$ as a measure of reduced core stability, has been suggested in the literature. Unfortunately, based on the tests performed in this study, these hypotheses can not be addressed.

Neither this nor previous studies ${ }^{1,31}$ have identified adductor length as a risk factor for groin injury in soccer, and stretching programs do not seem to influence injury risk. ${ }^{29}$ A study from Belgian elite soccer found no predictive value of adductor flexibility measurements. ${ }^{34}$ Still, Arnason et al. found decreased range of motion in hip abduction to be a significant risk factor 
for groin injuries, which is in contrast with the present findings. In the present study, however, hip range of motion was only examined clinically.

Age and experience have been suggested as risk factors in elite ice hockey. ${ }^{7}$ The present study found these factors to be strongly associated with injury risk in the univariate, but not in the multivariate analysis. This is in accordance with previous studies from soccer ${ }^{1}$ and other sports. ${ }^{7,27}$

It seemed reasonable to hypothesize that explosive athletes with a dominant fast-twitch muscle fiber type would be more prone to strain injuries. However, in this study neither the 40 $\mathrm{m}$ sprint test nor the counter movement jump test result was associated with injury risk in the main analysis. This is in accordance with Arnason et al, who found no predictive effect of jump tests. ${ }^{1}$ However, it should be noted that using acute time-loss injuries only as the end point identified the $40 \mathrm{~m}$ sprint test and functional testing of the abdominal muscles as significant risk factors. This could indicate that the risk for acute injuries is increased among "explosive" players, and that previous injury is less important as risk factor for new acute injuries. However, as this analysis is based on only 22 acute time-loss injuries it needs to be interpreted with caution.

The present study is one of the largest cohort studies on risk factors for groin injuries to date, with as many as 61 groin injuries in total. Still, the statistical power is limited for the multivariate tests, where a number of subjects had to be excluded because of missing test data. Nevertheless, the odds ratios of the candidate risk factors included do not indicate that any of these would be helpful as screening tools. As pointed out by Bahr \& Holme ${ }^{2}$ in their review, the present number of injuries should be sufficient to detect clinically relevant risk factors. 
Overuse injuries where no time-loss had occurred were also included in our definition of groin injuries. As MRI or ultrasound examinations were not readily available we did this to include painful conditions about the groin, because some players still elect to play despite discomfort in the area. However, we can not be sure if all of these represented true strain injuries to the groin muscles.

This study was carried out among subelite male soccer players, and should not be extrapolated to other sports, females, youth players or other levels of play.

\section{Conclusions}

Using multivariate analyses, a history of a previous acute groin injury and weak adductor muscles were found to be significant risk factors for new groin injuries. Previously injured players have a more than twice as high risk of sustaining a new groin injury, while the risk is four times higher in players with weak adductor muscles. 


\section{Acknowledgements}

The Oslo Sports Trauma Research Center has been established at the Norwegian School of Sport Sciences through generous grants from the Royal Norwegian Ministry of Culture, the South-Eastern Norway Regional Health Authority, the International Olympic Committee, the Norwegian Olympic Committee \& Confederation of Sport, and Norsk Tipping AS. We thank all personnel for making this study possible. 
Fig 1. Flow chart showing movement of numbers of players participating.

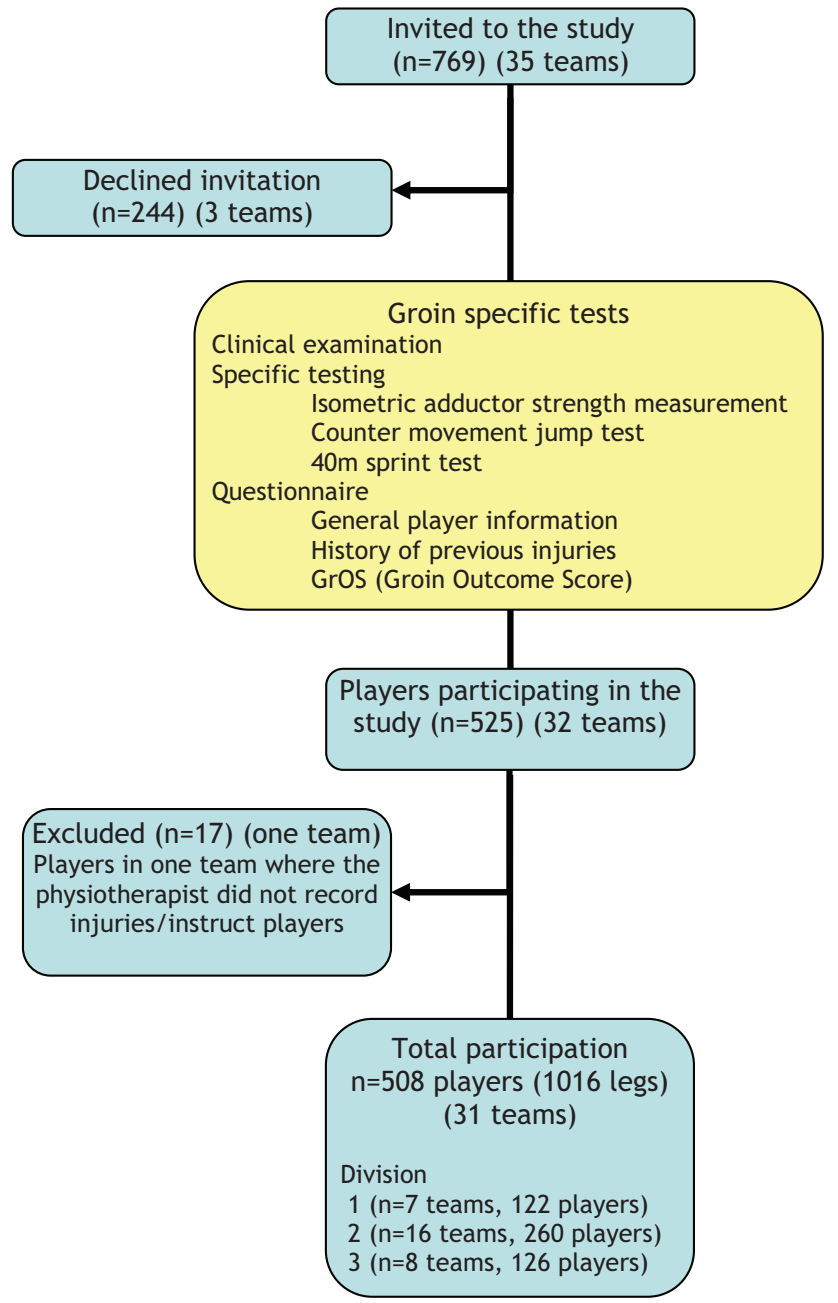




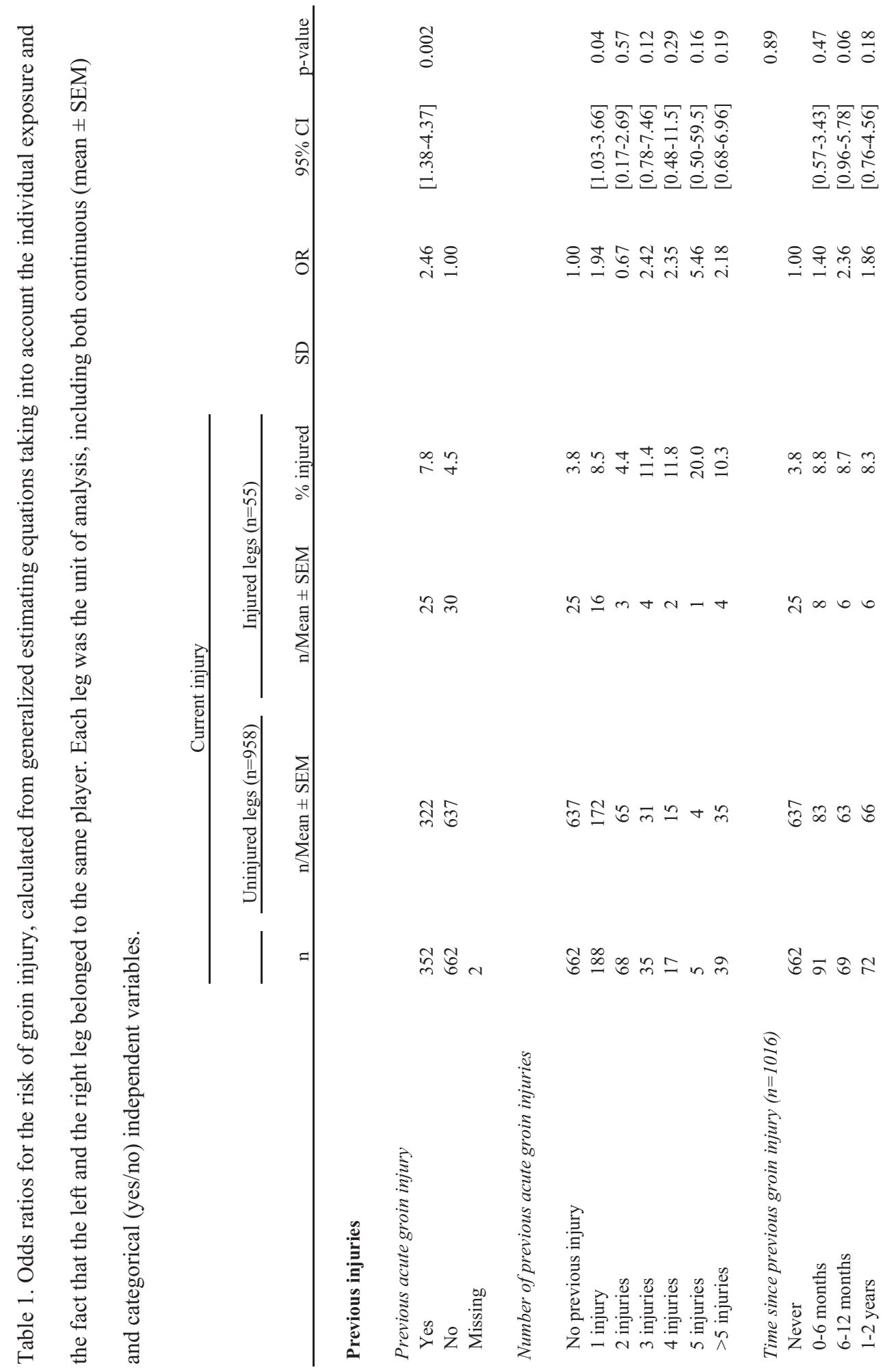




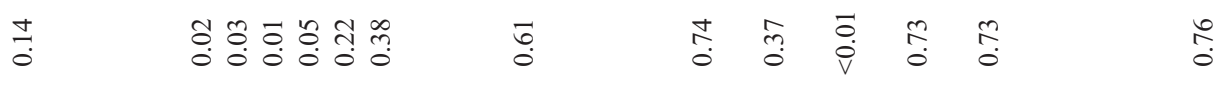

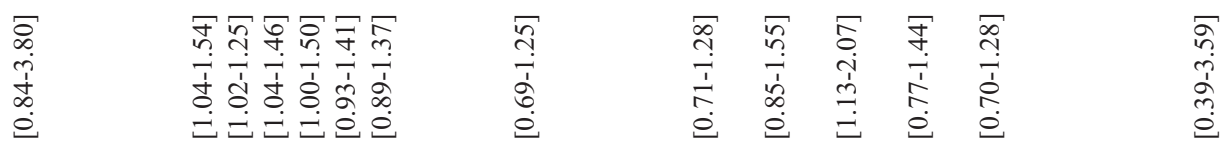

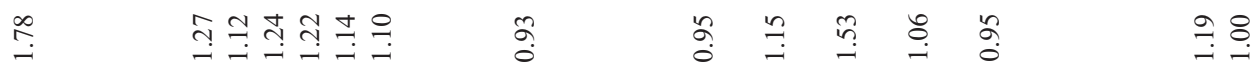

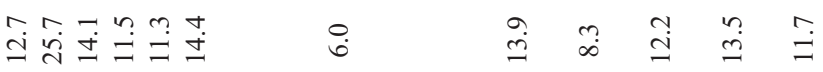

$$
\begin{aligned}
& \underset{\infty}{\infty}
\end{aligned}
$$

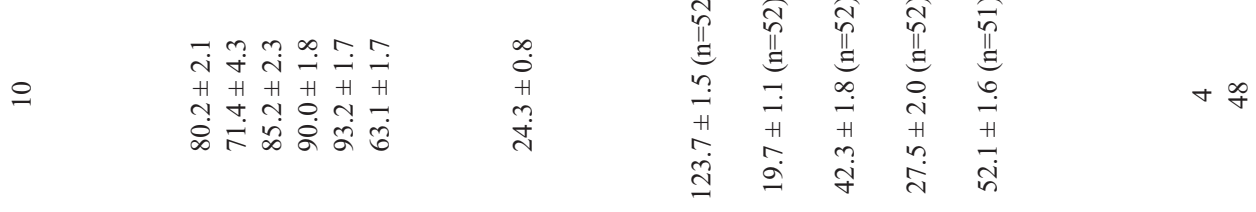

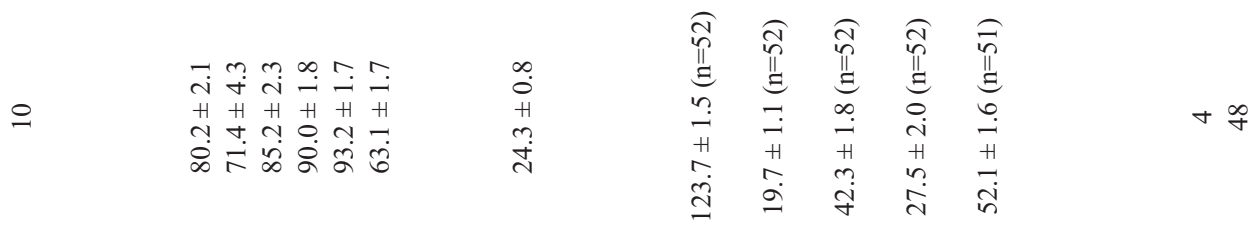

$$
\begin{aligned}
& \text { 눙 }
\end{aligned}
$$

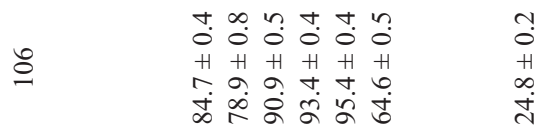

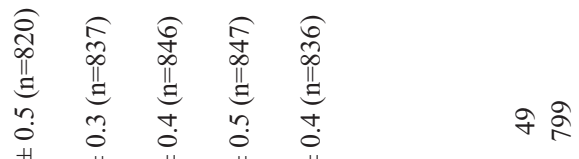

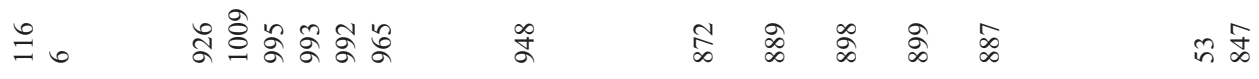

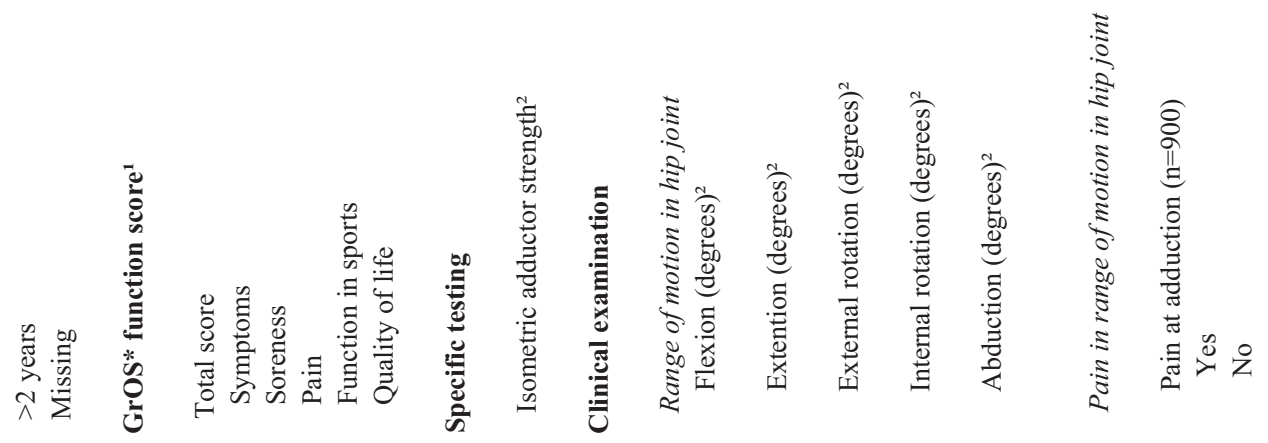




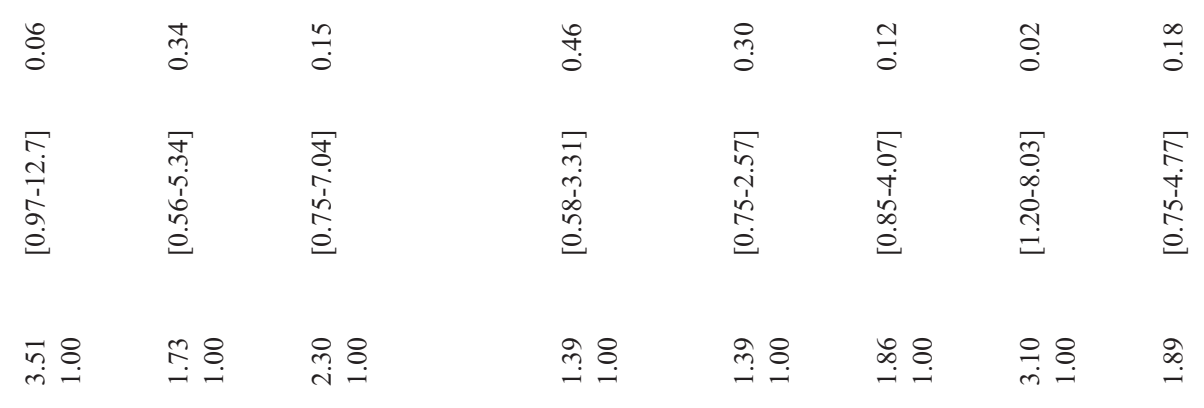

递品

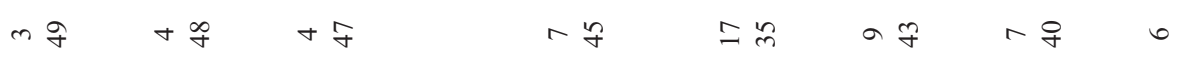

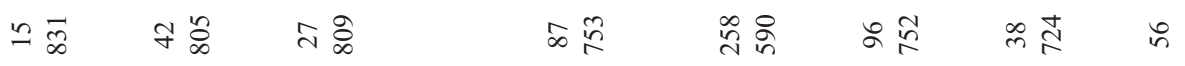

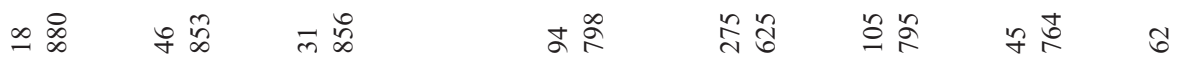

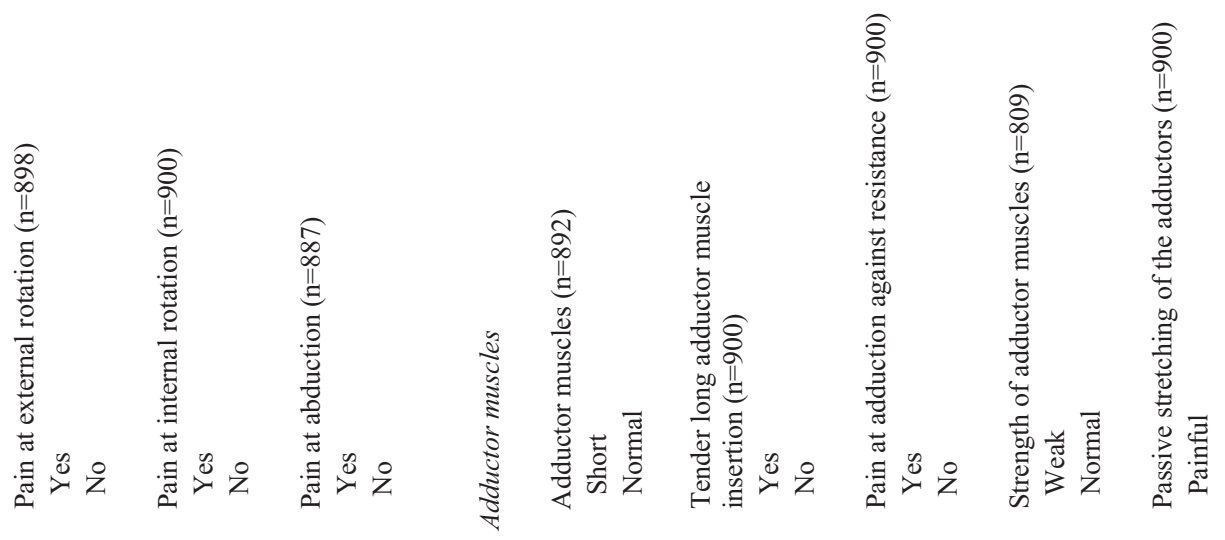




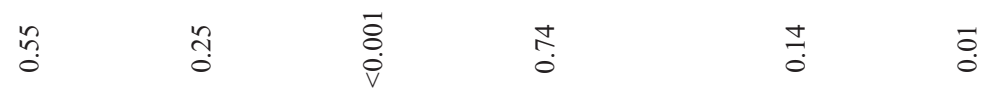

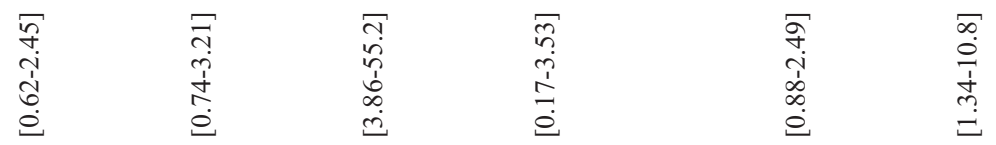

$$
\begin{aligned}
& \text { \& } \quad \text { İ }
\end{aligned}
$$

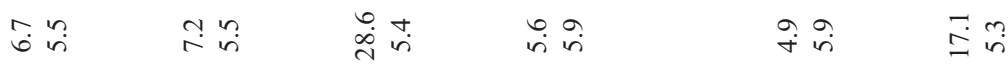

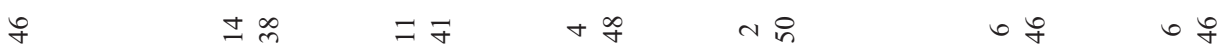

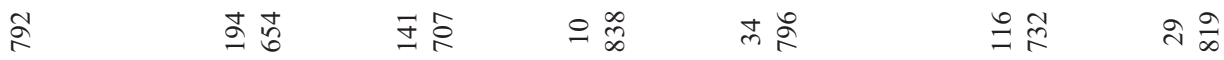

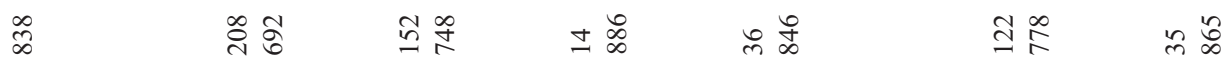

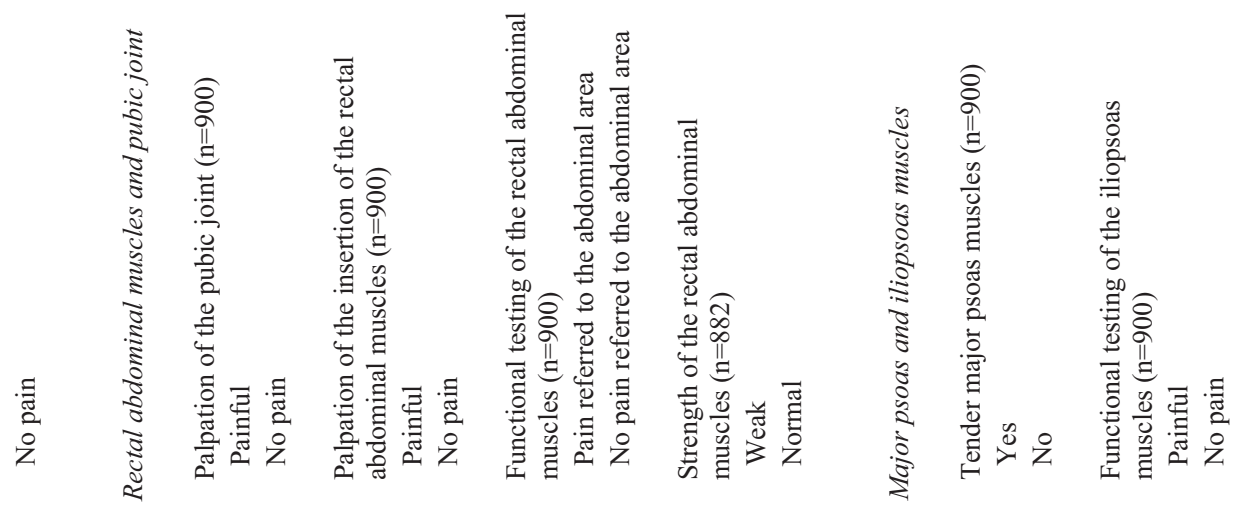




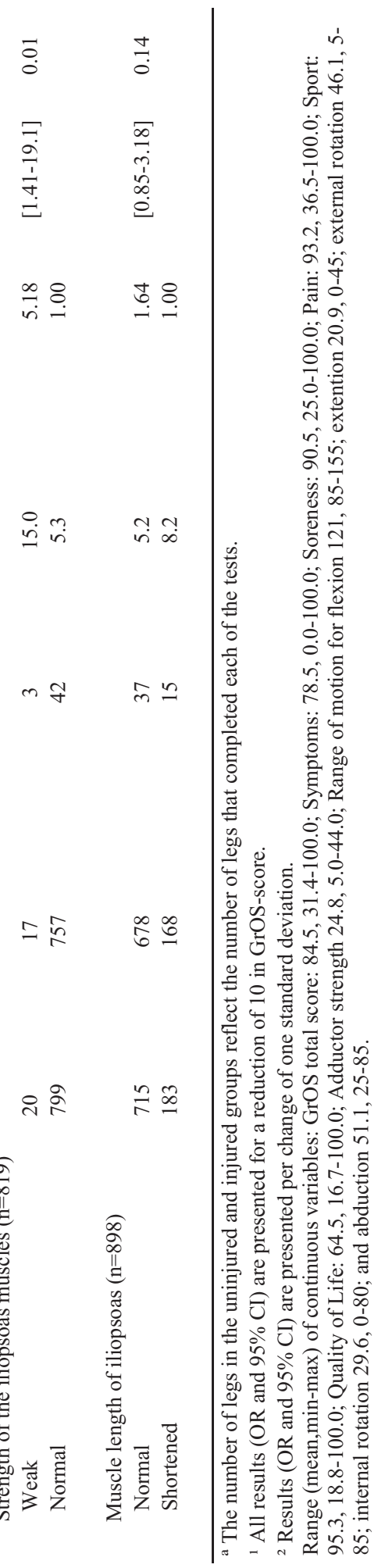




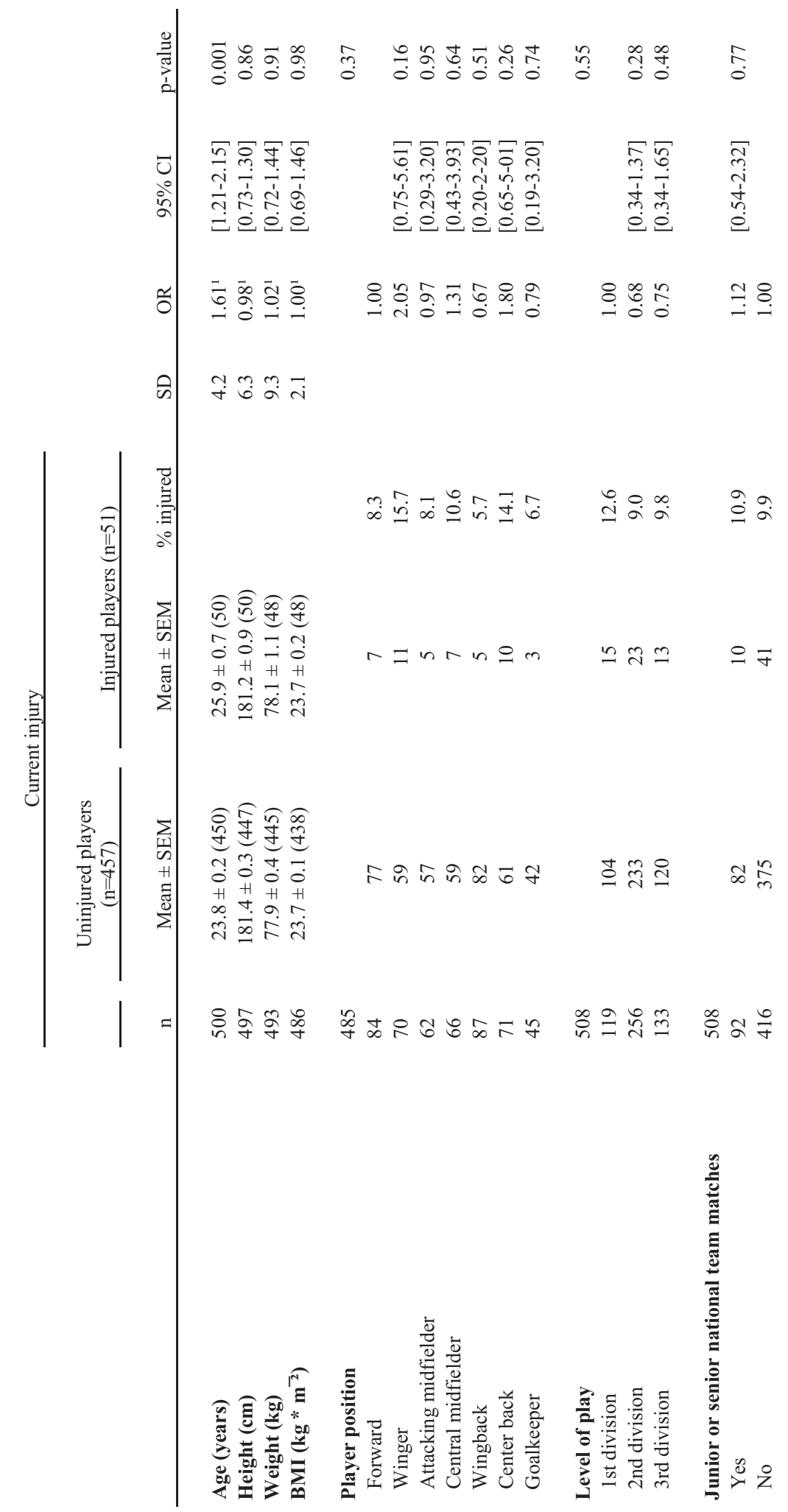




$$
\begin{aligned}
& \stackrel{0}{0} \div
\end{aligned}
$$

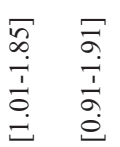

$$
\begin{aligned}
& \text { 임 } \\
& \text { † } \stackrel{\infty}{\circ} \\
& \text {. } \\
& \text { 跣) }
\end{aligned}
$$

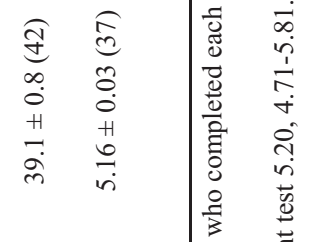

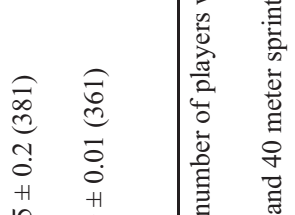

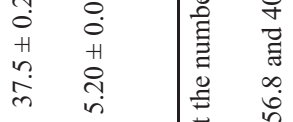

$$
\begin{aligned}
& \text { के की }
\end{aligned}
$$

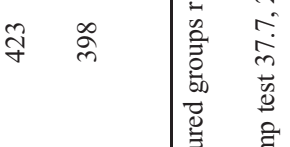

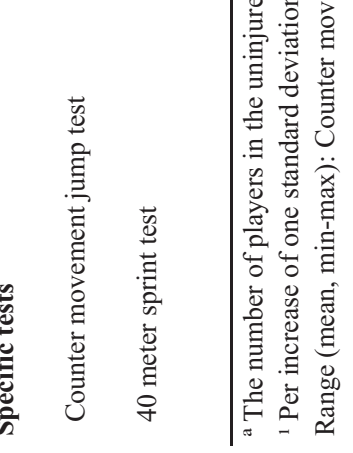




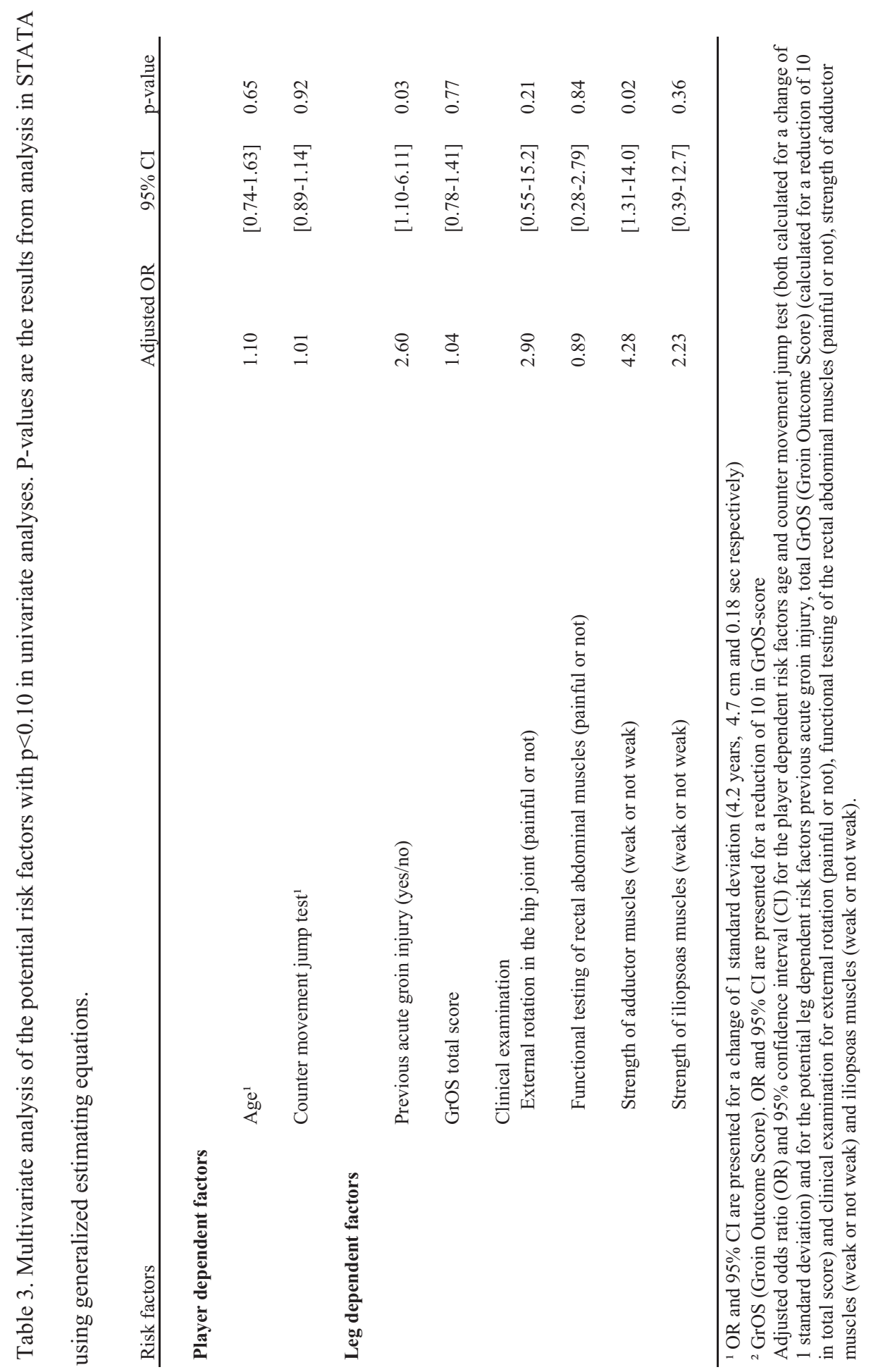




\section{REFERENCES}

1. Arnason A, Sigurdsson SB, Gudmundsson A, et. al.: Risk factors for injuries in football. Am J Sports Med 32: 5S-16S, 2004

2. Bahr R, Holme I: Risk factors for sports injuries--a methodological approach. Br $J$ Sports Med 37: 384-392, 2003

3. Cowan SM, Schache AG, Brukner P, et. al.: Delayed onset of transversus abdominus in long-standing groin pain. Med Sci Sports Exerc 36: 2040-2045, 2004

4. Dvorak, J. and Junge, A. Football Medicine Manual - Pre-season medical assessment. 2005. Zurich, Switzerland: F-MARC. FIFA; 2005.

5. Ekstrand J, Gillquist J: The avoidability of soccer injuries. Int J Sports Med 4: 124-128, 1983

6. Emery, C. A. Does decreased muscle strength cause acute muscle strain injury in sport? A systematic review of the evidence. 4(3), 141-151. 1999. Phys Ther Rev.

7. Emery CA, Meeuwisse WH: Risk factors for groin injuries in hockey. Med Sci Sports Exerc 33: 1423-1433, 2001

8. Engebretsen AH, Myklebust G, Holme I, et. al.: Prevention of injuries among male soccer players: a prospective, randomized intervention study targeting players with previous injuries or reduced function. Am J Sports Med 36: 1052-1060, 2008 
9. Engebretsen AH, Myklebust G, Holme I, et. al.: Intrinsic risk factors for acute ankle injuries among male soccer players: a prospective cohort study. Scand J Med Sci Sports. 2009 Jun 23. [Epub ahead of print]

10. Engebretsen, A. H., Myklebust, G., Holme, I., Engebretsen, L., and Bahr, R. Intrinsic risk factors for acute knee injuries among male soccer players - a prospective cohort study. Scand J Med Sci Sports. 2010 Mar 11. [Epub ahead of print].

11. Engebretsen, A. H., Myklebust, G., Holme, I., Engebretsen, L., and Bahr, R. Intrinsic risk factors for hamstring injuries among male soccer players - a prospective cohort study. Am J Sports Med. 2010 Mar 24. [Epub ahead of print].

12. Garrett WE, Jr., Safran MR, Seaber AV, et. al.: Biomechanical comparison of stimulated and nonstimulated skeletal muscle pulled to failure. Am J Sports Med 15: 448-454, 1987

13. Hagglund M, Walden M, Ekstrand J: Injury incidence and distribution in elite football-a prospective study of the Danish and the Swedish top divisions. Scand J Med Sci Sports 15: $21-28,2005$

14. Hagglund M, Walden M, Ekstrand J: Previous injury as a risk factor for injury in elite football: a prospective study over two consecutive seasons. Br J Sports Med 40: 767772,2006

15. Hagglund M, Walden M, Ekstrand J: Injuries among male and female elite football players. Scand J Med Sci Sports 2008

16. Hawkins RD, Fuller CW: A prospective epidemiological study of injuries in four English professional football clubs. Br J Sports Med 33: 196-203, 1999 
17. Holmich P: Long-standing groin pain in sportspeople falls into three primary patterns, a "clinical entity" approach: a prospective study of 207 patients. Br J Sports Med 41: 247252,2007

18. Holmich P, Holmich LR, Bjerg AM: Clinical examination of athletes with groin pain: an intraobserver and interobserver reliability study. Br J Sports Med 38: 446-451, 2004

19. Holmich P, Uhrskou P, Ulnits L, et. al.: Effectiveness of active physical training as treatment for long-standing adductor-related groin pain in athletes: randomised trial. Lancet 353: 439-443, 1999

20. Inklaar H, Bol E, Schmikli SL, et. al.: Injuries in male soccer players: team risk analysis. Int J Sports Med 17: 229-234, 1996

21. Krause DA, Schlagel SJ, Stember BM, et. al.: Influence of lever arm and stabilization on measures of hip abduction and adduction torque obtained by hand-held dynamometry. Arch Phys Med Rehabil 88: 37-42, 2007

22. Leetun DT, Ireland ML, Willson JD, et. al.: Core stability measures as risk factors for lower extremity injury in athletes. Med Sci Sports Exerc 36: 926-934, 2004

23. Lian O, Engebretsen L, Ovrebo RV, et. al.: Characteristics of the leg extensors in male volleyball players with jumper's knee. Am J Sports Med 24: 380-385, 1996

24. Maffey L, Emery C: What are the risk factors for groin strain injury in sport? A systematic review of the literature. Sports Med 37: 881-894, 2007

25. Meeuwisse WH. Assessing causation in sport injury: A multifactorial model. Clin J Sport Med 4, 166-170. 1994. 
26. Morelli V, Weaver V: Groin injuries and groin pain in athletes: part 1. Prim Care 32: 163-183, 2005

27. Orchard J, Wood T, Seward H, et. al.: Comparison of injuries in elite senior and junior Australian football. J Sci Med Sport 1: 83-88, 1998

28. Roos EM, Roos HP, Lohmander LS, et. al.: Knee Injury and Osteoarthritis Outcome Score (KOOS)--development of a self-administered outcome measure. J Orthop Sports Phys Ther 28: 88-96, 1998

29. Thacker SB, Gilchrist J, Stroup DF, et. al.: The impact of stretching on sports injury risk: a systematic review of the literature. Med Sci Sports Exerc 36: 371-378, 2004

30. Tyler TF, Nicholas SJ, Campbell RJ, et. al.: The effectiveness of a preseason exercise program to prevent adductor muscle strains in professional ice hockey players. Am J Sports Med 30: 680-683, 2002

31. Tyler TF, Nicholas SJ, Campbell RJ, et. al.: The association of hip strength and flexibility with the incidence of adductor muscle strains in professional ice hockey players. Am J Sports Med 29: 124-128, 2001

32. Walden M, Hagglund M, Ekstrand J: Injuries in Swedish elite football--a prospective study on injury definitions, risk for injury and injury pattern during 2001. Scand J Med Sci Sports 15: 118-125, 2005

33. Werner J, Hagglund M, Walden M, et. al.: UEFA injury study: a prospective study of hip and groin injuries in professional football over seven consecutive seasons. $\mathrm{Br} J$ Sports Med 43: 1036-1040, 2009 
34. Witvrouw E, Danneels L, Asselman P, et. al.: Muscle flexibility as a risk factor for developing muscle injuries in male professional soccer players. A prospective study. Am J Sports Med 31: 41-46, 2003 

Appendix 



\section{Regional komite for medisinsk forskningsetikk Sør-Norge (REK Sør)}

Dr. scient Grethe Myklebust

Senter for idrettskadeforskning

Norges idrettshogskole

Postboks 4014 Ullevål Stadion

0806 Oslo

Deres ref.: 16.12 .2003

Var ref.: S-032:31

Dato: 20.01 .04

Forebygging av skader blant mannlige fotballspillere - en prospektiv randomisert intervensjonsstudie

Prosjektleder: Dr. scient. Grethe Myklebust, Senter for idrettsskadeforskning, Norges idrettshøgskole

\section{Revidert informasjonsskriv}

Vi-takker for brev-av-16,12:2003 vedlagt revidert informasjons\$kriv: Konteen har-ingen merknader til informasjonsskrivet.

Komiteen har ikke mottatt orientering om hvordan rekrutteringen av utøverne er planlagt å skje, slik det er bedt om $\mathrm{i}$ komiteens vedtak, kfr. brev av 02.11.03. Komiteen tilrăr likevel at prosjektet giennomfores, men ber om at slik orientering ettersendes.

Vi ensker lykke til med prosjektet.

Vennligst oppgi komiteens referansnr. ved korrespondanse om et prosjekt. Det bidrar til ras. kere saksbehandling.

På grunn av stor saksmengde har vi dessverre ikke kunnet svare så raskt som vi ønsker.

$$
\text { Med vennlig bilsen }
$$

Sigurd Nitter-Hauge (sign)

Professor dr.med.

Leder

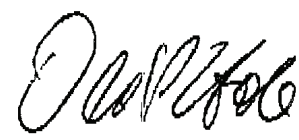

Ola P. Hole

Avdelingsleder

Sekretær 

"To myself I am only a child playing on the beach, while vast oceans of truth lie undiscovered before me"

Isaac Newton 
